\title{
Análise de Componentes Principais em Data Warehouses
}

\author{
Rafael Germano Rossi
}

TEXTO APRESENTADO

$\mathrm{AO}$

Instituto DE MATEMÁticA E EstatísticA

DA

UNIVERSIDADE DE SÃo PAUlo

PARA

OBTENÇÃO DO TÍTULO

$\mathrm{DE}$

Mestre em CiÊnCIAS

Programa: Ciência da Computação

Orientador: Prof. Dr. João Eduardo Ferreira

São Paulo, Agosto de 2017 



\section{Análise de Componentes Principais em Data Warehouses}

Esta versão da dissertação/tese contém correções e alterações sugeridas pela Comissão Julgadora durante a defesa da versão original do trabalho, realizada em 07/11/2017. Uma cópia da versão original está disponível no Instituto de Matemática e Estatística da Universidade de São Paulo.

Comissão Julgadora:

- Prof. Dr. João Eduardo Ferreira (orientador) - IME-USP

- Prof. Dr. Roberto Hirata Junior - IME-USP

- Prof. Dr. Luciano Antonio Digiampietri - EACH-USP 



\section{Agradecimentos}

Agradeço ao Prof. Dr. João Eduardo Ferreira pelo apoio e orientação dados durante a pesquisa, que foram essenciais para a conclusão do projeto e para meu desenvolvimento acadêmico.

Também agradeço os valiosos conselhos, sugestões e críticas recebidas dos meus colegas, agora amigos, de trabalho e de pesquisa, Marino, Rodrigo, Felipe, Eduardo e Edson.

Agradeço "uzirmão" que também me apoiaram como puderam.

Aos meus pais, Ângela e Luiz Natal, e meus irmãos, Gabriel e Guilherme, agradeço pelo incentivo e por tudo que fizeram por mim.

E, principalmente, agradeço à minha esposa Natália por me amparar quando precisei, me cobrar sempre que era necessário e pela paciência durante todos os anos desse mestrado. 


\section{Resumo}

Rossi, R. G. Análise de Componentes Principais em Data Warehouses. 2017. Dissertação (Mestrado) - Instituto de Matemática e Estatística, Universidade de São Paulo, São Paulo, 2017.

A técnica de Análise de Componentes Principais (PCA) tem como objetivo principal a descrição da variância e covariância entre um conjunto de variáveis. Essa técnica é utilizada para mitigar redundâncias no conjunto de variáveis e para redução de dimensionalidade em várias aplicações nas áreas científica, tecnológica e administrativa. Por outro lado, o modelo de dados multidimensionais é composto por relações de fato e dimensões (tabelas) que descrevem um evento usando métricas e a relação entre suas dimensões. No entanto, o volume de dados armazenados e a complexidade de suas dimensões geralmente envolvidas neste modelo, especialmente no ambiente de data warehouse, tornam a tarefa de interpretar a correlação entre dimensões muito difícil e às vezes impraticável. Neste trabalho, propomos o desenvolvimento de uma Interface de Programação de Aplicação (API) para a aplicação da PCA no modelo de dados multidimensionais para facilitar a tarefa de caracterização e redução de dimensionalidade, integrando essa técnica com ambientes de Data Warehouses. Para verificar a eficácia desta API, um estudo de caso foi realizado utilizando dados de produção científica e suas citações obtidas das Plataformas Lattes, Web of Science, Google Scholar e Scopus, fornecidas pela Superintendência de Tecnologia da Informação da Universidade de São Paulo.

Palavras-chave: PCA, modelo multidimensional, data warehouse, análise bibliométrica. 


\section{Abstract}

Rossi, R. G. Principal Components Analysis in Data Warehouses. 2017.. Dissertation (Masters Degree) - Institute of Mathematics and Statistics, University of São Paulo, São Paulo, 2017.

The Principal Component Analysis (PCA) technique has as the main goal the description of the variance and covariance between a set of variables. This technique is used to mitigate redundancies in the set of variables and as a mean of achieving dimensional reduction in various applications in the scientific, technological and administrative areas. On the other hand, the multidimensional data model is composed by fact and dimension relations (tables) that describe an event using metrics and the relationship between their dimensions. However, the volume of data stored and the complexity of their dimensions usually involved in this model, specially in data warehouse environment, makes the correlation analyses between dimensions very difficult and sometimes impracticable. In this work, we propose the development of an Application Programming Interface (API) for the application of PCA on multidimensional data model in order to facilitate the characterization task and dimension reduction, integrating the technique with Data Warehouses environments. For verifying the effectiveness of this API, a case study was carried out using the scientific production data obtained from the Lattes Platform, the Web of Science, Google Scholar and Scopus, provided by the IT Superintendence at University of São Paulo.

Keywords: PCA, multidimensional model, data warehouse, bibliometric analysis. 


\section{Sumário}

$\begin{array}{ll}\text { Lista de Abreviaturas } & \text { ix }\end{array}$

Lista de Figuras $\quad$ xi

Lista de Tabelas $\quad$ xiii

1 Introdução $\quad 1$

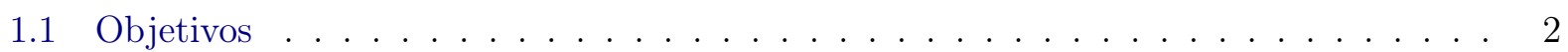

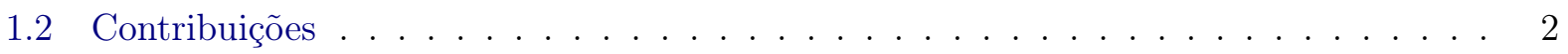

1.3 Organização do Trabalho . . . . . . . . . . . . . . . . . . . . . 3

2 Fundamentos $\quad 5$

2.1 Modelo Multidimensional . . . . . . . . . . . . . . . . . . . . 5

2.1 .1 Tabela fato . . . . . . . . . . . . . . . . . . . . 6

2.1 .2 Dimensão . . . . . . . . . . . . . . . . . . . . . . . 7

2.2 Análise de Componentes Principais . . . . . . . . . . . . . . . . . . 8

2.2 .1 Algoritmo . . . . . . . . . . . . . . . . . . . . . . . 9

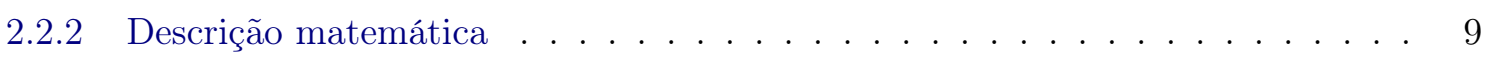

2.2 .3 Resultados da PCA . . . . . . . . . . . . . . . . . . . . . 11

2.3 Análise Bibliométrica . . . . . . . . . . . . . . . . . . . . . 11

2.3 .1 Índice-H . . . . . . . . . . . . . . . . . . . . . . . . . . . 12

2.3 .2 Plataforma Lattes . . . . . . . . . . . . . . . . . . . . . . . . 12

2.3.3 Conceito CAPES Qualis . . . . . . . . . . . . . . . . . . . 13

2.3 .4 Google Scholar . . . . . . . . . . . . . . . . . . . . . . . . . . 14

2.3 .5 Scopus . . . . . . . . . . . . . . . . . . . . . . 14

2.3.6 Web of Science . . . . . . . . . . . . . . . . . . . . . . . . . 14

2.4 Data Warehousing na USP . . . . . . . . . . . . . . . . . . . . . . . 14

2.4 .1 Arquitetura . . . . . . . . . . . . . . . . . . . . 15

$\begin{array}{lll}3 & \text { Trabalhos relacionados } & 17\end{array}$

3.1 Análise de índices bibliométricos . . . . . . . . . . . . . . . . . . . . . 17

3.2 PCA em Data Warehouses . . . . . . . . . . . . . . . . . . . . 18

3.3 PCA como apoio à interpretação de dados . . . . . . . . . . . . . . . . . . . . . 19

3.4 Outras aplicações de PCA . . . . . . . . . . . . . . . . . . . 20 
4 PCA em DWs corporativos $\quad 21$

4.1 Visão geral . . . . . . . . . . . . . . . . . . . . . . . . 21

4.1.1 API ............................... 21

4.1.2 Estudo de caso - USP . . . . . . . . . . . . . . . . . . . . . . . 21

4.1 .3 Modelo multidimensional . . . . . . . . . . . . . . . . . . . . . . . 22

4.2 Desenvolvimento da API . . . . . . . . . . . . . . . . . . . . . . . . . . . 23

4.3 Cálculo incremental da matriz de covariâncias . . . . . . . . . . . . . . . . . . . 28

4.3.1 Algoritmo .. . . . . . . . . . . . . . . . . . . . . . . 29

4.3.2 Avaliação da performance . . . . . . . . . . . . . . . . . . . . . . . . 32

4.4 Integração da API com o DW . . . . . . . . . . . . . . . . . . . . . . . . . . 33

4.4.1 Dimensões . . . . . . . . . . . . . . . . . . . . . . . . . . . 33

4.4 Fatos .................................. 33

4.4.3 Integração com as cargas periódicas . . . . . . . . . . . . . . . . . . . . . . . 34

4.4.4 Análise de performance . . . . . . . . . . . . . . . . . . . . . . . . . . . . . . 40

$\begin{array}{lll}5 & \text { Experimentos } & \mathbf{4 7}\end{array}$

5.1 Corretude da API . . . . . . . . . . . . . . . . . . . . . . . . . . 47

5.1.1 Duas variáveis . . . . . . . . . . . . . . . . . . . . . . . . . 47

5.2 Estudos de caso . . . . . . . . . . . . . . . . . . . . . . . . . . . . 48

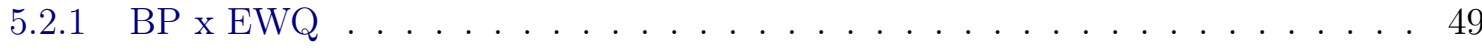

5.2.2 (PCW, PCG, PCS) x (IHW, IHG, IHS) x (CITW, CITG, CITS) x EWQ . . 52

5.2.3 (APL, TJRL, TEL, LCL, DPL) x (TME, TDO) . . . . . . . . . . . . . . . 54

6 Conclusões $\quad 59$

6.1 Comentários finais . . . . . . . . . . . . . . . . . . . . . . 59

6.2 Trabalhos futuros . . . . . . . . . . . . . . . . . . . . . 60

Referências Bibliográficas $\quad 61$ 


\section{Lista de Abreviaturas}

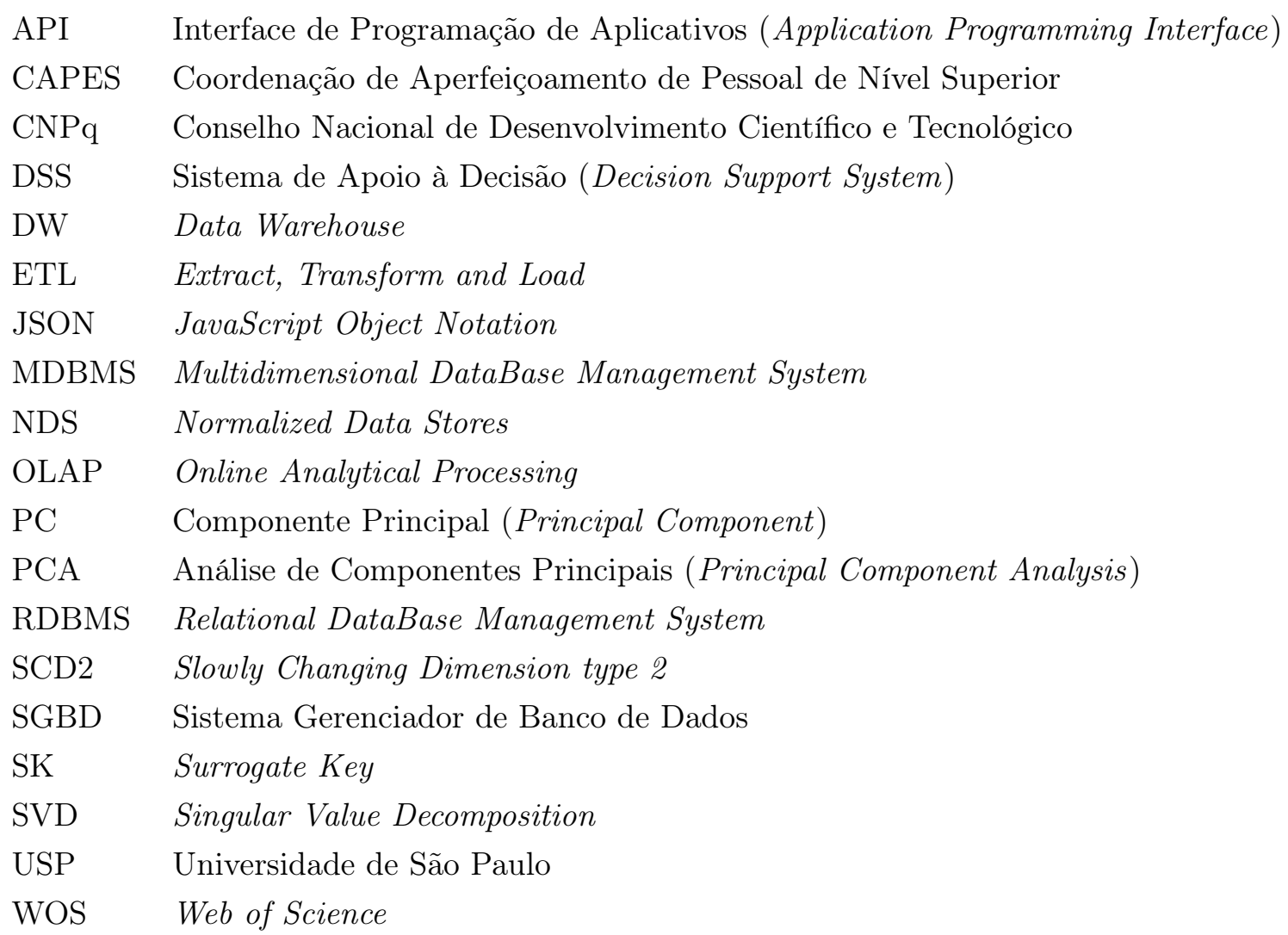




\section{Lista de Figuras}

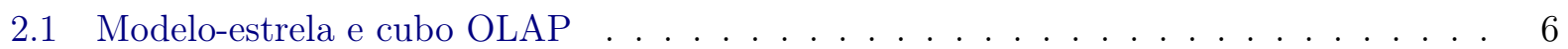

2.2 Tabela fato de vendas . . . . . . . . . . . . . . . . . . 7

2.3 Gráfico com resultado da PCA . . . . . . . . . . . . . . . . . . . . 12

2.4 Índice-H . . . . . . . . . . . . . . . . . . . . . . . . . . . 13

2.5 Arquitetura do ambiente de DW da USP . . . . . . . . . . . . . . . . 16

4.1 Processo de extração de dados para o estudo na USP . . . . . . . . . . . . . . . . . . 22

4.2 Modelo produção Lattes . . . . . . . . . . . . . . . . . . . . . . . . . 23

4.3 Diagrama de classes . . . . . . . . . . . . . . . . . . . . 25

4.4 Diagrama de sequência da PCA . . . . . . . . . . . . . . . . 26

4.5 Modelo de dados utilizado pela API . . . . . . . . . . . . . . . . . 27

4.6 Performance do método de Hall . . . . . . . . . . . . . . . . . . . . . . . . 32

4.7 Diagrama de sequência - inicialização . . . . . . . . . . . . . . . . . 37

4.8 Diagrama de sequência - nova consulta . . . . . . . . . . . . . . . . . . . . 39

4.9 Diagrama de sequência - atualização de consulta . . . . . . . . . . . . . . . . 41

4.10 Análise da performance - trigger . . . . . . . . . . . . . . . . . . 42

4.11 Análise da performance - batch sql . . . . . . . . . . . . . . . . . . 43

4.12 Análise da performance - batch_java . . . . . . . . . . . . . . . . 44

4.13 Análise da performance - batch_java não incremental . . . . . . . . . . . . . 45

5.1 Gráfico de dispersão - duas variáveis . . . . . . . . . . . . . . . . . . . . . . 48

5.2 Principais Componentes - duas variáveis . . . . . . . . . . . . . . 50

5.3 Gráfico de fatores - duas variáveis . . . . . . . . . . . . . . . . . . . . 51

5.4 Gráfico de fatores (abril de 2017) - BP x EWQ . . . . . . . . . . . . . . 52

5.5 Gráfico de fatores - BP x EWQ . . . . . . . . . . . . . . . . . . 53

5.6 Gráfico de fatores (abril de 2017) - (PCW, PCG, PCS) x (IHW, IHG, IHS) x (CITW,

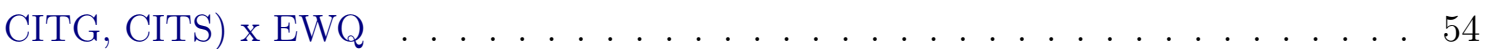

5.7 Gráfico de fatores - (PCW, PCG, PCS) x (IHW, IHG, IHS) x (CITW, CITG, CITS)

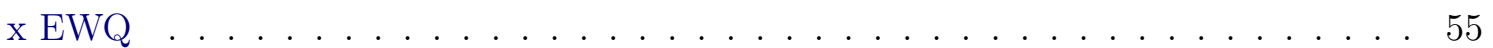

5.8 Gráfico de fatores - (APL, TJRL, TEL, LCL, DPL) x (TME, TDO) $\ldots \ldots \ldots$

5.9 Gráfico de dispersão - (APL, TJRL, TEL, LCL, DPL) x (TME, TDO) . . . . . . . . 57 


\section{Lista de Tabelas}

4.1 Variáveis que foram analisadas na aplicação de PCA. . . . . . . . . . . . . . . . . . 24

4.2 Parâmetros de configuração. . . . . . . . . . . . . . . . . . . . . . 35

5.1 Indicador quantitativo para representar a bolsa de produtividade do CNPq. . . . . . 50 


\section{Capítulo 1}

\section{Introdução}

Sistemas de apoio à tomada de decisões (Decision Support System, DSS) são fundamentais para a administração de instituições. Com o advento da internet, as fontes de dados que alimentam esses sistemas cresceram muito em quantidade e variedade. Além dos dados de sistemas corporativos, as instituições têm acesso a dados externos para analisar seu posicionamento dentro de sua área de atuação. Esse grande volume de dados de diferentes fontes e formatos demanda formas de armazenamento e consulta eficientes. Como solução de arquitetura para o armazenamento de dados, o Data Warehouse (DW) já é consolidado no mundo corporativo. O DW permitiu integrar em um único repositório dados provenientes de diferentes fontes e, com isso, ofertar aos usuários de DSSs a possibilidade de realizar análises complexas e dinâmicas sobre dados que não eram facilmente obtidos.

Porém, essa abundância de dados pode dificultar a compreensão de como as diferentes variáveis analisadas se relacionam. O DW, por sua característica desnormalizada, pode aumentar a dimensionalidade da análise, tornando o número de variáveis analisadas muito alto e aumentando, assim, sua complexidade. A técnica estatística de Análise de Componentes Principais (Principal Component Analysis, PCA) tem como um de seus objetivos reduzir a dimensionalidade do sistema, por meio da definição de uma nova base, cujos componentes são as Componentes Principais (PC), obtidas a partir da matriz de covariância das variáveis originais.

A construção de um DW na Universidade de São Paulo (USP) introduziu um novo paradigma para os usuários dos sistemas corporativos, em particular a alta gestão da instituição, ao oferecer sistemas analíticos, nos quais são apresentados relatórios das diferentes atividades-fim da universidade e há a possibilidade de se gerar relatórios dinâmicos, construídos pelos próprios usuários. Essa nova maneira de analisar a instituição pode conferir maior produtividade e confiabilidade na geração de informações. No entanto, a quantidade de dados oferecidos pode ser excessiva caso não haja a capacidade analítica necessária do lado do usuário. Ou seja, um sistema analítico bem sucedido requer capacitação dos usuários. Portanto, ferramentas que auxiliem o usuário a compreender os 
dados oferecidos são importantes nesse tipo de sistema.

Em uma instituição de ensino superior, os indicadores relacionados à atividade-fim de pesquisa são muito importantes. Indicadores bibliométricos, como o total de produção científica e citações, dentre outros índices, são uma maneira bastante utilizada para mensurar a produtividade e qualidade da pesquisa científica da instituição. Essa análise pode fundamentar a alocação de recursos de fomento à pesquisa, de modo a otimizá-los e tornar a produção científica mais eficiente. Atualmente, é possível acessar diversas fontes de pesquisa acadêmica para obter diferentes indicadores bibliométricos, tornando a análise da atividade de pesquisa cada vez mais rica e complexa. Por outro lado, o excesso de complexidade pode dificultar a análise, sendo necessário reduzi-la para compreender melhor todas as variáveis envolvidas.

Nessa linha, foi desenvolvida neste projeto uma ferramenta para a aplicação de PCA em modelos de dados multidimensionais, visando auxiliar o usuário a compreender a relação entre as diferentes variáveis analisadas, e foi realizado um estudo de caso sobre os dados de produção científica da Universidade de São Paulo.

\subsection{Objetivos}

O projeto de mestrado teve como objetivo a construção de uma API que permitisse a aplicação da técnica de PCA em modelos de dados multidimensionais, fornecendo ao usuário uma análise da correlação das variáveis envolvidas para melhor compreendê-las, e a integração dessa API aos DWs corporativos, especificamente o da Universidade de São Paulo.

\subsection{Contribuições}

Este trabalho contribui para a pesquisa na área de computação analisando a aplicação da técnica de PCA em modelos de dados multidimensionais e oferecendo uma API que facilite essa análise. Essa API foi desenvolvida de modo a atender diferentes padrões de modelagem multidimensional, realizando os cálculos de modo eficiente, incremental e resiliente a mudanças periódicas nos dados uma característica inerente dos Data Warehouses. Foi estudada a complexidade computacional da ferramenta e como os diferentes modelos podem influenciar na aplicação da técnica. Serão discutidas neste trabalho as estratégias de integração da API com o DW e o impacto dessas nas cargas periódicas de dados.

Além disso, o estudo de caso contribui para a área de pesquisa de índices bibliométricos, ao apresentar um estudo sobre os indicadores da USP, evidenciando como eles se correlacionam e analisando os resultados obtidos. Essa análise pode ser utilizada como um guia para as demais universidades realizarem suas próprias análises. 
A disponibilização da ferramenta para usuários da USP contribui no planejamento estratégico da instituição, auxiliando a compreensão dos indicadores das diversas atividades-fim e amparando a tomada de decisões pela alta gestão da universidade.

\subsection{Organização do Trabalho}

No Capítulo 2, apresentamos os conceitos que fundamentam a pesquisa realizada, especificamente o modelo dimensional, PCA, análise bibliométrica e o DW na USP. Em seguida, no Capítulo 3 são apresentados trabalhos que se relacionam com o tema de pesquisa proposto, separado em diferentes linhas de acordo com o assunto estudado. No Capítulo 4 são apresentadas uma visão geral do conteúdo desenvolvido durante a pesquisa de mestrado, a descrição da implementação da API e uma discussão sobre as estratégias de integração da ferramenta com o DW, bem como suas performances. Os experimentos para validação da API e estudos de caso relacionados aos indicadores bibliométricos são apresentados no Capítulo 5. Por último, o Capítulo 6 contém comentários finais sobre este trabalho e seus frutos e traz sugestões de algumas linhas para que trabalhos futuros possam dar continuidade à pesquisa. 


\section{Capítulo 2}

\section{Fundamentos}

O trabalho apresenta uma ferramenta para a aplicação de PCA em modelos multidimensionais. A ferramenta foi aplicada no modelo multidimensional que representa a produção científica da USP, extraída de plataformas externas à universidade, como as plataformas Lattes, CAPES, Web of Science e Scopus. Neste capítulo serão descritos os conceitos que fundamentam o trabalho, limitando-se ao escopo do caso analisado. Nas primeiras seções, 2.1, 2.2 e 2.3, descrevemos os conceitos do modelo multidimensional, as técnicas para PCA e alguns conceitos de análise bibliométrica, respectivamente. Em seguida, na seção 2.4, será apresentada a arquitetura do DW da USP.

\subsection{Modelo Multidimensional}

Os DDSs evoluíram muito desde suas primeiras aparições na década de 1970, ganhando força no ínicio da década de 1990 com a proposição do DW corporativo [SWC ${ }^{+}$02]. O termo Data Warehouse foi oficialmente introduzido por Bill Inmon em 1990 [Inm05]. Apesar disso, dentre as várias maneiras de se projetar um DW, a abordagem que Ralph Kimball propôs em seu livro é, discutivelmente, a mais utilizada no mundo corporativo [KC04]. Por esse motivo e pelo fato de que essa é a abordagem utilizada na USP, a proposta apresentada neste trabalho baseia-se somente nela. Os modelos multidimensionais, segundo essa abordagem, são compostos por tabelas fato e dimensões, como descritas a seguir:

- Tabelas fato: descrevem um processo ou operação por meio de relacionamento de dimensões, que fornecem uma descrição qualitativa do fato, e métricas, que o descrevem quantitativamente.

- Dimensões: descrevem entidades que contextualizam e classificam o processo de negócio evidenciado pela tabela fato.

Os dados podem ser armazenados sistemas gerenciadores de bases de dados relacionais (RDBMS) 
ou multidimensionais (MDBMS). No primeiro caso, denominamos o relacionamento entre tabelas fato e dimensões de modelo-estrela enquanto que nos MDBMS, o nome dado para esse relacionamento é cubo OLAP (Online Analytical Processing), como ilustrado na Figura 2.1. A ferramenta desenvolvida e o caso estudado se aplicam a bases de dados relacionais. Portanto, os cubos OLAP não serão abordados neste trabalho.

Vale citar que o projeto de um DW envolve várias etapas que não serão abordadas a fundo neste trabalho, como por exemplo os processos de ETL (Extract, Transform and Load) para carga do DW, a organização dos modelos em data marts, dentre outros. A referência [KC04] contém mais informações sobre o projeto completo de um DW.
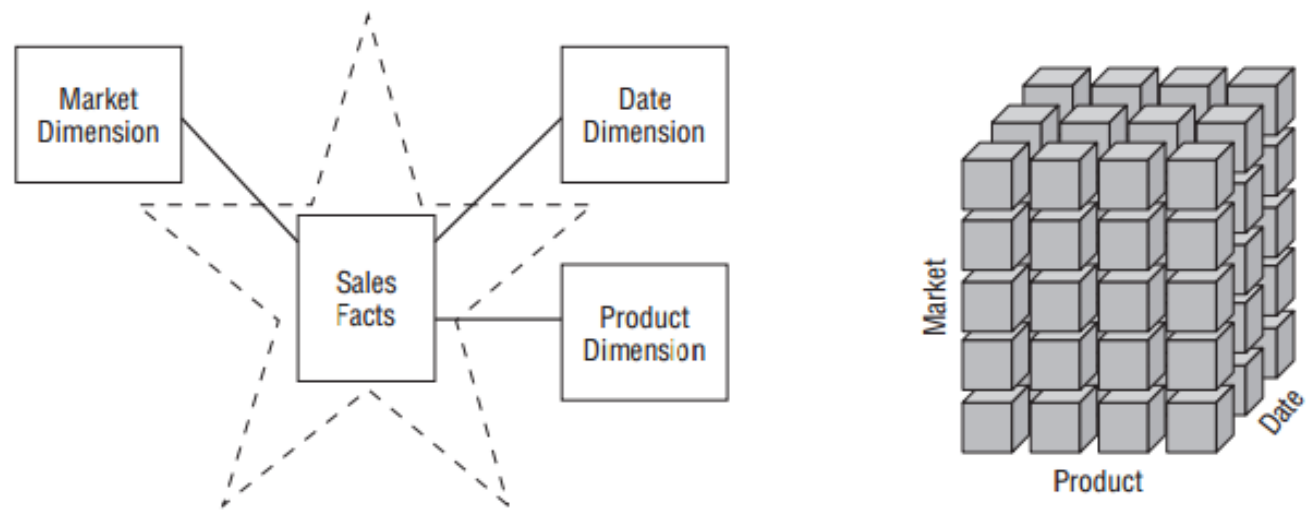

Figura 2.1: Modelo-estrela e cubo OLAP.

Figura retirada da referência [KC04].

Nas subseções seguintes, serão descritos com mais detalhes cada um dos componentes do modeloestrela.

\subsubsection{Tabela fato}

As tabelas fato descrevem um processo ou operação da instituição, como ilustrado na Figura 2.2. Chamamos de granularidade o que cada linha dessa tabela representa exatamente. As colunas das tabelas fatos são as chaves estrangeiras das dimensões associadas (ou também dimensões degeneradas, como será visto adiante) e colunas de métricas, que descrevem quantitativamente o fato e na maior parte dos casos são numéricas. As tabelas fato podem ser separadas em diferentes tipos, como os seguintes, que são utilizados no modelo da USP:

- Fato transacional: cada linha da tabela corresponde a uma transação relacionada a um evento operacional da instituição em um instante e local. Esse tipo de fato pode conter um número grande de dimensões.

- Fato snapshot: sumarizam diferentes fatos de mesma granularidade em um determinado período, como dias, semanas ou meses. 
- Fato sem fato: tabelas fato que não possuem métricas.

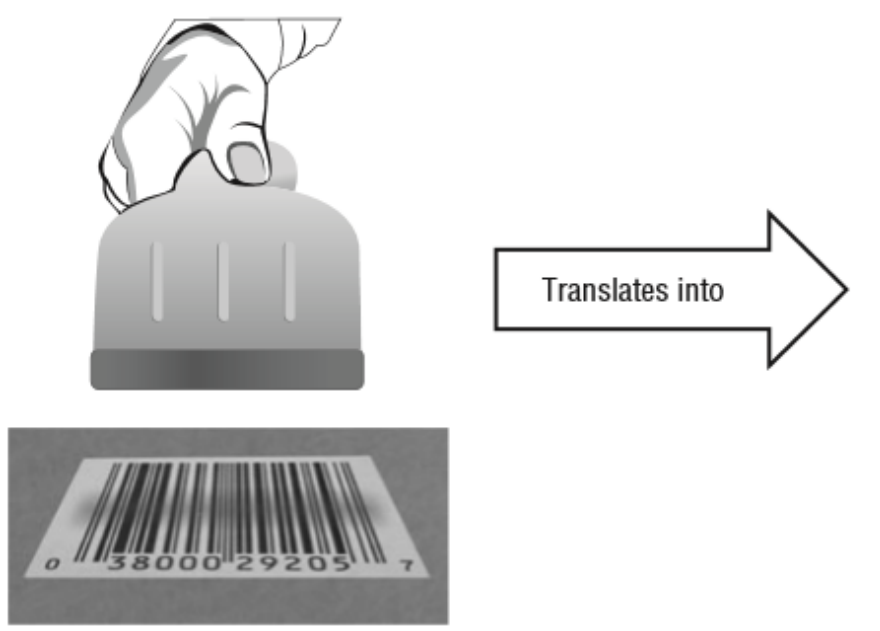

\begin{tabular}{|l|}
\hline \multicolumn{1}{|c|}{ Retail Sales Facts } \\
\hline Date Key (FK) \\
Product Key (FK) \\
Store Key (FK) \\
Promotion Key (FK) \\
Customer Key (FK) \\
Clerk Key (FK) \\
Transaction \# \\
Sales Dollars \\
Sales Units \\
\hline
\end{tabular}

Figura 2.2: Processo de negócio de vendas modelado em uma tabela fato. As dimensões estão representadas com as chaves estrangeiras: Data, Produto, Loja, Promoção, Cliente e Atendente. Além dessas, o número da transação representa uma dimensão degenerada. As métricas da tabela são o valor da venda em dólares e o total de unidades vendidas.

Figura retirada da referência [KC04].

\subsubsection{Dimensão}

As dimensões descrevem qualitativamente o fato, respondendo às perguntas "Quem? Onde? Quando? Como?" associadas ao evento medido. As tabelas possuem vários atributos textuais pelos quais as consultas analíticas são restringidas e as métricas são agrupadas. Além desses atributos, as dimensões possuem uma chave primária artificial, denominada Surrogate Key (SK), que substitui as chaves naturais do modelo operacional de origem. Essa chave é migrada para as tabelas fato e deve ser um inteiro para otimizar a performance das consultas ao se fazer joins entre fatos e dimensões. Outro motivo de se criar essa chave artificial para cada linha da dimensão é o fato de a maioria das dimensões armazenarem os dados históricos das entidades que representam. Nesse caso, cada alteração ocorrida na tabela origem das bases operacionais corporativas implica uma nova versão da entidade e uma nova linha na dimensão no DW. Cada versão é identificada com um número sequencial, uma data de início e uma de fim, que identificam o período em que aquela versão era válida. Esse tipo de dimensão é chamada Slowly Changing Dimension type 2 (SCD2). Existem outras maneiras de se manter o histórico de entidades no modelo dimensional, como a criação de uma nova coluna para cada atributo com o objetivo de armazenar o dado da versão anterior. Nesse caso, só se armazenam as duas últimas versões da entidade. No modelo da USP, porém, todas as dimensões possuem a estrutura de SCD2, exceto dimensões de tempo, que não possuem histórico.

Assim como as tabelas fato, as dimensões também podem ser classificadas em tipos, como os seguintes: 
- Dimensões conformadas: são dimensões comuns entre diversos modelos estrela. Essas dimensões são de grande importância no modelo dimensional, pois permitem relacionar fatos de mesma granularidade em modelos e data marts distintos. No âmbito da USP, podemos citar como exemplo as dimensões de Data e Unidade de Ensino.

- Dimensões degeneradas: as dimensões degeneradas não são armazenadas em tabelas físicas separadas, mas sim em atributos diretamente na tabela fato.

- Role-playing dimensions: são dimensões que podem ter significados diferentes nas tabelas fato. Por exemplo, a mesma dimensão de Pessoa na USP pode significar um aluno em um fato de concluintes de graduação ou um docente em um fato de disciplinas ministradas.

- Junk dimensions: são dimensões criadas por meio do produto cartesiano de dimensões de baixa cardinalidade. Por exemplo, em um modelo de vendas, em vez de se criar uma dimensão contendo os tipos de pagamento (dinheiro, cartão de crédito, cheque, etc.) e outra com as bandeiras de cartão de crédito, cria-se uma única dimensão com ambas as informações.

Outra característica das dimensões é a ausência de atributos nulos. No caso de dados não informados ou dados que não se aplicam à dimensão, como no exemplo da Junk dimension acima, no qual a informação de bandeiras de cartão de crédito não se aplica ao tipo de pagamento em dinheiro, deve-se preencher o atributo com um texto informando que o dado não se aplica ou não foi informado.

\subsection{Análise de Componentes Principais}

A técnica de Análise de Componentes Principais é uma ferramenta estatística que tem como objetivo descrever a estrutura de variância e covariância de um conjunto de variáveis ou dimensões, por meio de combinações lineares dos membros desse conjunto. Aplicada sobre amostras de medições em um dado sistema, a PCA nos mostra como e com qual importância essas dimensões impactam na variação dos valores medidos, frequentemente explicitando relacionamentos ocultos entre elas. Além disso, a PCA é uma ferramenta utilizada para mitigar redundâncias e reduzir a dimensionalidade do conjunto de variáveis utilizadas na observação do sistema por meio da criação de uma nova base, cujas componentes são linearmente independentes e em menor número, a partir das principais componentes apontadas pela PCA dentre o conjunto inicial de dimensões. Essas novas componentes são ordenadas de modo a manter a maior parcela da variância original nas primeiras componentes. Assim, a principal componente (PC) resultante da aplicação da PCA representa o eixo da nova base com a maior dispersão dos dados originais. 


\subsubsection{Algoritmo}

O algoritmo para a aplicação de PCA resume-se aos seguintes passos:

1. Organize os dados das medições em uma matriz $\mathrm{n} \times \mathrm{m}$, onde $\mathrm{m}$ é o número de variáveis medidas, ou dimensões, e n é o número de amostras.

2. Caso seja necessário, divida as medições de cada dimensão pelo seu desvio padrão para normalizá-las e evitar a sensibilidade da PCA à diferença de escala entre dimensões.

3. Calcule a matriz de covariância da matriz resultante dos passos anteriores (caso o passo 2 tenha sido efetuado, essa matriz será a de correlações).

4. Calcule os autovetores e autovalores associados à matriz de covariância.

5. Ordene os autovetores de acordo com os autovalores associados. Desse modo, o primeiro autovetor é a componente principal, o segundo é a segunda componente principal, e assim por diante.

6. Descarte as componentes de menor relevância. Para isso, defina o percentual da variância original que deve ser mantido e escolha as componentes principais de modo que a soma dos autovalores associados seja maior ou igual a esse percentual.

Existem outros algoritmos similares para calcular a PCA, como os que utilizam SVD (Singular Value Decomposition), uma generalização para a troca de bases. Esses algorítmos são tão relacionados que a PCA é muitas vezes chamada de SVD e vice-versa. Para dados de alta dimensionalidade, a aplicação de PCA iterativa pode ser uma alternativa mais viável [And09].

\subsubsection{Descrição matemática}

Seja o vetor $\mathbf{X}^{\prime}=\left[\mathbf{X}_{\mathbf{1}}, \mathbf{X}_{\mathbf{2}}, \cdots, \mathbf{X}_{\mathbf{p}}\right]$ com matriz de covariância $\boldsymbol{\Sigma}$, cujos autovalores são $\lambda_{1} \geq \lambda_{2} \geq \cdots \geq \lambda_{p} \geq 0$ e os autovetores associados $e_{1}, e_{2}, \cdots, e_{p}$.

Seja $a=\left[\begin{array}{c}a_{1} \\ a_{2} \\ \vdots \\ a_{p}\end{array}\right]$, então $Y=a^{t} X=a_{1} X_{1}+a_{2} X_{2}+\cdots+a_{p} X_{p}$ é uma combinação linear dos elementos do vetor $X$. 
Agora, considerem-se as combinações lineares:

$$
\begin{gathered}
Y_{1}=a_{1}{ }^{t} X=a_{11} X_{1}+a_{12} X_{2}+\cdots+a_{1 p} X_{p} \\
Y_{2}=a_{2}{ }^{t} X=a_{21} X_{1}+a_{22} X_{2}+\cdots+a_{2 p} X_{p} \\
\vdots \\
Y_{p}=a_{p}{ }^{t} X=a_{p 1} X_{1}+a_{p 2} X_{2}+\cdots+a_{p p} X_{p}
\end{gathered}
$$

Temos que:

$$
\begin{aligned}
& \operatorname{Var}\left(Y_{i}\right)=a_{i}{ }^{t} \Sigma a_{i} \quad i=1,2, \cdots, p \\
& \operatorname{Covar}\left(Y_{i}, Y_{k}\right)=a_{i}{ }^{t} \Sigma a_{k} \quad i, k=1,2, \cdots, p
\end{aligned}
$$

As componentes principais são as combinações lineares não correlacionadas $Y_{1}, Y_{2}, \cdots, Y_{p}$ para as quais a variância é a maior possível, decrescendo de $Y_{1}$ a $Y_{p}$.

Escolhendo os valores de $a_{i}$ como sendo os autovetores $e_{i}$ da matriz de covariância $\Sigma$ do vetor $X$, temos que a i-ésima componente principal, $Y_{i}$, é:

$Y_{i}=e_{i}{ }^{t} X=e_{i 1} X_{1}+e_{i 2} X_{1}+\cdots+e_{i p} X_{p} \quad i=1,2, \cdots, p$

E então,

$$
\begin{array}{rl}
\operatorname{Var}\left(Y_{i}\right)=e_{i}{ }^{t} \Sigma e_{i}=\lambda_{i} & i=1,2, \cdots, p \\
\operatorname{Covar}\left(Y_{i}, Y_{k}\right)=e_{i}{ }^{t} \Sigma e_{k}=0 & i, k=1,2, \cdots, p
\end{array}
$$

Para escolher as componentes principais de modo a manter a proporção $P_{v}$ da variância original dos dados, deve-se escolher as componentes $Y_{1}, \cdots, Y_{k}$ tais que: 


$$
\frac{\sum_{i=1}^{k} \lambda_{i}}{\sum_{i=1}^{p} \lambda_{i}} \geq P_{v}
$$

Ou seja, cada componente principal $Y_{k}$ representa uma proporção da variância de

$$
\frac{\lambda_{k}}{\sum_{i=1}^{p} \lambda_{i}}
$$

Mais detalhes da formalização da PCA podem ser obtidos na referência [JW ${ }^{+}$92].

\subsubsection{Resultados da PCA}

A PCA, segundo Johnson e Wichern [JW+92], é mais um meio para se atingir um resultado final do que um resultado por si só. Essa técnica é comumente utilizada para alcançar alguns objetivos como a redução de dimensionalidade em conjuntos de dados com muitas variáveis aplicando uma transformação para a base formada pelas componentes principais, mantendo a maior parte da variância original. Outra utilidade da PCA é explicitar correlações ocultas entre as variáveis, por meio de visualizações do resultado obtido pela aplicação da técnica. Essa nova apresentação dos dados pode auxiliar na interpretação dos mesmos, ao evidenciar tendências, tornar clara a relevância de variáveis para a variância original dos dados e mostrar redundâncias no conjunto original de variáveis. A Figura $2.3^{1}$ ilustra o resultado da aplicação de PCA sobre um conjunto de dados.

\subsection{Análise Bibliométrica}

A análise de índices bibliométricos é cada vez mais relevante no meio acadêmico como uma forma de classificar pesquisadores e produções qualitativamente e quantitativamente [DMCdM $\left.{ }^{+} 14\right]$. Um dos objetivos dessa análise é a obtenção de um critério para a alocação de fundos provenientes de instituições de fomento à pesquisa. Muitas variáveis podem ser analisadas nessa área, desde o simples total de publicações por autor e o número de citações das publicações a indicadores mais elaborados, como o indice-h. A proposição desse indicador, em 2005, causou um aumento no

\footnotetext{
${ }^{1}$ Figura retirada de http://www.joyofdata.de/public/pca-3d/ acessado em 05/05/2016
} 


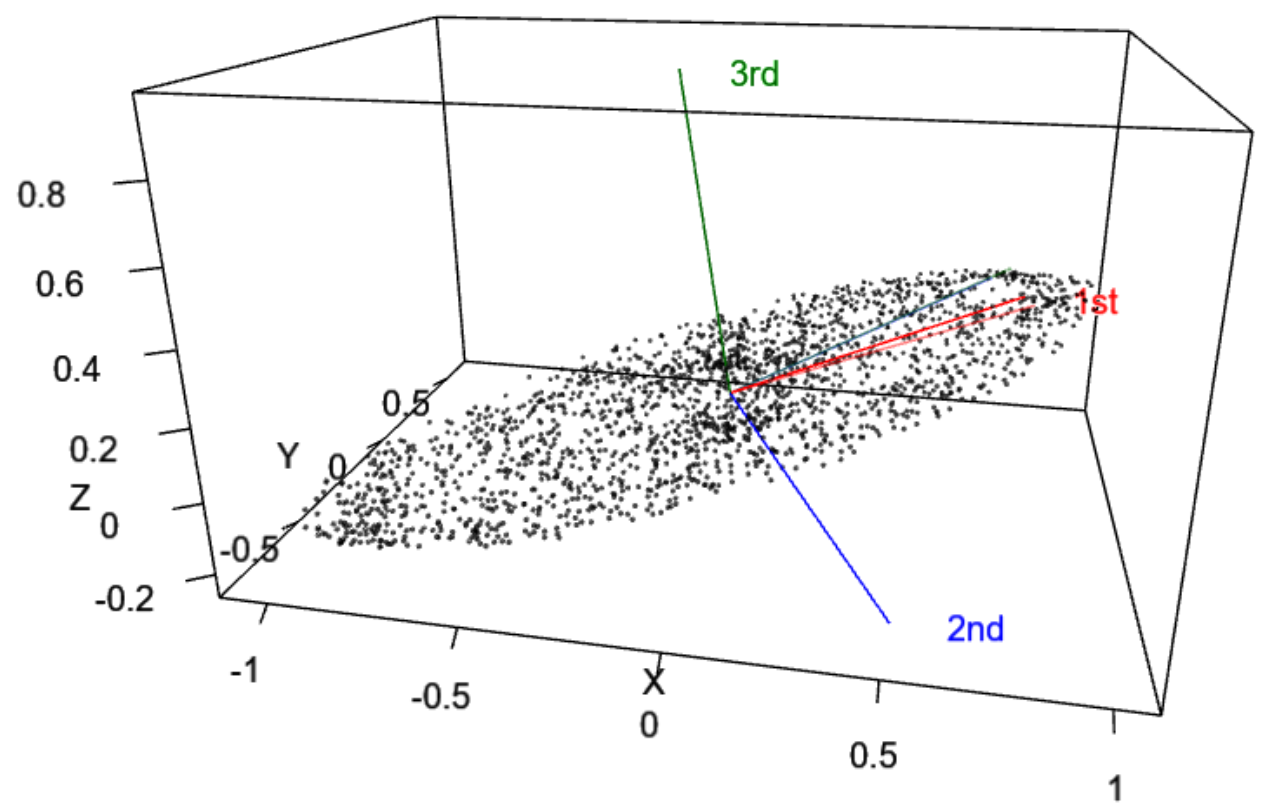

Figura 2.3: Gráfico com as principais componentes obtidas após a aplicação da técnica sobre um conjunto de dados.

interesse de pesquisa nessa área, o que implicou na tentativa de melhoria do mesmo e na criação de outros indicadores.

Nesta seção serão apresentados os conceitos utilizados no estudo de caso da USP.

\subsection{1 Índice-H}

O índice-H foi proposto em 2005 por Hirsch [Hir05] como uma métrica para caracterizar a produção científica de um pesquisador e é definido pelo número de publicações $\mathrm{H}$ que possuem pelo menos H citações, como ilustrado na Figura 2.4, extraída da publicação de Hirsch. Esse indicador é apresentado em importantes plataformas de pesquisa científica, como o Google Scholar e o Scopus. Porém, sua eficácia para a classificação de pesquisadores é discutível, já que a curva de citações do pesquisador não é analisada por inteiro. Algumas das desvantagens do índice-H podem ser encontradas nos trabalhos [GSKM15, ACHVH09], bem como alternativas para a caracterização de pesquisadores em relação à sua produção científica.

\subsubsection{Plataforma Lattes}

A Plataforma Lattes ${ }^{2}$, mantida pelo Conselho Nacional de Desenvolvimento Científico e Tecnológico $(\mathrm{CNPq})$, integra bases de dados de currículos, grupos de pesquisa e instituições em um único sistema. Por meio do Currículo Lattes (CV Lattes) preenchido pelos pesquisadores, as informações profissionais e acadêmicas dos mesmos são disponibilizadas para consulta pública, tornando a pla-

\footnotetext{
${ }^{2}$ Site da Plataforma Lattes - http://lattes.cnpq.br/
} 


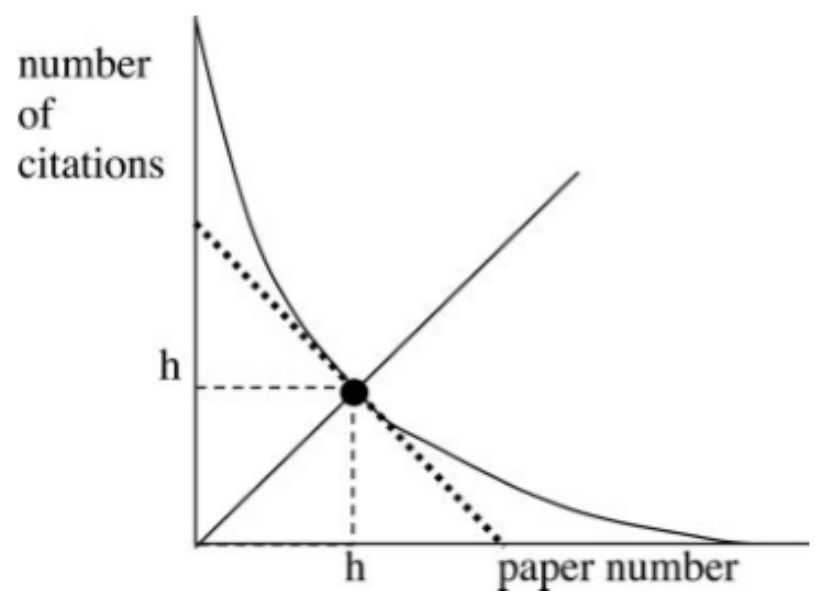

Figura 2.4: Gráfico representando a curva de citações de um autor. O ponto onde a curva intersecta a reta de inclinação 45 graus define o indice-h do autor. À esquerda desse ponto, as produções têm mais citações que $h$ e à direita, menos.

taforma a principal fonte de dados de produções científicas do Brasil, por conter virtualmente todas as publicações do país. Além disso, o CNPq possibilita a firmação de convênios com as universidades para a obtenção dos dados dos CV Lattes de pesquisadores da instituíção por meio de web-services. Todavia, como os dados são cadastrados manualmente pelos pesquisadores, podem ocorrer erros de digitação, duplicações e outros potenciais problemas para análises estatísticas, sendo, portanto, necessário validar os dados inicialmente e, se preciso, corrigir eventuais problemas.

\subsubsection{Conceito CAPES Qualis}

A Coordenação de Aperfeiçoamento de Pessoal de Nível Superior (CAPES), fundada pelo Ministério da Educação (MEC), tem como linhas de ação, segundo o site da instituição ${ }^{3}$, a avaliação da pós-graduação stricto sensu, acesso e divulgação da produção científica, investimentos na formação de recursos de alto nível no país e exterior, a promoção da cooperação científica internacional e a indução e fomento da formação inicial e continuada de professores para a educação básica. Por meio das informações na Plataforma Sucupira, a CAPES permite coletar dados, realizar análises e avaliações, colocando-se como base de referência do Sistema Nacional de Pós-Graduação (SNPG).

O conceito Qualis é um conjunto de procedimentos utilizado pela CAPES para estratificação da qualidade da produção intelectual dos programas de pós-graduação. Nesse sistema de avaliação, a produção é classificada indiretamente, por meio de conceitos atribuídos aos veículos de publicação da produção, os periódicos. Esses conceitos podem ter os valores A1, A2, B1, B2, B3, B4, B5 e C, sendo que o conceito A1 é o mais elevado e o conceito C tem peso zero. Essa classificação é atualizada anualmente e os periódicos podem ter conceitos diferentes de acordo com a Área de Avaliação relacionada ao programa de pós-graduação vinculado ao autor da produção científica.

\footnotetext{
${ }^{3}$ Site da CAPES - http://www.capes.gov.br/
} 


\subsubsection{Google Scholar}

O Google Scholar ${ }^{4}$ é uma ferramenta pública de pesquisa acadêmica da Google. Nessa plataforma, é possível não somente realizar buscas por produções, mas também por autores. Nesse caso, além da lista de publicações possivelmente pertencentes ao autor, na qual cada item apresenta a informação adicional do número de citações da publicação, o resultado também inclui a informação da página do autor, na qual é possível verificar o número total de citações do autor, dentre as produções contidas na base de informações do Scholar e que foram associadas ao autor, o índice-H e o índice-i10. O índice-i10 é um indicador criado pelo Google em 2011 que representa o número de publicações do autor com pelo menos 10 citações [sho].

\subsubsection{Scopus}

O Scopus foi criado em 2004 e possui o maior banco de dados de citações e resumos de publicações com revisão paritária [sco], no que diz respeito ao total de itens armazenados. Porém, a consulta em suas bases não é aberta para acesso público. A USP adquiriu acesso à plataforma devido a um convênio firmado com a CAPES. Assim como o Google Scholar, é possível realizar buscas por documentos e autores e obter o total de citações e as publicações do pesquisador.

\subsubsection{Web of Science}

O Web of Science (WOS) e o Scopus são os banco de dados mais aceitos na área acadêmica $\left[\mathrm{ACSY}^{+}\right.$13]. O WOS foi desenvolvido a partir do Science Citation Index (SCI), lançado em 1964 pela Thomson Reuters e, até a aparição do Scopus em 2004, era a única fonte de informações de citações e publicações que cobria todas as áreas da ciência. Por ser mais antigo, o WOS possui uma forte cobertura de publicações e citações, já que possui dados dos anos 1900. Portanto, apesar do Scopus possuir o maior banco de dados pelo número de registros que possui, o WOS alega possuir maior profundidade e qualidade nas informações oferecidas. Os dados podem ser obtidos dessa plataforma por meio de uma API, o que facilita a extração dos mesmos. Assim como o Scopus, a USP adquiriu acesso à plataforma por meio de um convênio firmado com a CAPES.

\subsection{Data Warehousing na USP}

A Universidade de São Paulo é uma das maiores instituições de ensino superior público da América Latina, com 52 unidades de ensino, aproximadamente 6.000 docentes, 35.000 alunos de pósgraduação e 55.000 alunos de graduação. Esse grande número de pessoas produz grande quantidade de informações ao se relacionarem com as diferentes atividades-fim (Graduação, Pós-Graduação,

\footnotetext{
${ }^{4}$ Site do Google Scholar - https://scholar.google.com.br/
} 
Pesquisa, Cultura e Extensão) e atividades-meio (Gestão, Tecnologia da Informação, Segurança, entre outras). Como exemplo dentro do contexto da Pós-Graduação, podemos citar diversas etapas de processos que podem gerar informações relevantes para a gestão: credenciamento de docentes, orientações, matrícula de alunos, titulação de alunos, rendimento acadêmico nas disciplinas, evasão, produção científica e muitas outras. Esse grande número de operações e as consequentes informações geradas justifica a construção de um Data Warehouse, para que seja possível implantar um sistema analítico eficiente e confiável que apoie a tomada de decisões pela universidade, como o DataUSP ${ }^{5}$.

\subsubsection{Arquitetura}

Para a construção do Data Warehouse, optou-se por utilizar o modelo dimensional conforme proposto por Ralph Kimball [KC04]. As fontes de dados para a construção do DW da universidade são as bases de dados corporativas, segmentadas em bases diferentes para cada sistema atrelado a uma área de negócio, e algumas fontes externas como a Fundação Universitária para o Vestibular (FUVEST), CAPES, CNPq, Scopus, Google Scholar e WOS.

Para que os processos de carga do DW não onerem a performance dessas bases, nas quais ocorrem as operações da universidade - como matrículas, inserção de notas, geração de folha de pagamento, entre outras - as tabelas usadas como fonte no carregamento do DW são replicadas para bases isoladas, chamadas Normalized Data Stores (NDS). Existe uma NDS para cada área de atividade e essas bases também são utilizadas como áreas para staging e profiling de dados, que são as etapas de pré-processamento, nas quais os dados são conformados, desnormalizados e verificam-se seus metadados, como tipo de dado, tamanho e distribuição.

Utilizando uma ferramenta ${ }^{6}$ de código aberto para processos de ETL (Extract, Transform and Load), é feito o profiling dos dados e os scripts para a carga do modelo dimensional em uma base ainda relacional (RDBMS), na qual se localiza o DW corporativo. Esse DW é carregado usando a abordagem bottom-up de Kimball: são construídos primeiramente os data marts, que juntos compõem o DW. Os scripts para a carga do modelo são executados de forma automática diariamente, semanalmente ou mensalmente. O agendamento das execuções é definido em função da variação dos dados nas bases operacionais, estimada a priori. No caso da produção científica extraída da Plataforma Lattes do CNPq, por exemplo, a execução tem sido semanal, devido à alta frequência de atualização dos currículos dos docentes.

Como estratégia para otimizar a performance do processo, são realizadas cargas incrementais com o auxílio de tabelas de controle, que são povoadas por meio de triggers aplicadas nas tabelasfonte dos bancos de dados operacionais. A estrutura dessas tabelas de controle é composta por primary keys do modelo relacional, o tipo de alteração de dados (i.e. insert, update ou delete) e a

\footnotetext{
${ }^{5}$ Site do DataUSP: https://uspdigital.usp.br/datausp

${ }^{6}$ Pentaho Data Integration - http://community.pentaho.com/projects/data-integration/
} 
data em que a alteração ocorreu. Em uma outra tabela, são registradas as execuções dos processos de carga do modelo dimensional, com o nome do processo, tabela atualizada e a data da execução da ETL. Com essa data, é possível verificar nas tabelas de controle da carga incremental quais atualizações ocorreram após a última carga do DW e assim carregar somente as linhas alteradas ou inseridas.

A arquitetura do ambiente de DW na USP está ilustrada na Figura 2.5.

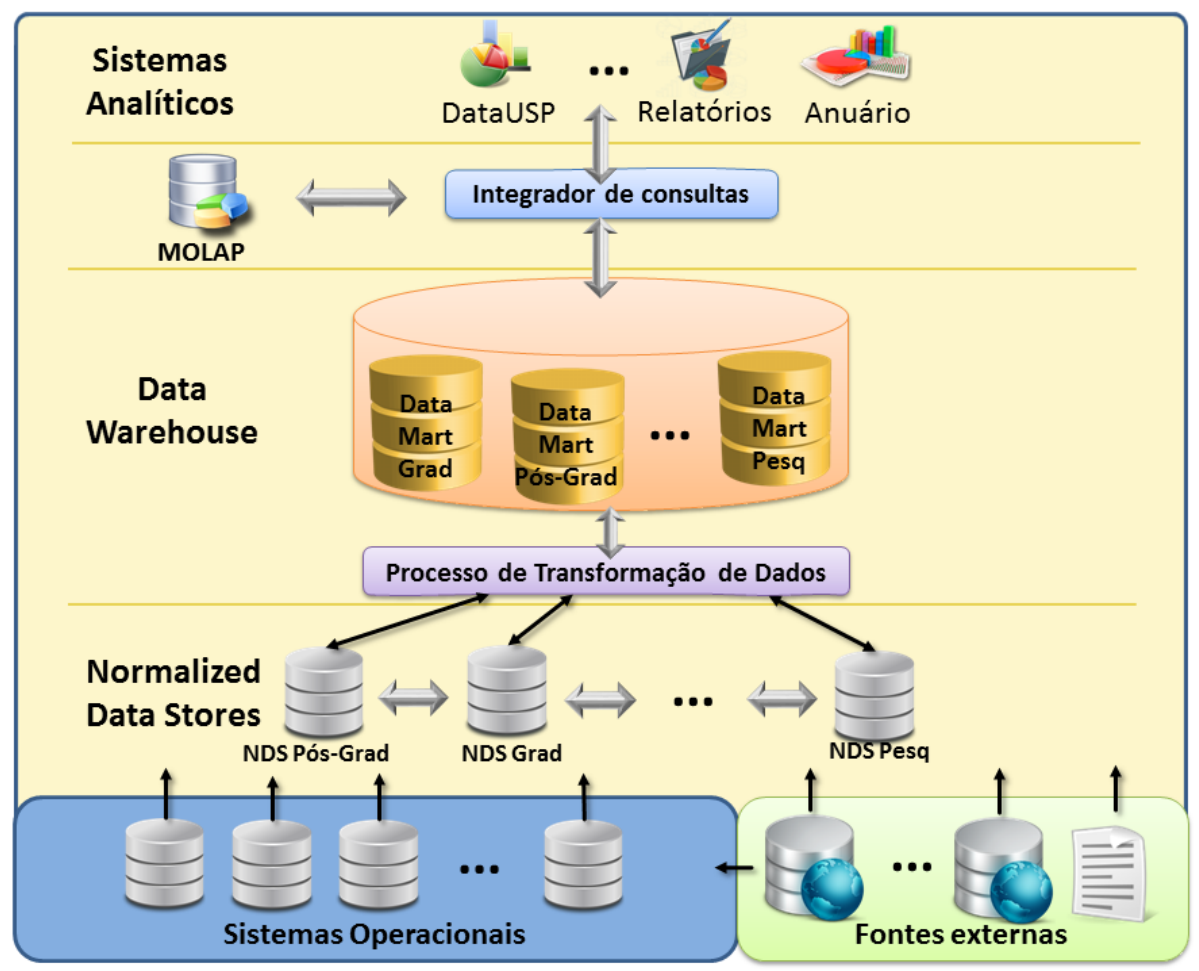

Figura 2.5: Arquitetura do ambiente de DW da USP. 


\section{Capítulo 3}

\section{Trabalhos relacionados}

A PCA é uma técnica estatística muito utilizada em diversas áreas, o que leva a uma abundância na literatura acadêmica sobre esse tema. Sua aplicação especificamente em DW, porém, não é encontrada facilmente. As fontes de consulta utilizadas foram a biblioteca digital da ACM (Association for Computing Machinery) ${ }^{1}$, a base do IEEE (Institute of Electrical and Electronics Engineers $)^{2}$ e o Google Scholar. Para facilitar a consulta às referências, os trabalhos relacionados foram classificados em quatro categorias: análise de índices bibliométricos com uso de PCA, aplicações de PCA em DW, uso de PCA como apoio à interpretação de dados e aplicações diversas de PCA.

\subsection{Análise de índices bibliométricos}

O estudo de caso proposto neste projeto é a aplicação da técnica de PCA sobre um conjunto de dados referentes à atividade-fim de pesquisa na Universidade de São Paulo. Alguns índices bibliométricos serão coletados para tal fim, como o total de citações, total de produções científicas, índices-h e i10, dentre outros. O trabalho de Digiampietri et al $\left[\mathrm{DMCdM}^{+} 14\right]$ apresenta uma comparação dos programas da área de Ciência da Computação nas diversas universidades brasileiras utilizando a técnica de PCA, dentre outras técnicas estatísticas. Os dados utilizados no trabalho foram obtidos da Plataforma Lattes, do Google Scholar e de outras fontes e é abordada a fase de pré-processamento dos dados. Como resultado da análise, os autores puderam verificar a correlação entre os diversos indicadores bibliométricos utilizados e evidenciar alguma similaridade entre os programas melhor avaliados pela CAPES, por meio de um gráfico no qual os dados originais foram transformados para a nova base determinada pela aplicação da PCA. Nesse gráfico, os programas agruparam-se de acordo com o score relativo às principais componentes.

\footnotetext{
${ }^{1}$ Site da biblioteca digital da ACM - http://dl.acm.org/

${ }^{2}$ Site da biblioteca digital do IEEE - http://ieeexplore.ieee.org//
} 
Gogoglou et al [GSKM15] apresentam uma crítica ao índice-H já que, apesar de informativo, o indicador não analisa a curva de citação completa. O autor aplica a técnica de PCA para analisar como os índices bibliométricos se correlacionam. Como conjunto de dados, foi utilizado o ranking dos 20 melhores autores, segundo o índice-H, de um total de 345 autores de universidades gregas que publicaram na área de Ciência da Computação, Engenharia e Informática e seus indicadores bibliométricos, como o próprio índice-H, o Perfectionist Index (PI) [SKM15], que utiliza a curva de citações como um todo em seu cálculo, além de quatro outros índices propostos pelo próprio autor. É apresentado o ranking dos autores segundo as diversas métricas e pode-se notar que há grande diferença na informação transmitida por cada uma delas, evidenciando que a análise bibliométrica deve considerar indicadores distintos para possibilitar cobertura sobre os variados aspectos relacionados à pesquisa científica.

O trabalho de Bollen et al [BVdSHC09] provê uma visão geral de 39 índices bibliométricos, ao aplicar a PCA sobre esses indicadores. Além de utilizar índices baseados em citações, a análise leva em consideração dados de interação de usuários com as plataformas para pesquisa científica, como o total de downloads de textos completos e o número de cliques. Esses indicadores podem oferecer uma métrica imediatamente após a publicação, não sendo necessário esperar um grande tempo para que o trabalho seja citado por outro. Interpretando os clusters formados a partir do gráfico cujos eixos são as principais componentes apontadas pela PCA, no qual os indivíduos originais foram inseridos, o autor pôde classificar os índices de acordo com a visão que oferecem do impacto científico das publicações e oferecer, assim, um entendimento da relevância de cada indicador para a análise bibliométrica.

\subsection{PCA em Data Warehouses}

Na pesquisa realizada, não foram encontrados muitos trabalhos a respeito da aplicação específica de PCA em DWs. Os trabalhos de Elmansouri et al [EZEA12, EEZ13] propõem a utilização da técnica para a fragmentação de DWs já construídos, de modo a otimizar a resposta de consultas OLAP, baseando-se nos clusters formados a partir da projeção dos dados nas principais componentes encontradas. Tebourski et al [TBAKBG14] introduzem uma abordagem para a construção de um DW baseada na aplicação de PCA. O algoritmo é dividido em quatro etapas: a primeira estuda a matriz de covariância dos dados, para identificar grupos de variáveis que poderão compor fatos ou dimensões; em seguida, são escolhidas as principais componentes resultantes da aplicação de PCA, de modo que a variância total explicada seja suficientemente grande. O número de componentes principais obtido será o número de objetos no modelo dimensional - fato e dimensões; na terceira etapa, um especialista analisa a correlação entre as componentes principais e as variáveis originais, 
para identificar o que cada uma representa e nomeá-las de acordo com as dimensões correlacionadas; no último passo, é gerado um modelo estrela no qual uma componente principal é o fato e as demais são as dimensões.

A construção de um DW permite a aplicação de técnicas de mineração de dados de diferentes fontes. Para isso, esses dados devem ser movidos das diferentes fontes para o repositório central, que é o DW. Alternativamente, os trabalhos de Chandra et al [CA11] e Qi et al [QWB04] aplicam a técnica de PCA para redução de dimensionalidade em sistemas ditribuídos de mineração de dados, nos quais os dados estão armazenados em bancos de dados separados.

No mesmo tema de aplicação de PCA em bancos de dados distribuídos Elgamal et al [EYA $\left.{ }^{+} 15\right]$ analizam métodos para aplicação da técnica e introduzem uma implementação de aplicação de PCA escalável para sistemas de Big Data distribuídos em diferentes plataformas.

\subsection{PCA como apoio à interpretação de dados}

A PCA é uma técnica muito utilizada como meio para atingir diversos objetivos, como regressões múltiplas e análise de clusters. Porém, a apresentação dos dados nas bases formadas pelas principais componentes é, por si só, um resultado importante na interpretação do conjunto de dados iniciais. O trabalho de Müller et al [MNS06] mostra como a visualização do resultado de PCA pode ser utilizada para a descoberta de tendências entre as variáveis iniciais. Por meio de diversos formatos de visualização, o usuário pode compreender a relação entre as dimensões analisadas e aplicar filtros nos dados ou ordená-los de maneiras diferentes para auxiliar na interpretação dos mesmos.

Jeong et al [JZR $\left.{ }^{+} 09\right]$ apresentam uma ferramenta de visualização para auxiliar no entendimento da técnica de PCA, chamada Interactive PCA (iPCA). Utilizando uma técnica chamada Online SVD [Bra03], o cálculo de PCA é feito em tempo real, a partir da interação do usuário com a ferramenta, por meio de filtros e outras opções de controle. Os resultados são apresentados em gráficos e tabelas que permitem entender a contribuição dos dados no conjunto inicial e nas principais componentes apontadas pela PCA.

Outra ferramenta para aplicação automatizada de PCA foi implementada por Lê, Josse e Housson $\left[\mathrm{LJH}^{+}\right.$08, JLH] utilizando o software R de computação estatística ${ }^{3}$. Nessa ferramenta, o usuário pode selecionar as variáveis que serão levadas em consideração no cálculo da PCA e também selecionar variáveis suplementares, que aparecerão nos gráficos com os resultados finais. Além disso, esse trabalho leva em consideração variáveis qualitativas e não somente as quantitativas. Essas variáveis são representadas quantitativamente pela média das demais variáveis numéricas calculada para cada valor diferente que a variável qualitativa pode receber. Nos gráficos resultantes, os pontos são coloridos de acordo com a variável qualitativa escolhida na análise.

\footnotetext{
${ }^{3}$ Site do projeto R - https://www.r-project.org/
} 


\subsection{Outras aplicações de PCA}

Na pesquisa bibliográfica deste projeto, foram analisadas aplicações da técnica de PCA em diversas áreas de pesquisa. Nesta seção, serão apresentadas algumas dessas aplicações.

Casimiro [CBF] apresenta a aplicação de PCA na área de marketing digital, em um sistema de ordenação de anúncios em um dos maiores portais web do Brasil. Aplicando a técnica sobre um conjunto de variáveis relacionadas a anúncios digitais, como a taxa de cliques por impressão do anúncio (CTR, click through rate), dentre outras, o autor conseguiu compreender a relação entre cada indicador e desenvolver um modelo de ordenação e apresentação de anúncios para otimizar a performance comercial tanto do portal como dos anunciantes e também melhorar a experiência de navegação do usuário.

Driemeier et al $\left[\mathrm{DLP}^{+} 14\right]$ utilizam a PCA na área de agricultura de precisão, aplicada sobre um conjunto de dados relacionados à produção de cana-de-açúcar em larga escala. A análise é feita sobre dados coletados por meio de diferentes tecnologias e técnicas e tem como objetivo fornecer um guia para experimentações futuras e auxiliar na escolha das tecnologias mais viáveis para a agricultura de precisão em larga escala. 


\section{Capítulo 4}

\section{PCA em DWs corporativos}

\subsection{Visão geral}

Neste trabalho de mestrado foi construída uma API para aplicação de PCA em modelos de dados multidimensionais integrada a Data Warehouses, que foi disponibilizada na página do autor no GitHub: https://github.com/rafaelgermanorossi/pca-api. Também foram realizados estudos com a utilização dessa ferramenta sobre o modelo referente à produção científica da USP e os índices bibliométricos relacionados. A visão geral da API e do estudo de caso serão apresentados com mais detalhes a seguir.

\subsubsection{API}

Inicialmente cogitou-se desenvolver a API utilizando a linguagem Python. Porém, a API foi desenvolvida utilizando a linguagem Java para possibilitar a integração com os sistemas corporativos da USP, nos quais essa linguagem é o padrão. A ferramenta desenvolvida fornece métodos para a execução de cada passo do algoritmo da PCA, como o cálculo da matriz de covariância e a definição de autovetores e autovalores, além de métodos para a atualização dos cálculos a cada nova observação inserida no ambiende de DW. A definição de configurações para conexão aos bancos de dados e especificação das consultas são feitas em arquivos texto contendo propriedades. Os resultados da PCA e outras classes Java são apresentados no formato JSON, para facilitar a integração com diversas ferramentas de visualização.

\subsubsection{Estudo de caso - USP}

Para o estudo de caso da USP, os dados relativos aos docentes ativos foram extraídos das diferentes plataformas de pesquisa acadêmica, especificamente o WOS, Google Scholar, Scopus, Plataforma Lattes e CAPES Qualis, e carregados em bases de dados relacionais. As produções científicas foram obtidas da Plataforma Lattes, por meio de arquivos XML (eXtensible Markup Language) recebidos 
via web service fornecido pelo $\mathrm{CNPq}$, e do WOS, por meio da API disponibilizada pela própria plataforma. Os dados de citações, índices-H e i10 foram obtidos por meio de scripts de crawling, executados nas plataformas WOS, Google Scholar e Scopus. Os dados da avaliação CAPES Qualis foram obtidos manualmente na página web da instituição. Em seguida, os dados foram convertidos para modelos multidimensionais por meio de processos de ETL, sobre os quais a ferramenta desenvolvida será aplicada. O processo de extração de dados está ilustrado na Figura 4.1.

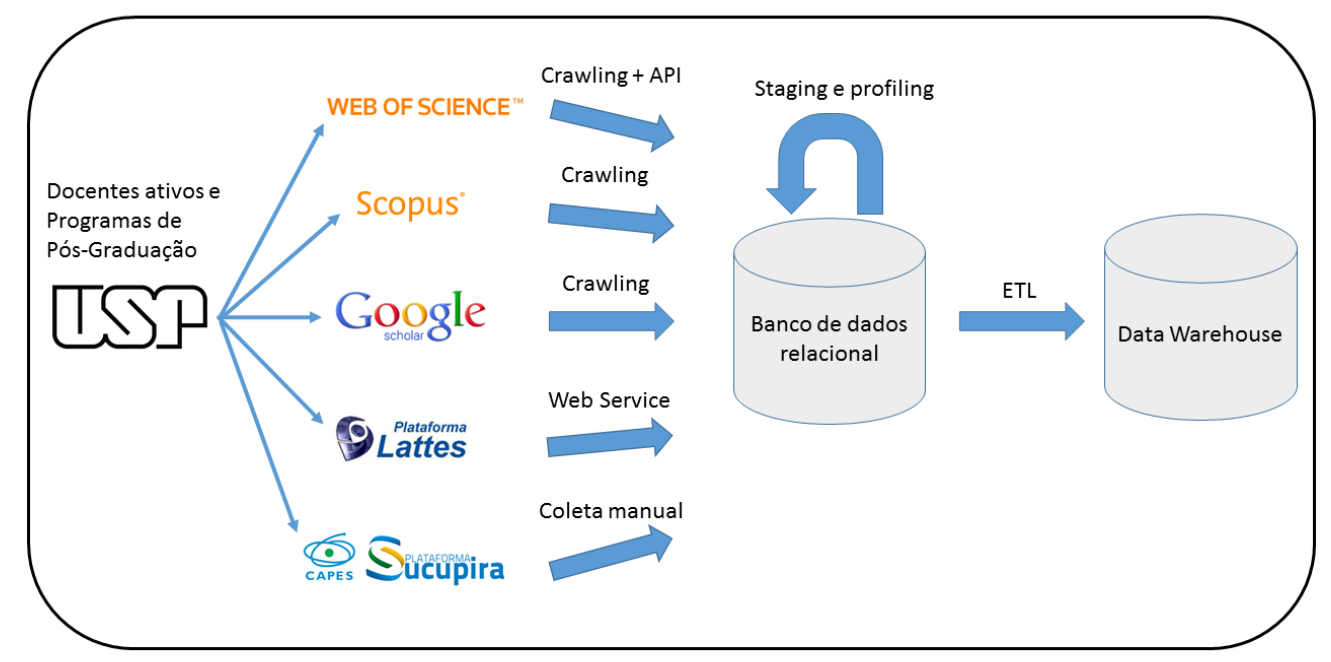

Figura 4.1: As consultas nas plataformas de pesquisa científica são feitas com base nos docentes ativos da USP e dos programas de pós-graduação, no caso da CAPES. Os dados das pesquisas são extraídos por diferentes maneiras, dependendo da fonte, e carregados em bancos de dados relacionais. Em seguida, é feito o pré-processamento dos dados nesse mesmo banco. Por fim, processos de ETL carregam os modelo multidimensionais no Data Warehouse.

\subsubsection{Modelo multidimensional}

Atualmente, o DW da USP possui modelos carregados nos data marts das áreas de pósgraduação, graduação, RH, pesquisa, cultura e extensão, relações internacionais e alumni (egressos). No modelo da atividade-fim pesquisa, estão incluídos dados da produção científica, citações, índices H e i10 e conceito Qualis das produções científicas dos docentes, obtidos da Plataforma Lattes do CNPq, WOS, Scopus, Scholar e CAPES. As produções dos docentes obtidas da Plataforma Lattes, são carregadas em um fato sem métricas como ilustrado na Figura 4.2. A partir desse fato são gerados outros fatos agregados, com a totalização das produções agrupadas em diversas granularidades: total de produções por docente, por unidade de ensino, por departamento de ensino, etc.

Para este trabalho de mestrado, foi construída uma tabela fato contendo todos os índices bibliométricos obtidos das diferentes fontes, além de indicadores obtidos dos sistemas corporativos da universidade. Essa tabela possui a menor granularidade possível, para que seja possível a criação de tabelas agregadas a partir dela. Desse modo, foi possível aplicar a PCA e analisar a correlação 


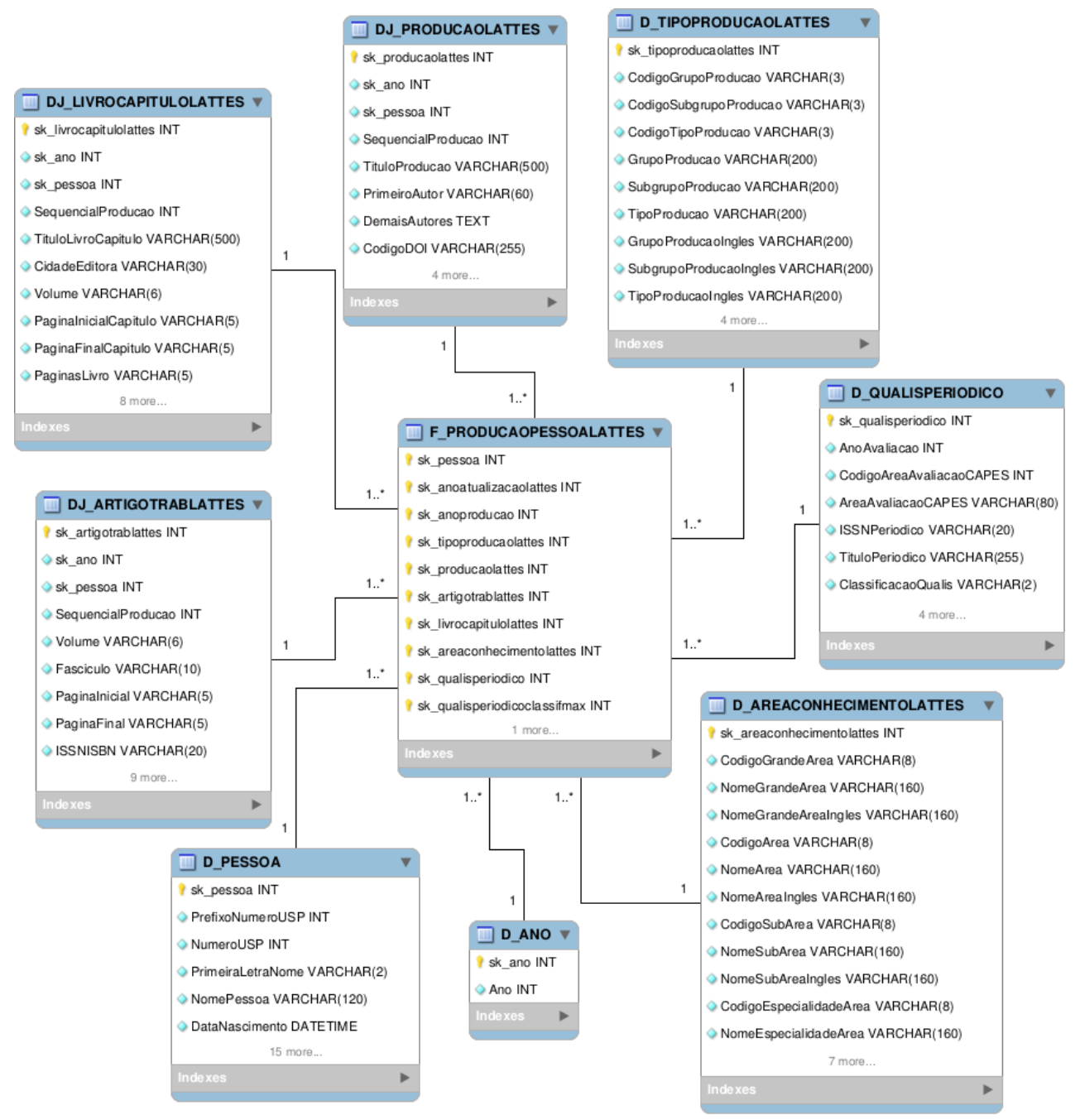

Figura 4.2: Modelo-estrela relativo à tabela fato contendo os dados das produções científicas de docentes USP obtidas da Plataforma Lattes, e suas dimensões.

de cada índice, e obtendo uma visão geral dos dados de produção científica da universidade sob diferentes perspectivas. As variáveis que foram analisadas estão apresentadas na Tabela 4.1.

\subsection{Desenvolvimento da API}

A API proposta, disponibilizada no GitHub ${ }^{1}$, foi desenvolvida utilizando-se a linguagem Java e essa escolha foi baseada na fluência do mestrando na linguagem e também por ser o padrão de desenvolvimento de sistemas na Divisão de Sistemas da Superintendência de Tecnologia da Informação da USP. Os modelos de dados e os objetos Java de acesso aos dados foram implementados com compatibilização com a base de dados Sybase, que é a utilizada na Universidade de São Paulo, na versão 12.5.4. Porém, como essa base de dados possui licença comercial, a API também foi compatibilizada com a base $M y S Q L$ versão 5, que é gratuita, para facilitar a reprodutibilidade dos estudos. Além disso, a API foi construída de modo a possibilitar a execução da PCA sobre dados

\footnotetext{
${ }^{1}$ Página da API: https://github.com/rafaelgermanorossi/pca-api
} 


\begin{tabular}{|c|l|}
\hline Variável & Descrição \\
\hline PCL & Total de produções científicas obtidas da plataforma Lattes \\
\hline APL & Total de artigos publicados obtidos da plataforma Lattes \\
\hline TJRL & Total de textos em jornais ou revistas obtidos da plataforma Lattes \\
\hline TEL & Total de trabalhos em eventos obtidos da plataforma Lattes \\
\hline LCL & Total de livros ou capítulos de livros obtidos da plataforma Lattes \\
\hline AAPL & Total de artigos aceitos para publicação obtidos da plataforma Lattes \\
\hline DPL & Total de demais produções obtidas da plataforma Lattes \\
\hline PCW & Total de produções científicas obtidas da plataforma WOS \\
\hline PCG & Total de produções científicas obtidas da plataforma Google Scholar \\
\hline PCS & Total de produções científicas obtidas da plataforma Scopus \\
\hline CITW & Total de citações obtidas da plataforma WOS \\
\hline CITG & Total de citações obtidas da plataforma Google Scholar \\
\hline CITS & Total de citações obtidas da plataforma Scopus \\
\hline IHW & Índice-H obtido da plataforma WOS \\
\hline IHG & Índice-H obtido da plataforma Google Scholar \\
\hline IHS & Índice-H obtido da plataforma Scopus \\
\hline I10G & Índice-i10 obtido da plataforma Google Scholar \\
\hline TME & $\begin{array}{l}\text { Total de títulos de mestrado outorgados a alunos do docente obtido dos sistemas corpora- } \\
\text { tivos da USP }\end{array}$ \\
\hline TDO & $\begin{array}{l}\text { Total de títulos de doutorado outorgados a alunos do docente obtido dos sistemas corpo- } \\
\text { rativos da USP }\end{array}$ \\
\hline EWQ & Estrato Web Qualis, obtido da CAPES, segmentado em total de produções por estrato \\
\hline BP & Bolsa de produtividade do CNPq \\
\hline AC & Área de ciências \\
\hline
\end{tabular}

Tabela 4.1: Variáveis que foram analisadas na aplicação de PCA.

obtidos de arquivos texto no formato CSV (Comma Separated Values).

A codificação foi voltada para o uso de interfaces e classes abstratas, com o intuito de tornar a ferramenta facilmente extensível e modificável (por exemplo, para compatibilização com demais bases de dados, tipos de arquivos de entrada e diferentes implementações dos cálculos). A arquitetura da API segue a seguinte segmentação, como pode ser visto no diagrama de classes da Figura 4.3: a entrada de dados pode ser feita por meio de arquivos CSV ou resultados de consultas a banco de dados armazenados na classe ResultSet, do pacote padrão java.sql. Para cada tipo de entrada, foram desenvolvidas classes que implementam a interface IDataSetConversor, que têm como objetivo a conversão desses dados para uma estrutura padrão para ser usada internamente na API. Essa estrutura é representada pela classe abstrata AbstractDataSet, para a qual foi fornecida uma implementação padrão. Nessa classe, são armazenados os dados numéricos e classificatórios, cuja segmentação é feita de acordo com o tipo de dado, isto é, se é possível converter o dado original em um número - nesse caso, o dado é numérico e pode ser usado no cálculo da PCA - ou não nesse caso, o dado é classificatório e pode ser usado para descrever as observações em classes. Cada dimensão presente nos dados originais é armazenada em uma estrutura do tipo Bean, chamada 
DimensionBean, que possui atributos para descrevê-la e também atributos para auxiliar os cálculos (e.g. label, que descreve o nome da dimensão e currentAverage, que contém a atual média dos valores da dimensão, aplicado para as dimensões numéricas).

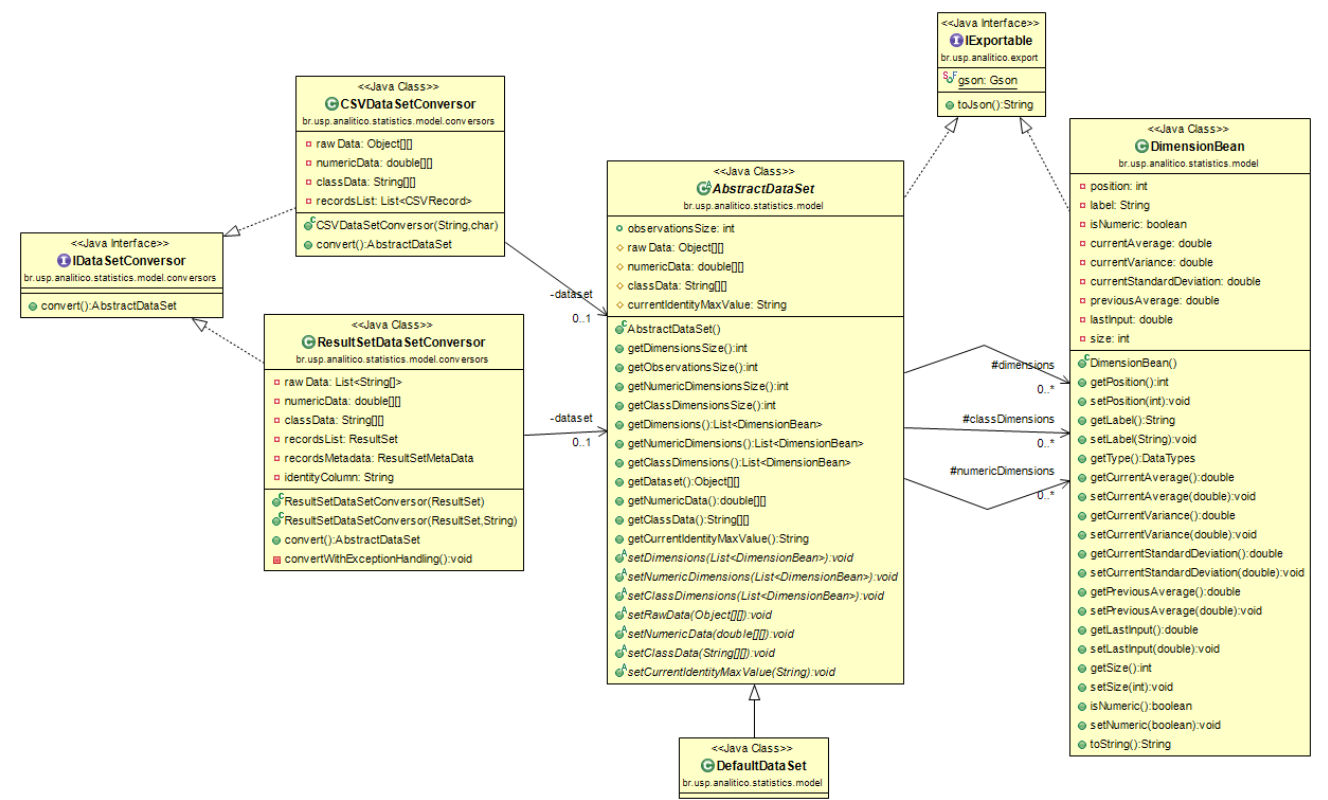

Figura 4.3: Diagrama de classes gerado a partir da modelo de dados implementado na API. A codificação é voltada para o uso de interfaces e classes abstratas.

Os cálculos estatísticos e de álgebra linear, como por exemplo o cálculo de variância e desvio padrão, normalização de vetores e matrizes, cálculo de autovetores, composição de matrizes de covariâncias e atualização incremental dessa matriz, entre outros, são feitos em uma classe de apoio, denominada Statistics.

A coordenação entre a estrutura de dados interna e os cálculos sobre ela para a aplicação da PCA é feita por meio de uma classe denominada PrincipalComponentAnalysis. A variância total que deve ser representada pelas principais componentes é configurável e possui o valor padrão de 0,95. Também é possível, por meio de um parâmetro booleano com valor padrão verdadeiro, escolher normalizar os dados antes da aplicação da PCA e, nesse caso, aplicá-la sobre a matriz de correlação dos dados originais. As principais componentes encontradas pela aplicação do método são armazenadas em uma estrutura denominada PrincipalComponent que armazena alguns atributos como o vetor e magnitude da componente (autovetor e autovalor da matriz de covariâncias/correlações), a proporção da variância explicada por ela e sua classificação baseada nesse valor. A PrincipalComponentAnalysis, assim como outras classes, como DimensionBean e PrincipalComponent, implementam a interface IExportable, que provê o método padrão toJson(), cujo resultado é uma String no formato JSON com os atributos da classe. Para a composição dessa String, foi utilizada a biblioteca Gson da Google, na versão 2.8.0. A Figura 4.4 apresenta o diagrama de sequência originado a partir do uso dessa classe. 


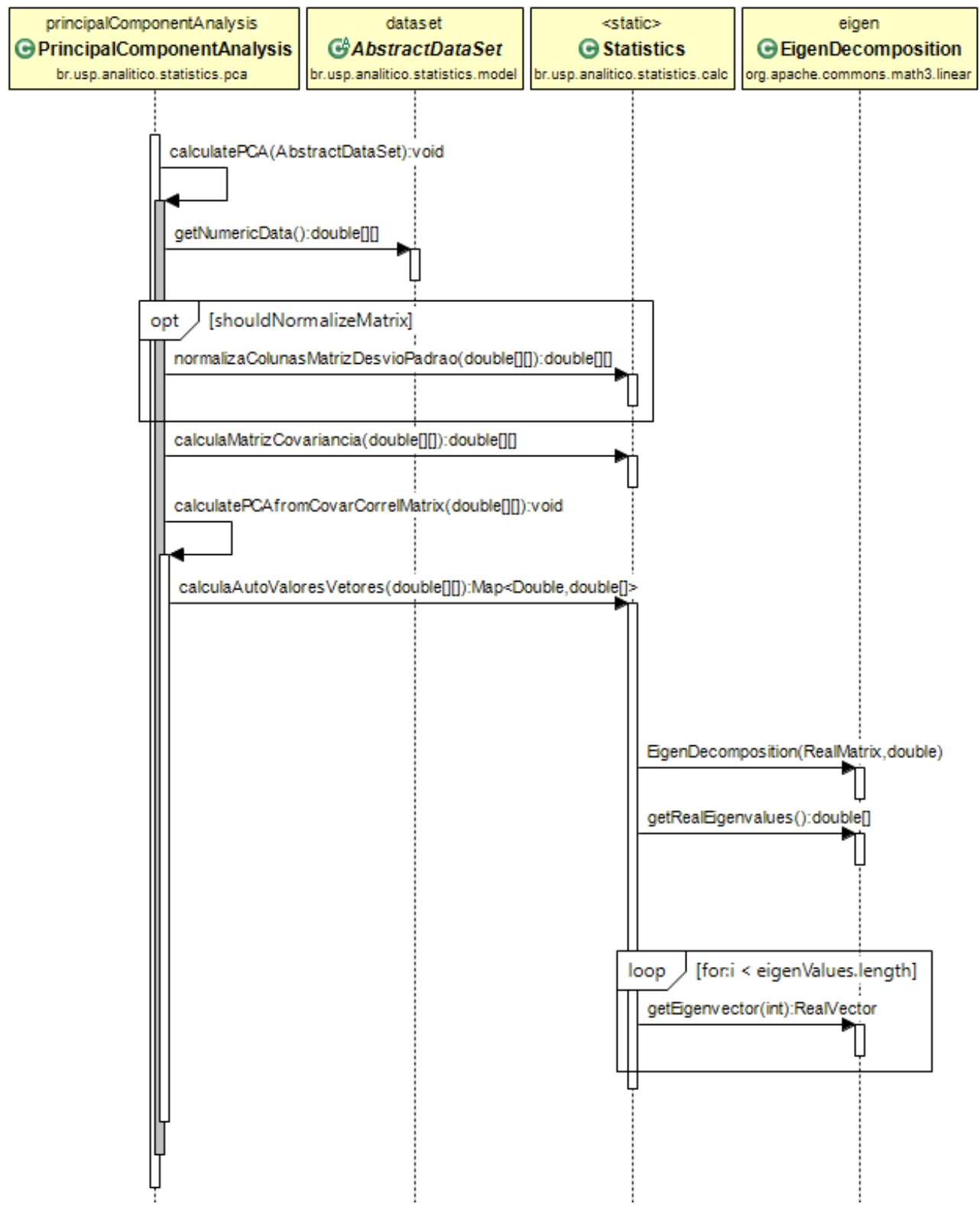

Figura 4.4: Diagrama de sequências ilustrando o cálculo da PCA utilizando a API.

Para evitar que os cálculos sejam refeitos a cada aplicação da PCA, foi desenvolvido um modelo de dados, apresentado na Figura 4.5, para persistir os valores pré-calculados no caso em que a entrada de dados é feita por meio de consultas à bases de dados. Desse modo, só é necessário recalculá-los se houver mudança nos dados de entrada. Como consequência, é possível calcular a matriz de covariâncias e os desvios padrão das dimensões de maneira incremental, quando a consulta retornar um resultado com a característica de incrementalidade, otimizando o cálculo, como descrito na seção 4.3, abaixo. As tabelas criadas para tal finalidade são as seguintes:

- queries: armazena as consultas sobre as quais as análises serão feitas. Além da chave primária e do texto da consulta, essa tabela possui atributos utilizados na integração da API com o DW, como será descrito na seção 4.4. 
- query_dependencies: armazena as tabelas dependentes, que são utilizadas nas consultas.

- dimensions: armazena as colunas presentes no resultado das consultas, seus tipos, nome e alguns valores pré-calculados, como média e desvio padrão, para o caso das métricas. A persistência desses valores no banco de dados permite o cálculo incremental da matriz de covariâncias.

- covariances: armazena as covariâncias pré-calculadas entre cada dimensão numérica das queries analisadas, para representar a matriz de covariâncias, de maneira normalizada, ou seja, cada valor da matriz é armazenado em uma linha da tabela. A matriz de covariâncias é simétrica e, portanto, não é necessário armazenar todas as suas posições. Mantendo a matriz de covariâncias na base de dados, é possível calcular não somente as PCs por meio da PCA, mas também aplicar outras análises, como a matriz de coeficientes de correlação de Pearson, dividindo seus valores pelos desvios padrão associados às dimensões.

- api_aux_table: tabela auxiliar usada para a carga incremental da matriz de covariâncias.

Nela são armazenadas as chaves das novas observações, como será explicado na próxima seção.

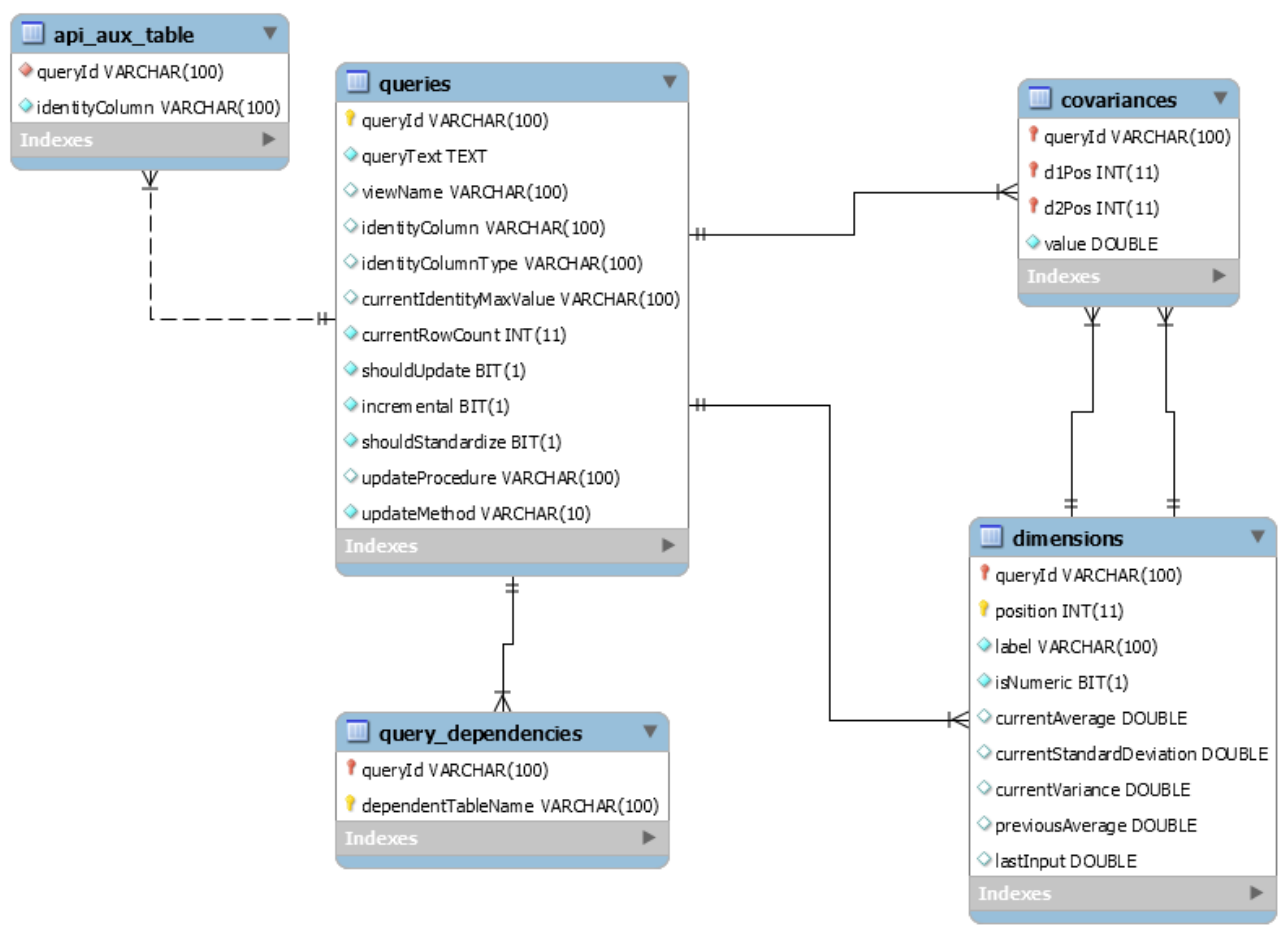

Figura 4.5: Figura do modelo de dados utilizado pela API como aplicado no SGBD MySQL.

O acesso a essas tabelas, tanto para escrita como para consulta, é coordenado por meio de classes que estendem a classe abstrata AbstractDBManager e classes do tipo objeto de acesso a dados (Data Access Object, DAO) que estendem a classe abstrata AbstractDBDAO. Ambas as classes foram criadas para cada Sistema Gerenciador de Banco de Dados (SGBD) compatível (i.e. 
Sybase e $M y S Q L$ ), levando em consideração suas diferenças de sintaxe e recursos disponíveis. A configuração de acesso à base de dados e as consultas que serão submetidas são armazenadas em uma classe do tipo Bean, chamada ConfigBean. A classe DBManagerFactory converte um arquivo json localizado no diretório resources em uma instância de ConfigBean e retorna uma implementação do AbstractDBManager de acordo com a configuração explicitada nesse arquivo.

Por fim, foram desenvolvidas classes de apoio à visualização para uso nos exemplos e experimentos, que geram gráficos de fatores e dispersão, utilizando a biblioteca javafx.

\subsection{Cálculo incremental da matriz de covariâncias}

Data Warehouses têm como característica a incrementalidade, já que seus dados são gerados a partir de operações de um processo de negócio modelado e consolidações de métricas sobre essas operações, que ocorrem em um momento ou período específico no tempo. As tabelas fatos resultantes obedecem, segundo Kimball, à regra de sempre possuírem uma dimensão temporal associada, que conferem ao fato a continuidade e incrementalidade inerentes a essas dimensões. Em fatos do tipo snapshot periódico essa característica é clara, já que cada linha representa a consolidação de métricas em um determinado período (e.g. semana ou mês) e, findado um novo período, uma nova linha é criada na tabela. Esse tipo de fato, dentre outros, nada mais é que uma série temporal sobre várias métricas.

O cálculo da matriz de covariâncias, uma das etapas da aplicação da PCA, possui complexidade $\mathbf{O}\left(\mathbf{N} \times \mathbf{P}^{2}\right)$, onde $\mathbf{N}$ é o número de observações do conjunto de amostras e $\mathbf{P}$ é o número de dimensões analisadas. Em aplicações de reconhecimento de imagem, por exemplo, nas quais cada pixel da imagem é uma dimensão e, portanto, comumente $\mathbf{P} \gg \mathbf{N}$, a influência do número de observações não é tão relevante quanto o número de pixels da imagem. Já nos DWs, não é raro que as tabelas fatos tenham milhões ou bilhões de linhas, sobrepujando o número de dimensões em muito (ou seja, $\mathbf{N} \gg \mathbf{P}$ e até mesmo $\mathbf{N} \gg \mathbf{P}^{\mathbf{2}}$ ). Nesse caso, o número de observações se torna um fator limitante no cálculo da matriz de covariâncias.

Para o caso em que $\mathbf{P} \gg \mathbf{N}$, como no reconhecimento de imagens, a referência [TP91] apresenta uma solução para encontrar as primeiras principais componentes, reduzindo o cálculo dos autovetores de uma matriz $\mathbf{P} \times \mathbf{P}$ para matrizes $\mathbf{N} \times \mathbf{N}$. Pode-se, também, calcular as principais componentes sequencialmente de maneira iterativa, como nos algoritmos discutidos em [And09]. Deve-se notar, porém, que um desses algoritmos sofre de perda de ortogonalidade e só pode ser utilizado para determinar as primeiras componentes.

No caso em que $\mathbf{N} \gg \mathbf{P}$ e $\mathbf{P}$ é manejável, como em diversos fatos do DW da USP (e.g. o fato que modela a produção científica dos docentes como cadastrada na base Lattes, em que cada 
linha é uma produção do docente, resultando em milhões de linhas), a limitação está em calcular a matriz de covariância e não em encontrar seus autovetores e autovalores. Como a carga de dados é feita periodicamente, faz-se necessário recalcular a matriz de covariâncias a cada execução do procedimento de carga, o que se torna um problema quando $\mathbf{N}$ é muito grande. Porém, para os fatos com a característica de incrementalidade, pode-se otimizar esse cálculo, como descrito por Hall, Marshal e Martin [HMM98]. Calculando a matriz de covariâncias de forma incremental, a cada nova observação, reduz-se a complexidade do procedimento para $\mathbf{O}\left(\mathbf{N}^{\prime} \times \mathbf{P}^{\mathbf{2}}\right)$, onde $\mathbf{N}^{\prime}$ é o número de novas observações inseridas na carga de dados. Como a cada carga de dados a razão $\mathbf{N}^{\prime} / \mathbf{N}$ se torna cada vez menor, ao longo da vida do DW temos que $\mathbf{N}^{\prime} \rightarrow \mathbf{N}^{\prime} \ll \mathbf{N}$ e então haverá um ganho de performance relevante, como apresentado na seção 4.3.2.

No cálculo da PCA implementado na API desenvolvida, pode-se escolher normalizar os dados das observações sobre as dimensões analisadas pelo desvio padrão de cada vetor de dimensões, para que o resultado não seja susceptível a variações de escala. Como será demonstrado na Etapa 3 da seção 4.3.1, a padronização dos dados pode ser feita a posteriori diretamente sobre os coeficientes da matriz de covariâncias. Portanto, uma etapa prévia foi adicionada ao algoritmo para recalcular a variância das observações de uma dimensão de forma incremental e, consequentemente, o desvio padrão. O cálculo incremental da variância foi proposto em 1962 por Welford [Wel62] e ainda é utilizado nos dias de hoje.

Entretanto, é importante levar em consideração que nos cálculos incrementais há perda de significância devido ao arredondamento dos valores nas operações aritméticas a cada iteração, embora reduzida quanto menor a razão $\mathbf{N}^{\prime} / \mathbf{N}$.

A seguir será apresentado o algoritmo para calcular incrementalmente a matriz de covariâncias e os testes de performance comparativos.

\subsubsection{Algoritmo}

O algoritmo parte do pressuposto que temos pré-calculados o número de observações $\mathbf{N}$, a matriz de covariâncias $\boldsymbol{\Sigma}_{\mathbf{N}}$ e, para cada dimensão $\mathbf{P}_{\mathbf{i}}$, o valor da variância das observações $\sigma_{\mathbf{i}}^{2}$ e a média das observações $\overline{\mathbf{x}}_{\mathbf{i} \mathbf{N}}$. Seria possível realizar os cálculos sobre a média e a matriz de covariâncias já normalizadas, porém seria necessário realizar mais operações para multiplicá-las pelos desvios padrão antes da nova observação, o que incorreria em maior perda de significância devido a arredondamentos. Portanto, para o cálculo incremental os valores são armazenados sem a normalização pelo desvio padrão e, se o usuário desejar, pode-se fazê-la sobre a matriz nãonormalizada no momento do cálculo da PCA.

Denotamos a nova observação como o vetor $\underline{\mathbf{x}}_{\mathbf{N}+\mathbf{1}}=\left[\mathbf{x}_{\mathbf{1 N}+\mathbf{1}}, \mathbf{x}_{\mathbf{2}+\mathbf{1}}, \cdots, \mathbf{x}_{\mathbf{p}_{\mathbf{N}+\mathbf{1}}}\right]$. 
Etapa 1: cálculo incremental da nova média, variância e desvio padrão

A nova média dos dados e a nova variância, para a dimensão $\mathbf{P}_{\mathbf{i}}$, podem ser calculadas pelas fórmulas abaixo:

$$
\begin{aligned}
\bar{x}_{i N+1} & =\bar{x}_{i_{N}}+\frac{\left(x_{i N+1}-\bar{x}_{i_{N}}\right)}{N+1} \\
\sigma_{i_{N+1}}^{2} & =\frac{N \sigma_{i_{N}}^{2}+\left(x_{i_{N+1}}-\bar{x}_{i_{N+1}}\right)\left(x_{i_{N+1}}-\bar{x}_{i_{N}}\right)}{N+1}
\end{aligned}
$$

Em seguida, podemos calcular o novo desvio padrão $\sigma_{\mathbf{i N}+\mathbf{1}}$ de $(2)$ :

$$
\sigma_{i N+1}=\sqrt{\sigma_{i_{N+1}^{2}}^{2}}=\sqrt{\frac{N \sigma_{i}^{2}+\left(x_{i N+1}-\bar{x}_{i N+1}\right)\left(x_{i N+1}-\bar{x}_{i N}\right)}{N+1}}
$$

Como os cálculos (1) a (3) devem ser executados para todas as $\mathbf{P}$ dimensões, a complexidade total é $\mathbf{O}(\mathbf{P})$, já que (1), (2) e (3) são executados em $O(1)$.

Portanto, essa etapa completa possui complexidade $\mathbf{O}(\mathbf{P})$.

\section{Etapa 2: atualização da matriz de covariâncias}

Com a nova observação $\underline{x}_{N+1}$, as médias antes dessa observação $\underline{\bar{x}}_{N}$ e a matriz de covariâncias $\Sigma_{N}$, calcula-se $\Sigma_{N+1}$ pela fórmula:

$$
\Sigma_{N+1}=\frac{N}{N+1} \Sigma_{N}+\frac{N}{(N+1)^{2}}\left(\underline{x}^{\prime}\right)^{T} \underline{x}^{\prime}
$$

onde $\underline{x}^{\prime}=\underline{x}_{N+1}-\underline{\bar{x}}_{N}$.

O cálculo do primeiro termo da soma em (4) tem complexidade $O\left(P^{2}\right)$, pois é uma multiplicação de um escalar por todos os termos da matriz de covariâncias $\Sigma_{P \times P}$. O segundo termo envolve uma multiplicação entre o vetor da nova observação $(1 \times P)$ e seu transposto $(P \times 1)$, resultando em uma matriz $P \times P$, por meio de $P^{2}$ multiplicações. Em seguida há uma nova multiplicação de um escalar por uma matriz $P \times P$. Portanto, o cálculo do segundo termo tem complexidade 
$O\left(P^{2}+P^{2}\right)=O\left(P^{2}\right)$. Finalmente, a soma dos dois termos, que são matrizes $P \times P$, também será $O\left(P^{2}\right)$. Logo, essa etapa possui complexidade $\mathbf{O}\left(\mathbf{P}^{2}\right)+\mathbf{O}\left(\mathbf{P}^{2}\right)+\mathbf{O}\left(\mathbf{P}^{2}\right)=\mathbf{O}\left(\mathbf{P}^{2}\right)$

\section{Etapa 3: normalização da matriz de covariâncias}

Temos que, para duas dimensões $P_{i}$ e $P_{j}$, a covariância entre elas é dada por:

$$
\operatorname{Covar}\left(P_{i}, P_{j}\right)=\sum_{n=1}^{N}\left(P_{i n}-\bar{P}_{i}\right)\left(P_{j_{n}}-\bar{P}_{j}\right)
$$

Se normalizarmos cada dimensão pelos seus desvios padrão $\sigma_{i}$ e $\sigma_{j}$ (e, consequentemente suas médias), temos que a nova covariância será:

$$
\begin{aligned}
\operatorname{Covar}_{\text {norm }}\left(P_{i_{\text {norm }}}, P_{j_{\text {norm }}}\right) & =\sum_{n=1}^{N}\left(\frac{P_{i_{n}}}{\sigma_{i}}-\frac{\bar{P}_{i}}{\sigma_{i}}\right)\left(\frac{P_{j_{n}}}{\sigma_{j}}-\frac{\bar{P}_{j}}{\sigma_{j}}\right) \\
& =\sum_{n=1}^{N} \frac{1}{\sigma_{i}}\left(P_{i n}-\bar{P}_{i}\right) \frac{1}{\sigma_{j}}\left(P_{j_{n}}-\bar{P}_{j}\right) \\
& =\frac{1}{\sigma_{i} \sigma_{j}} \sum_{n=1}^{N}\left(P_{i n}-\bar{P}_{i}\right)\left(P_{j_{n}}-\bar{P}_{j}\right) \\
& =\frac{1}{\sigma_{i} \sigma_{j}} \operatorname{Covar}\left(P_{i}, P j\right)
\end{aligned}
$$

Portanto, devemos dividir cada termo $c_{i j}$ da matriz de covariâncias pelos novos desvios padrão calculados em (3), para obter a nova matriz corrigida pelo novo desvio padrão. Como os desvios padrão são armazenados na tabela dimensions, essa divisão pode ser feita no momento do cálculo da PCA, dependendo da configuração do usuário.

Caso a normalização deva ocorrer, o cálculo (5) deve ser feito para todos os pares de dimensões $P_{i}$ e $P_{j}$ distintos, pois a matriz de covariância é simétrica. Logo, sua execução se dá em $O\left(\frac{P^{2}+P}{2}\right)=\mathbf{O}\left(\mathbf{P}^{2}\right)$.

A etapa 3 deve ser executada somente uma vez, ao final de todas as iterações. As etapas 1 e 2 devem ser executadas para cada nova observação. Por conseguinte, se forem adicionadas $N^{\prime}$ novas observações ao conjunto de amostras inicial, temos que a complexidade do algoritmo será $\mathbf{O}\left(\mathrm{N}^{\prime} \times \mathrm{P}^{2}\right)$. 


\subsubsection{Avaliação da performance}

Os experimentos para avaliar a performance da otimização com a implementação do método proposto por Hall et al foram realizados sobre dados gerados randomicamente, variando-se os parâmetros $\mathbf{N}$ e $\mathbf{N}^{\prime}$ : número de observações inicial e número de novas observações, respectivamente. O cenário de cálculo incremental a partir da matriz de covariâncias $\mathbf{N} \times \mathbf{N}$ pré-calculada foi comparado com o de cálculo completo a partir do total de amostras $\mathbf{N}^{\prime}+\mathbf{N}$. Para cada situação, foram realizados 10 testes distintos e a mediana do tempo foi utilizada para as comparações. Foi utilizada a versão Java 1.8 para a implementação dos experimentos e sua execução foi feita em ambiente com sistema operacional Windows 7 Enterprise 64 bits, dois processadores Intel Xeon CPU E7 - $2870 @$ $2.40 \mathrm{GHz}$ e memória RAM de 8GB.

A Figura 4.6 mostra o resultado da análise de performance. Nota-se que o tempo de execução do cálculo completo ( "Full", no gráfico) é praticamente constante, como esperado, já que o valor de $N+$ $N^{\prime}$ é constante. Já o tempo de execução do cálculo incremental é menor quanto menor a razão $N^{\prime} / N$. Com isso, conclui-se que a otimização é válida para tabelas fato que já possuam um certo número de linhas. Pode-se definir um valor limiar para a transição entre o cálculo total e o incremental para se beneficiar dos dois cenários. Entretanto, vale lembrar que o cálculo incremental sofre de erros de aproximação em maior quantidade que o completo e, portanto, a matriz de covariâncias e demais valores devem ser recalculados periodicamente para corrigir tais discrepâncias.

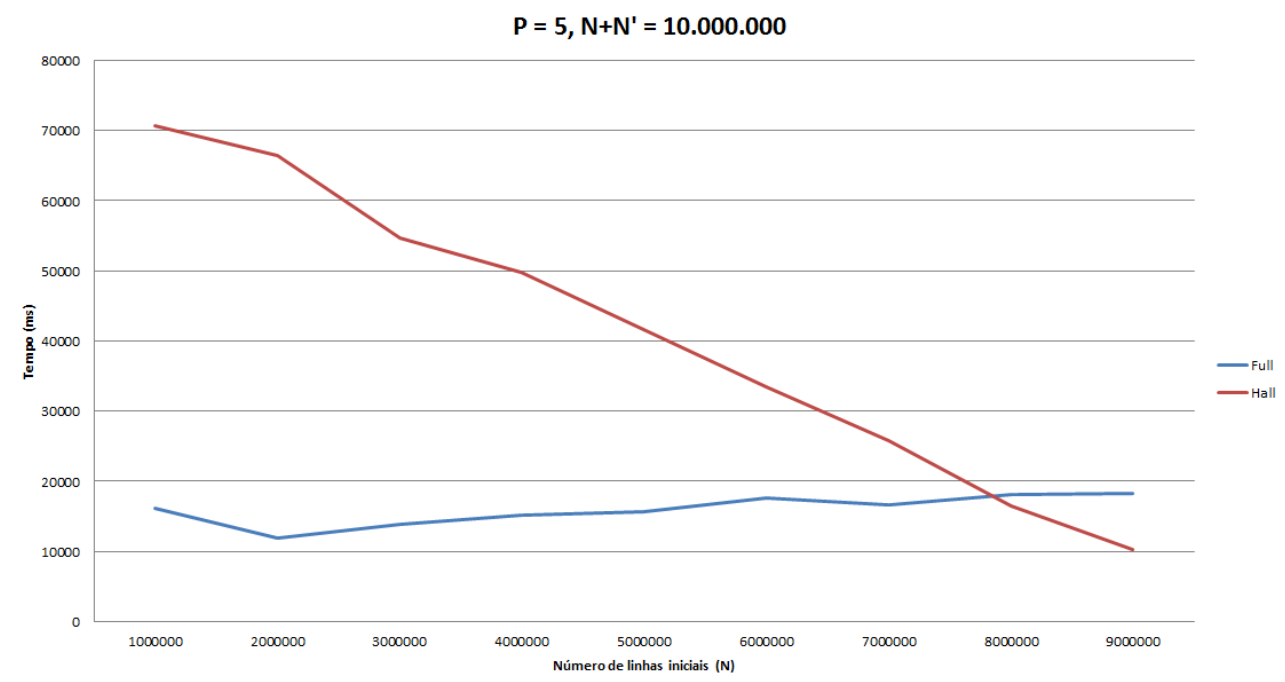

Figura 4.6: Comparação entre os tempos de execução do método incremental de Hall e o cálculo completo da matriz de covariâncias. Pode-se definir um limiar de transição entre os métodos, definido na intersecção das retas. Nesse exemplo, o limiar da razão $N^{\prime} / N$ é 0,25. 


\subsection{Integração da API com o DW}

Nesta seção, será apresentada uma discussão sobre a integração da API ao Data Warehouse da USP. Serão feitos comentários sobre a influência do modelo dimensional e seus diferentes tipos de fatos e dimensões na aplicação da PCA e os cuidados que devem ser tomados em relação à performance de carga e consultas.

\subsubsection{Dimensões}

Nas dimensões dos modelos estrela, muitas vezes são geradas SKs, que são chaves artificiais sequenciais, como descrito na seção 2.1.2. Essas chaves, apesar de serem campos numéricos, não podem ser usadas na PCA, pois sua variação não tem significado semântico. Em dimensões SCD2, por exemplo, duas linhas podem representar a mesma entidade em versões distintas, com períodos de validade diferentes e, portanto SKs diferentes. Desse modo, a variação desse campo entre as duas versões pode ser de magnitude elevada, mesmo se tratando da mesma entidade, pois a segunda versão pode ter sido criada após a inserção de muitos registros na mesma tabela - incrementando o valor das SKs, por conseguinte. Ou seja, o campo numérico da SK pode apresentar grande variação enquanto a maior parte dos atributos que descrevem essa mesma entidade não variaram. Do mesmo modo, ao utilizar o campo da SK como atributo classificatório/descritivo - para plotar o gráfico de dispersão posteriormente e não para o cálculo da PCA -, deve-se tomar o mesmo cuidado, pois valores diferentes podem representar a mesma entidade em versões distintas. Para mitigar essa questão, faz-se necessário utilizar os atributos descritivos da dimensão, ou seja, deve-se fazer o join da tabela dimensão com a tabela fato e selecionar os atributos relevantes para a análise, sejam eles numéricos ou não.

Entretanto, há exceções para esses casos, como nas dimensões temporais Data e Ano, por exemplo. Nelas, as SKs podem ser criadas com valor semântico (e.g. data juliana para a dimensão Data ou o valor do ano para a dimensão Ano) e utilizadas no cálculo da PCA, pois, nesses casos, a variação dessas chaves possui significado: uma variação temporal.

\subsubsection{Fatos}

Nesta seção, cada tipo de fato será analisado quanto ao seu impacto na aplicação da PCA.

\section{Fato sem fato}

Nesse tipo de fato, não é possível aplicar a PCA, pois não existem métricas numéricas sobre as quais calcular a variância - há apenas as chaves das dimensões e dimensões degeneradas. 


\section{Fato snapshot cumulativo}

Esse tipo de fato é usado para modelar um processo de negócio cuja sequência de etapas é bem definida temporalmente. Ao fim de cada etapa, a mesma linha do fato referente a essa instância do processo é atualizada, marcando o início da etapa seguinte. Em cada uma dessas atualizações, as métricas correspondentes são atualizadas. Portanto, é necessário que os cálculos para aplicação da PCA sejam refeitos a cada nova atualização de dados.

\section{Fato snapshot periódico}

Os fatos do tipo snapshot periódico sumarizam as métricas em relação a um período (e.g. total de compras na semana, ou no mês). Ao final de cada período definido na granularidade do fato, é inserida uma nova linha, com métricas agrupadas nesse período. Essas métricas não fazem parte de um mesmo processo, necessariamente, mas devem possuir a mesma granularidade. A natureza incremental e periódica dessas tabelas permite tratá-las como séries temporais e utilizar a otimização para o cálculo da PCA, descrita na seção 4.3.

\section{Fato transacional}

Esses fatos refletem as operações relacionadas ao processo modelado. São inseridas novas linhas na tabela a cada operação e as remoções comumente são marcadas com uma coluna indicando a remoção, em vez da deleção do registro da tabela. Deve-se levar em consideração essas remoções para o cálculo da PCA, já que as métricas de uma linha removida devem ser descartadas. Se há a garantia da incrementalidade, ou seja, não há remoção de linhas, também pode-se otimizar o cálculo da PCA, como nos fatos do tipo snapshot periódico.

\subsubsection{Integração com as cargas periódicas}

O desafio da integração era prover uma ferramenta resiliente a mudanças periódicas dos dados, de forma a realizar as adequações automaticamente a cada nova carga do DW. Para isso, foi criado o modelo introduzido na seção 4.2 e que será explicado com mais detalhes nesta seção juntamente com algumas das possíveis estratégias para essa integração.

\section{Arquivo de configuração}

O arquivo de configuração, que é convertido para um objeto do tipo ConfigBean, contém as informações relativas às conexões à base de dados e às consultas analisadas. Por padrão de projeto, foram definidas duas bases de dados a serem configuradas: uma onde estão os dados para a análise, isto é, o DW (DWDB); e outra onde as tabelas com os metadados das análises serão criadas pela 


\begin{tabular}{|c|c|c|}
\hline Parâmetro & Descriçãoo & Exemplo \\
\hline dbType & Tipo de SGBD utilizado & $M y S Q L$ ou Sybase \\
\hline dbUser & Usuário para se conectar ao SGBD & api \\
\hline dbPwd & Senha para o usuário se conectar ao SGBD & 12345 \\
\hline dbURL & $\begin{array}{l}\text { String de conexão ao servidor da base de } \\
\text { dados }\end{array}$ & $\begin{array}{l}\text { jdbc:mysql://localhost:3309 ou } \\
\text { jdbc:jtds:sybase://localhost:5000 }\end{array}$ \\
\hline metadataSchema & $\begin{array}{l}\text { Nome do banco de dados onde as tabe- } \\
\text { las com metadados serão criadas pela API } \\
\text { (METADB) }\end{array}$ & dw_meta \\
\hline dataSchema & $\begin{array}{l}\text { Nome do banco de dados onde está o DW } \\
\text { e para o qual as consultas serão submetidas } \\
\text { (DWDB) }\end{array}$ & $\mathrm{dw}$ \\
\hline queries & Lista de consultas & {$[<$ query $>,<$ query $>, \ldots]$} \\
\hline \multicolumn{3}{|l|}{$\overline{<\text { query }>}$} \\
\hline queryId & Identificador da consulta & q1 \\
\hline queryText & Texto da consulta & select $*$ from fact_table \\
\hline incremental & Indentifica uma consulta incremental & true ou false \\
\hline identityColumn & $\begin{array}{l}\text { Nome da coluna de identidade (apenas para } \\
\text { consultas incrementais) }\end{array}$ & fact_row_id \\
\hline identityColumnType & $\begin{array}{l}\text { Tipo da coluna identidade (apenas para } \\
\text { consultas incrementais) }\end{array}$ & int, timestamp, ... \\
\hline updateMethod & $\begin{array}{l}\text { Tipo de estratégia de atualização das tabe- } \\
\text { las de metadados da api }\end{array}$ & $\begin{array}{ll}\text { trigger, } & \text { batch_sql } \\
\text { batch_java } & \end{array}$ \\
\hline shouldStandardize & $\begin{array}{l}\text { Indica que os dados devem ser normalizados } \\
\text { pelo desvio padrão na aplicação da PCA }\end{array}$ & true ou false \\
\hline
\end{tabular}

Tabela 4.2: Parâmetros de configuração.

API (METADB). Essas bases devem estar localizadas em um mesmo servidor, para que seja possível acessar facilmente os dados de ambas em uma única consulta. O usuário que se conecta a essas bases deve ter privilégio de criação, remoção, atualização e consulta a objetos (incluindo criação de base de dados, pois se a base onde serão armazenados os metadados não existir, ela será criada pela API) e também deve ser definido no arquivo, juntamente com sua senha para conexão. O tipo de banco de dados (i.e. MySQL ou Sybase) deve ser configurado no arquivo para que as classes de controle e acesso ao banco de dados apropriadas sejam instanciadas na API. Por último, o arquivo deve conter o parâmetro queries: uma lista na qual cada objeto é uma consulta a ser analisada, que será convertida para o objeto QueryBean. A tabela 4.2 descreve cada parâmetro definido no arquivo de configuração.

\section{Inicialização}

Com o arquivo de configurações definido, uma instância de classe concreta que estende a classe abstrata AbstractDBManager é criada por meio da classe DBManagerFactory, para o controle de acesso às bases de dados. A escolha da classe concreta é feita baseada no parâmetro dbType das 
configurações. Em seguida, o METADB é inicializado: caso não existam, são criadas a base de dados e as tabelas utilizadas pela API. Com a garantia da estrutura de dados criada no METADB, as consultas definidas no arquivo de configurações podem ser inseridas ou atualizadas, caso já existam no METADB. O diagrama de sequências para a inicialização da API e atualização de consultas pode ser visto na Figura 4.7 e as etapas de inserção e atualização de consultas serão detalhadas nas seções subsequentes.

\section{Inserção de nova consulta}

As consultas devem ser configuradas no arquivo de configuração de acordo com a Tabela 4.2. As consultas incrementais possuem dois parâmetros obrigatórios, que definem uma coluna identidade. Essa coluna identidade deve ser crescente e, com ela, é possível selecionar apenas as novas linhas inseridas desde a ultima atualização de dados e então realizar o cálculo incremental da matriz de covariâncias, médias e variâncias dos dados. A base MySQL possui o comando OFFSET, LIMIT, que permite filtrar apenas uma porção dos dados do resultado da consulta e, com isso, selecionar apenas as novas linhas. Porém, na execução desse comando todas as linhas são selecionadas e então o filtro é aplicado. Portanto, o uso obrigatório de uma coluna identidade crescente juntamente com um índice nessa coluna permite a seleção mais eficiente das novas linhas. Além disso, a versão do SGBD Sybase utilizada não possui um comando similar ao do MySQL. A coluna de identidade deve estar presente no resultado das consultas incrementais, mas não é considerada uma dimensão pela API - seu uso é somente para a seleção das novas linhas inseridas. Apesar de não ser comum, pode-se criar uma SK em um fato em algumas situações, como sugerido por Kimball na seção de técnicas avançadas de tabelas fato de seu livro [KC04]. Essa SK poderia ser criada como uma coluna do tipo auto-increment sem significado - como nas tabelas dimensões - e então ser utilizada pela API. Em fatos similares a séries temporais, como os do tipo snapshot periódico, em que cada linha corresponde a um período, a coluna da dimensão temporal (e.g. Data, Ano, etc.) poderia ser utilizada como identidade. Porém, caso essa dimensão seja um fator importante para a análise, ela deve ser selecionada novamente na consulta, com um alias diferente, para não ser descartada pela API.

A nova consulta especificada no arquivo de configuração fornecido pelo usuário é submetida ao DWDB, e o resultado é convertido para a estrutura interna de dados na sua implementação padrão DefaultDataSet, por meio da classe ResultSetDataSetConversor. Com o DefaultDataSet, a instância de QueryBean que representa a consulta é atualizada para conter o total de linhas atual e o valor máximo atual da coluna identidade, para uso nas consultas incrementais.

Em seguida, cria-se uma view no DWDB com o texto da consulta para que seja possível encontrar nas tabelas de sistema dos SGBDs as tabelas dependentes utilizadas nessa view (e, portanto, na 


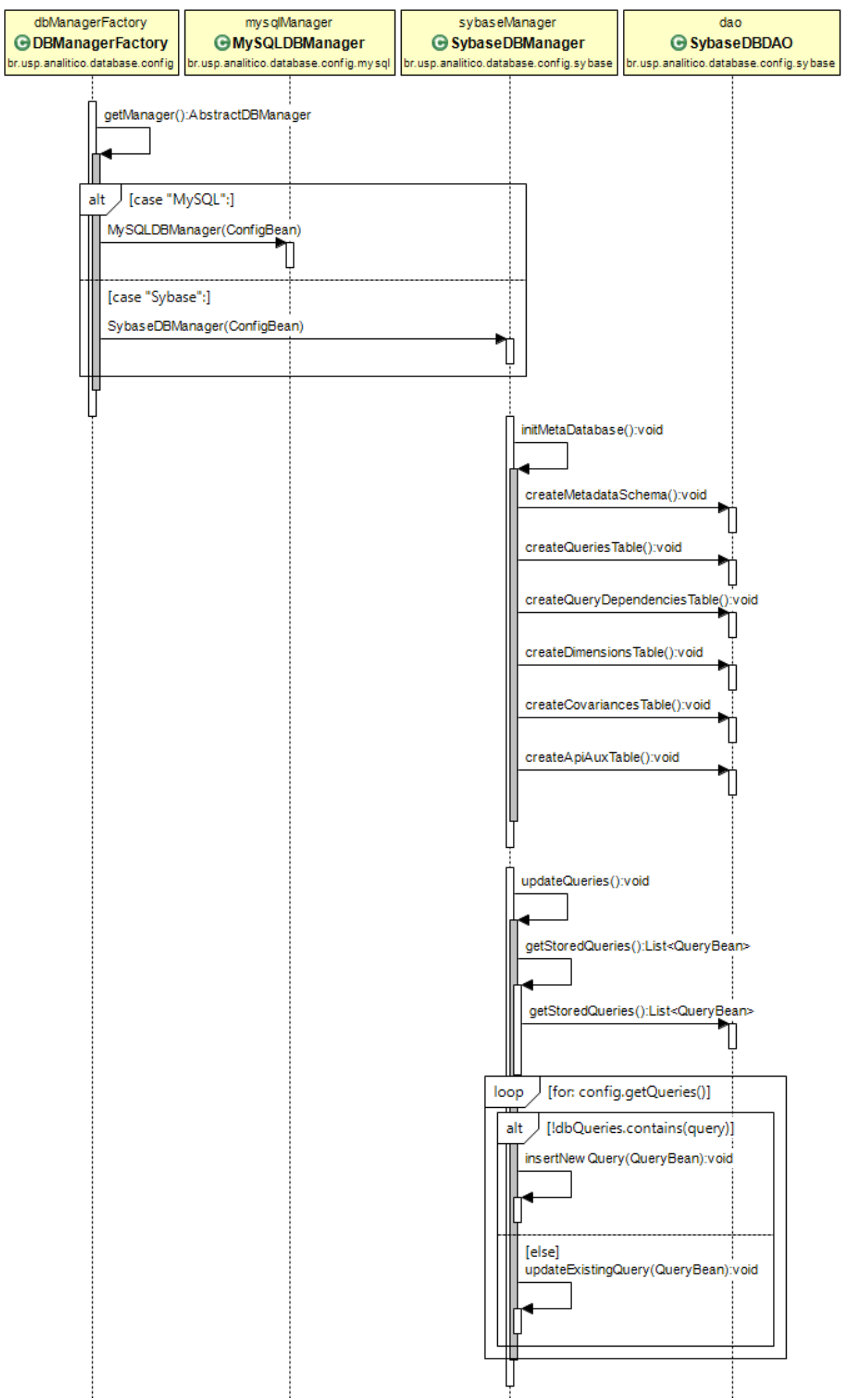

Figura 4.7: Diagrama de sequência simplificado da etapa de inicialização do METADB e atualização das consultas.

consulta original) e armazená-las na tabela query_dependencies do METADB. No caso de consultas não incrementais, essa view é removida da base. Já no caso das consultas incrementais, a view 
é mantida e as consultas são feitas sobre ela, para garantir a ordenação das linhas baseada em uma coluna identidade, especificada pelo usuário nas configurações da consulta. Para cada tabela dependente distinta, é criada uma trigger que é acionada a cada inserção de dados nessa tabela e atualiza a coluna shouldUpdate da tabela queries com o valor 1, para as consultas que possuem dependência com essa tabela, indicando que a matriz de covariâncias e demais dados do METADB devem ser atualizados, pois houve mudança nos dados do DWDB.

A nova consulta é inserida na tabela queries e as dimensões associadas na tabela dimensions, com os valores atuais da média, variância e desvio padrão. A matriz de covariâncias é calculada por meio da classe de apoio Statistics, a partir dos dados numéricos obtidos do DefaultDataSet e é inserida na tabela covariances.

Por último, para consultas incrementais cujos dados presentes no METADB são atualizados por SQL - e não Java -, é criada uma stored procedure para atualização da matriz de covariâncias e as variâncias, médias e desvios padrão das dimensões associadas. Caso o tipo de atualização definido seja por trigger (os tipos serão detalhados na seção seguinte), também é criada uma trigger na tabela queries para a atualização incremental.

A Figura 4.8 apresenta o diagrama de sequências do método insertNewQuery(), da classe SybaseDBManager.

\section{Atualização de consulta existente}

A cada novo dado inserido nas tabelas dependentes da consulta, a trigger aplicada atualiza o atributo na tabela queries que indica que a consulta deve ser atualizada. No arquivo de configurações, o usuário especifica o método de atualização para cada consulta, por meio das colunas incremental e updateMethod. A primeira indica se a consulta tem característica de incrementalidade e a segunda define a estratégia para a atualização dos cálculos. As possíveis estratégias são:

- incremental - trigger: nessa estratégia, os cálculos são refeitos assim que uma nova linha é inserida nas tabelas dependentes, por meio de uma trigger criada na tabela queries, que é acionada quando a coluna shouldUpdate é atualizada com o valor 1, e que invoca a stored procedure de atualização para essa consulta, criada na etapa de inserção, cujo nome fica armazenado na tabela queries.

- incremental - batch_sql: para consultas definidas com essa estratégia, a coluna shouldUpdate permanece com o valor 1 após a inserção da nova observação até que a stored procedure de atualização dessa consulta seja invocada manualmente. Portanto, as novas observações podem se acumular entre cada execução. 


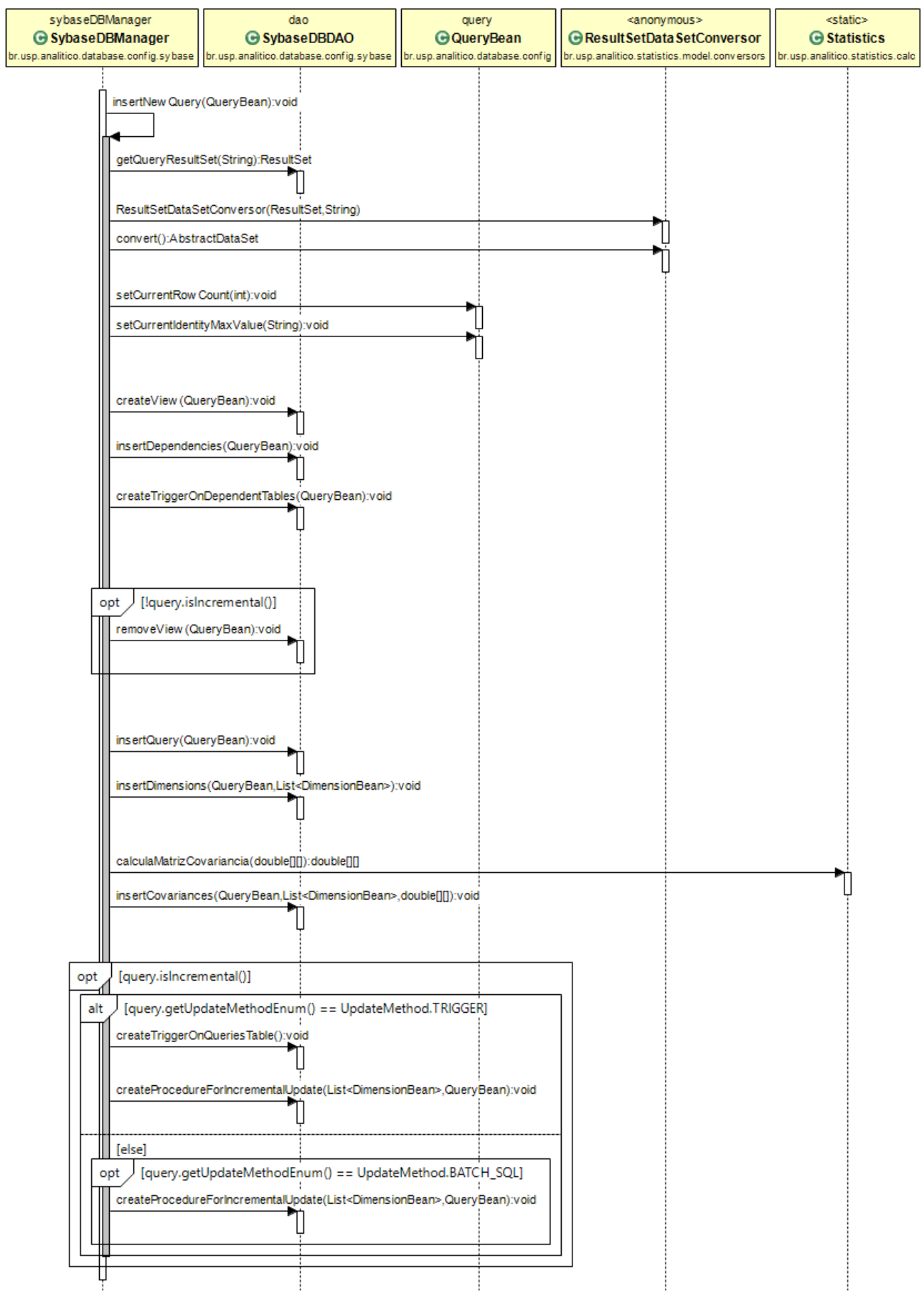

Figura 4.8: Diagrama de sequência simplificado da etapa de inserção de uma nova consulta no METADB.

- incremental - batch_java: essa estratégia é similar à batch_sql, porém a atualização incremental é feita por meio de métodos Java invocados na API, e não via stored procedures SQL.

- não-incremental - batch_java: para consultas incrementais, o resultado completo da execução da consulta é novamente convertido para a estrutura de dados interna e a matriz de covariâncias e demais variáveis estatísticas são recalculadas, por meio de métodos Java invocados na API. 
O método updateExistingQuery(QueryBean query), da classe AbstractDBManager e suas implementações concretas, é utilizado para atualizar a matriz de covariâncias e demais cálculos de uma consulta. Caso a consulta esteja com o valor indicador shouldUpdate igual a 1, o método de atualização é invocado, de acordo com a estratégia definida: stored procedure, método Java incremental ou método Java completo. As consultas definidas com estratégia de atualização por trigger nunca serão atualizadas por esse método, já que a atualização ocorre imediatamente na base de dados.

A Figura 4.9 apresenta o diagrama de sequência da etapa de atualização de uma consulta.

\subsubsection{Análise de performance}

Nesta seção serão feitos comentários sobre o impacto da integração da API na performance da carga do Data Warehouse. Serão apresentados resultados de simulações de carga de tabelas fato comparando seus tempos de execução em diferentes cenários, cada qual adotando uma estratégia para a carga do modelo de dados relacionado à API.

\section{Carga incremental por triggers}

A primeira análise de performance da API e sua integração com o ambiente de DW da USP foi feita comparando os tempos de execução de uma simulação da carga de uma tabela fato com e sem a utilização da ferramenta. Foi criada uma tabela com uma coluna identidade e cinco métricas e, na configuração da API, foi definida uma consulta a essa tabela com a estratégia de carga incremental por meio de triggers. As cargas na tabela fato foram efetuadas com o uso da ferramenta de ETLs padrão da divisão de sistemas da STI da USP, o Pentaho Data Integration. Foram geradas linhas com valores aleatórios para serem inseridas na tabela fato, cujo número de linhas iniciais foi variado em cada execução do experimento, resultando em um total de 20000 linhas. Para cada um dos cenários, o experimento foi executado dez vezes e o valor utilizado para análise da performance foi a mediana de cada tempo de execução.

Era esperado que a carga levasse um tempo maior para concluir devido ao tempo para o cálculo da matriz de covariâncias e demais valores relacionados às dimensões. O gráfico apresentado na Figura 4.10 mostra o tempo de execução com a variação dos cenários.

A estratégia de carga por triggers tem como vantagem a automatização completa dos cálculos, já que esses são atualizados pelos procedimentos criados diretamente no banco de dados. Entretanto, essa opção pode se tornar inviável na prática, pois o tempo de carga do DW aumentará consideravelmente. Como frequentemente um DW possui muitas tabelas fato e dimensões, a duração da carga periódica nesses casos não é pequena e a janela para sua execução deve ser minuciosamente projetada pelos desenvolvedores, para não haver competição com as consultas realizadas pelos usuários de sistemas de apoio à gestão e demais consultas submetidas à essa base de dados. Portanto, 


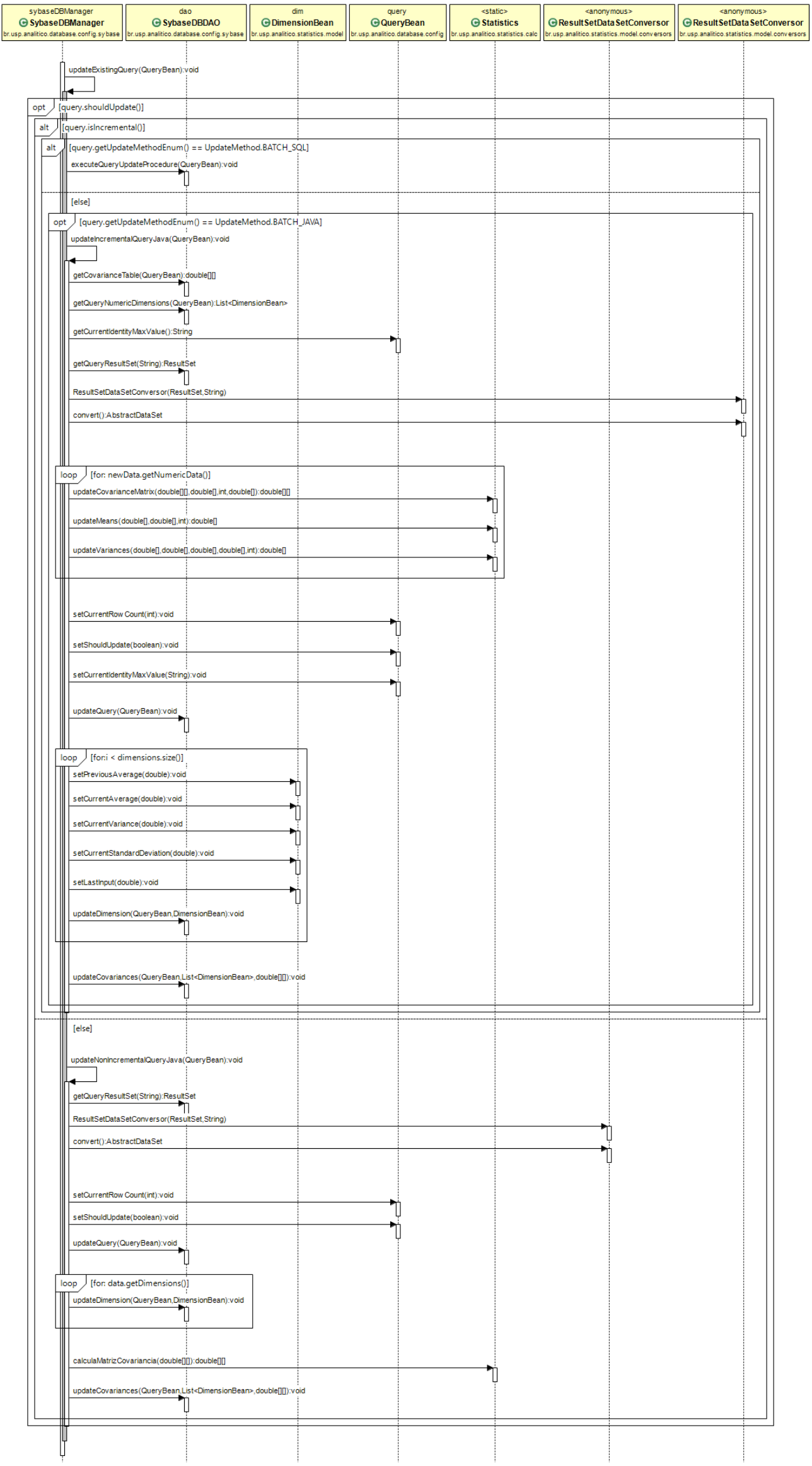

Figura 4.9: Diagrama de sequência simplificado da etapa de atualização de consulta existente no METADB. 
a estratégia de carga em batch com periodicidade maior do que a carga de dados do DW pode ser mais interessante em DW com grande volume de dados.

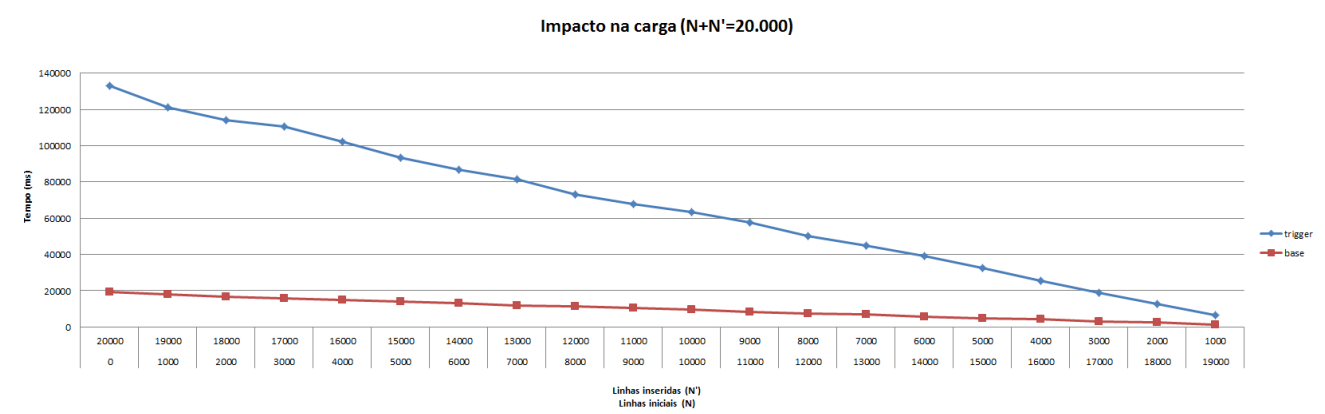

Figura 4.10: A figura mostra os tempos de carga para o cenário sem integração com a API (base) e com a API integrada seguindo a estratégia de carga incremental por trigger. Nota-se que o tempo de execução supera em seis vezes o tempo sem a integração.

\section{Carga incremental em batch via stored procedures}

Nesse experimento, a tabela fato descrita no experimento anterior foi carregada da mesma maneira. Porém, o cálculo dos valores utilizados na API foi feito a posteriori pela invocação manual da mesma stored procedure de atualização utilizada na estratégia de carga por triggers, como descrito na seção 4.4.3. O tempo total de execução da stored procedure foi somado ao tempo de carga das novas linhas na tabela fato para comparação com os demais cenários de integração. Era esperado que o tempo total de execução fosse similar à estratégia de carga por triggers, já que a mesma stored procedure foi executada para a atualização incremental linha a linha, porém em momentos diferentes. O gráfico da Figura 4.11 nos mostra o tempo de execução nos diferentes experimentos realizados com essa estratégia de atualização, comparados com a estratégia de carga por triggers. O tempo de execução demonstrou-se maior para a estratégia batch_sql, diferentemente do esperado. O aumento do tempo pode ser explicado pela implementação das iterações no cálculo incremental a cada observação inserida. O SGBD Sybase utilizado nos testes possui algumas limitações, como a ausência de um tipo de dados Array. Portanto, para criar as stored procedures de atualização dinamicamente e de maneira genérica, foi utilizado um cursor, que possui uma performance baixa, pois são realizadas muitas operações de rede em sua implementação. Porém, apesar de sua execução ser mais longa, a atualização em batch possui a vantagem de evitar a concorrência com a carga do DW. Pode-se esperar a acumulação de novas linhas até um certo limiar ou até que uma nova análise seja feita e então realizar a atualização das estatísticas ativamente de acordo com a demanda. Como outra desvantagem da estratégia podemos citar exatamente o fato da falta de sincronia entre as estatísticas e os dados reais. Porém, quanto mais linhas a tabela fato e sua consulta já possuírem, menor será o impacto de novas observações nos valores calculados. 


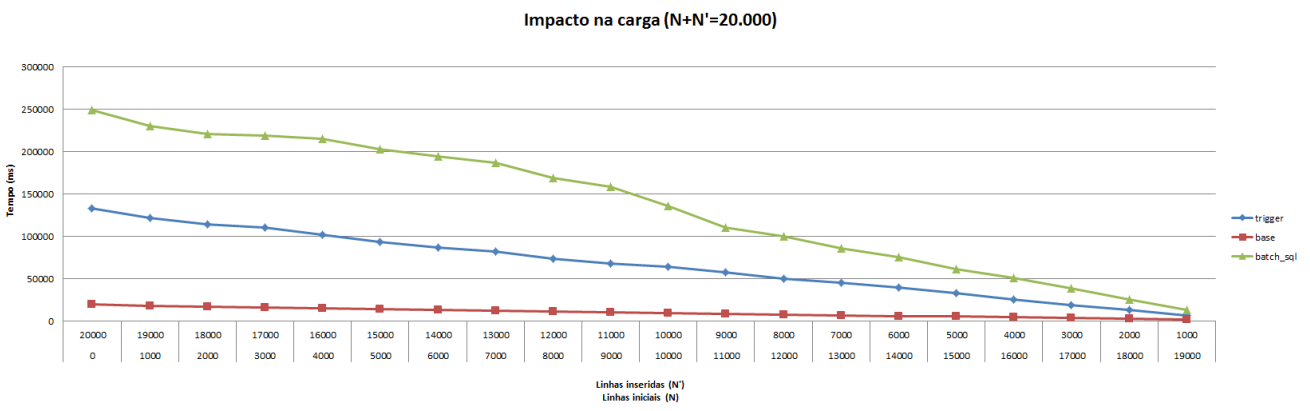

Figura 4.11: A figura mostra a comparação dos tempos de carga para o cenário de carga em batch via sql em relação aos cenários anteriores.

\section{Carga incremental em batch via Java}

No cenário de carga incremental feita pela API diretamente no código Java utilizou-se os mesmos parâmetros dos experimentos anteriores. Como esperado, o tempo de execução foi muito menor que os demais, pois os cálculos são feitos em memória e a atualização das tabelas do modelo é feita uma única vez ao final da execução. Nos cenários anteriores, a atualização das tabelas é feita a cada nova observação, resultando em muitas operações de inserção e atualização no banco de dados, gerando um grande overhead na carga. A Figura 4.12 apresenta os gráficos do resultado desse experimento.

Essa estratégia se mostra muito superior às anteriores em relação ao tempo de execução, devido à limitações nos SGBDs utilizados. Caso existissem tipos de dados adequados, as cargas feitas por SQL poderiam ser otimizadas. Entretanto, ainda assim seria utilizada a memória da máquina onde se localizam os SGBDs para os cálculos, ou seja, os recursos seriam onerados e a performance da consulta de sistemas sobre essas bases poderia ser degradada. Utilizando um ambiente separado no qual a API estaria em funcionamento e configurando as consultas para utilizarem a estratégia de carga via Java, esse problema seria mitigado.

\section{Carga não-incremental em batch via Java}

Para consultas não-incrementais, a única estratégia implementada foi a de carga por meio de métodos da API na linguagem Java, porém os cálculos são facilmente implementáveis na linguagem SQL. Os parâmetros utilizados nos cenários anteriores não foram adequados para demonstrar a melhoria de performance da carga incremental em relação a estratégia não-incremental, como pode ser visto na Figura 4.13, pois o número de linhas inseridas não foi elevado, em relação às linhas existentes na tabela fato. Como demonstrado na Figura 4.6 da seção 4.3.2, a otimização ocorre quanto menor a razão $N^{\prime} / N$, para valores de $N$ elevados, ou seja, quanto maior a vida da tabela fato no DW, mais linhas ela deverá ter e mais eficaz será o método incremental. Portanto, para tabelas 


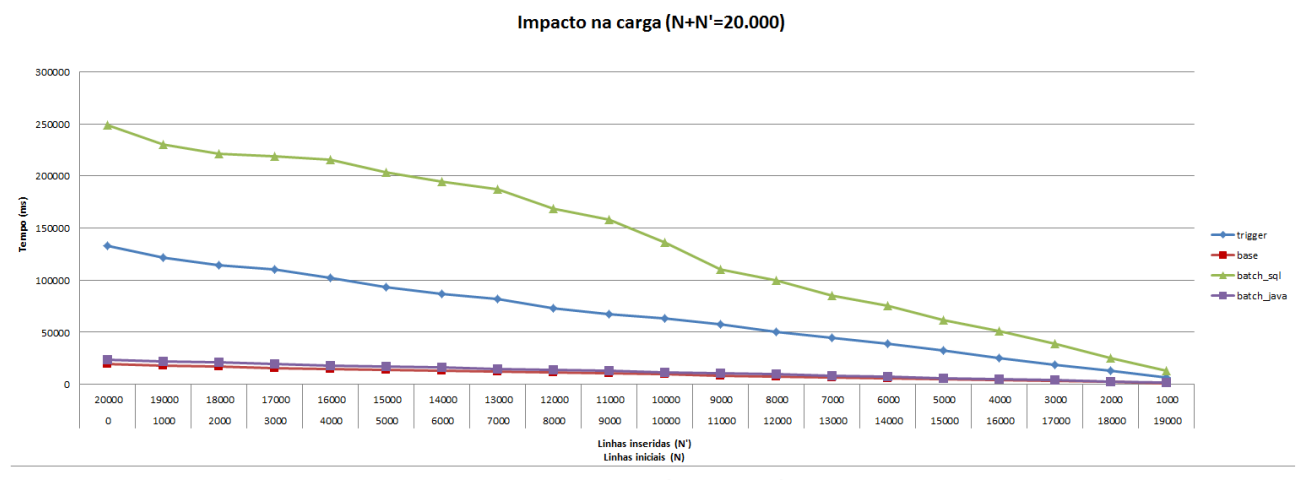

Impacto na carga $\left(\mathrm{N}+\mathrm{N}^{\prime}=\mathbf{2 0 . 0 0 0 )}\right.$

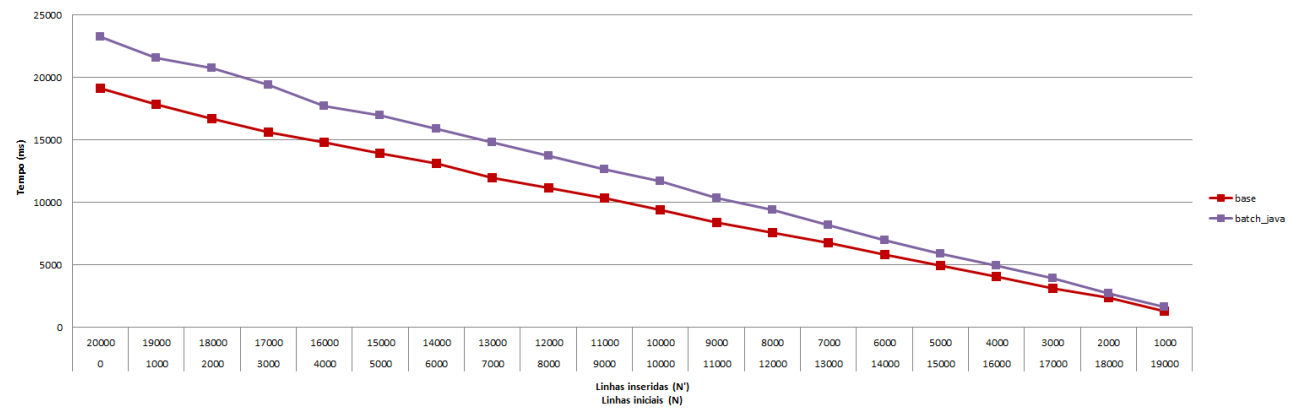

Figura 4.12: A figura mostra a comparação dos tempos de carga para o cenário de carga em batch_java por meio de métodos da API em relação aos cenários anteriores.

fato recentes, isto é, com poucas linhas já carregadas, o método incremental não apresenta melhoria de performance e o cálculo completo deve ser preferido, para evitar perda de significância devido a arredondamentos e dados truncados nas operações. Como na prática de data warehousing não é possível garantir a incrementalidade para todas as consultas, essa estratégia deverá ser utilizada frequentemente. Executando-a em ambiente separado do SGBD, evita-se a concorrência de recursos com as diversas aplicações que consultam o DW. No entanto, é necessária uma infraestrutura maior para possibilitar a separação dos ambientes e, portanto, pode-se fazer necessária a implementação do cálculo diretamente na base de dados, por meio de stored procedures apesar da performance não ser ótima, como demonstrado nos experimentos anteriores. 


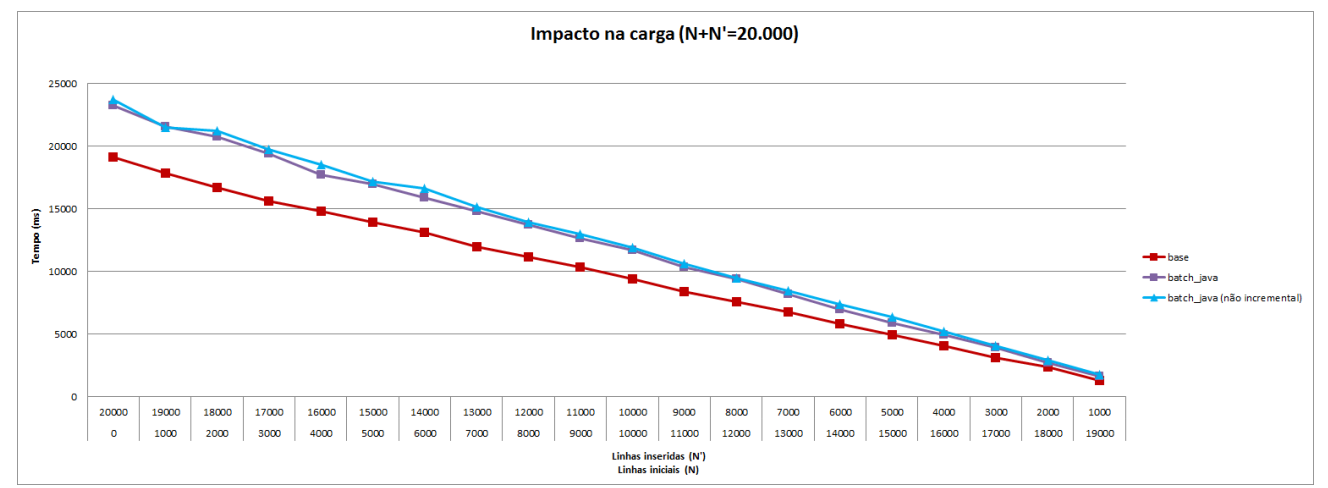

Figura 4.13: A figura mostra a comparação dos tempos de carga para o cenário de carga em batch_java por meio de métodos da API incremental e não incremental, em relação à carga de dados sem a utilização da API. 


\section{Capítulo 5}

\section{Experimentos}

Com a API desenvolvida, foram realizados diversos experimentos para verificar sua corretude, analisar sua performance em função do conjunto de dados de entrada e também aplicar a ferramenta em estudos de caso reais, elucidando a correlação entre os diferentes indicadores bibliométricos associados à produção científica dos docentes da Universidade de São Paulo. Neste capítulo, esses experimentos serão apresentados junto a uma discussão a respeito dos resultados obtidos.

\subsection{Corretude da API}

Para analisar a corretude da ferramenta utilizou-se um conjunto de dados controlados de entrada para que a saída fosse analisada, comparando-a com o resultado teórico esperado. Esse conjunto de dados foi criado de modo que a dispersão das observações de cada variável era conhecida.

\subsubsection{Duas variáveis}

No primeiro experimento, foram gerados 2000 pontos a partir de duas variáveis, $X$ e $Y$, cujos valores se distribuíam em torno da reta $\mathbf{X}=\mathbf{Y}$, como pode ser visto no gráfico de dispersão ilustrado na Figura 5.1. Esse valores foram gerados por meio do código abaixo:

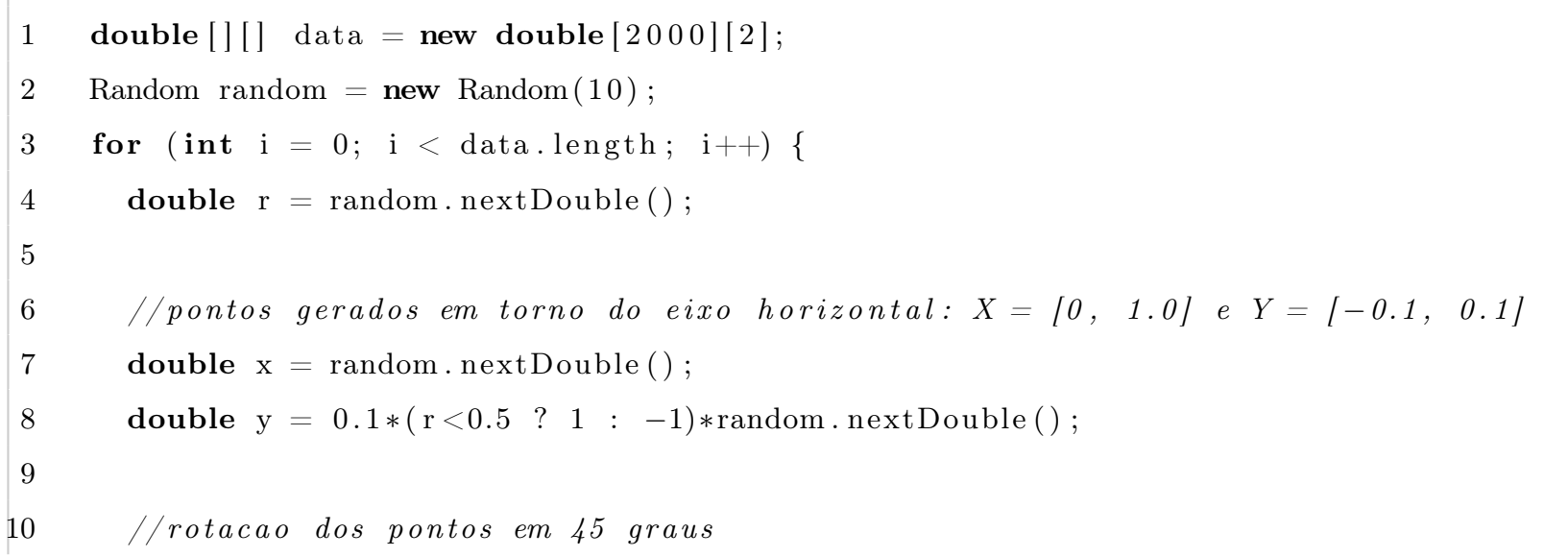


11 data[i] $[0]=($ Math. sqrt $(2) / 2.0) *(\mathrm{x}+\mathrm{y})$;

12 data $[\mathrm{i}][1]=($ Math. $\operatorname{sqrt}(2) / 2.0) *(\mathrm{x}-\mathrm{y})$;

$13\}$

Figura 5.1: Gráfico de dispersão dos dados do primeiro experimento para validar a corretude da ferramenta. Foram gerados pontos pseudo-aleatórios na vizinhança da reta $\mathbf{X}=\mathbf{Y}$.

Como resultado, esperava-se que a principal componente se aproximasse dessa reta, cuja direção apresentava maior variação dos dados de entrada. A segunda principal componente seria, portanto, próxima à reta $\mathbf{X}=-\mathbf{Y}$ já que as componentes devem ser ortogonais entre si. Com o valor mínimo desejado de variância acumulada padrão de $\mathbf{0 , 9 5}$, a segunda componente é descartada. Para que fossem apresentadas as duas principais componentes no gráfico da Figura5.2, a aplicação da técnica foi feita também utilizando $\mathbf{0 , 9 6}$ como esse valor. O resultado obtido foi como esperado, como pode ser visto no arquivo JSON abaixo e nas Figuras 5.2 e 5.3.

\subsection{Estudos de caso}

Os estudos de casos analisados neste trabalho baseiam-se nos dados referentes aos índices bibliométricos dos docentes da USP, obtidos das plataformas de pesquisa externas à universidade, bem como indicadores acadêmicos internos, apresentados na Tabela 4.1. O objetivo desses experimentos era entender melhor a correlação entre os diversos indicadores, para o conjunto de dados da USP.

Os experimentos foram realizados em dois momentos: o primeiro em abril de 2017 e o segundo 


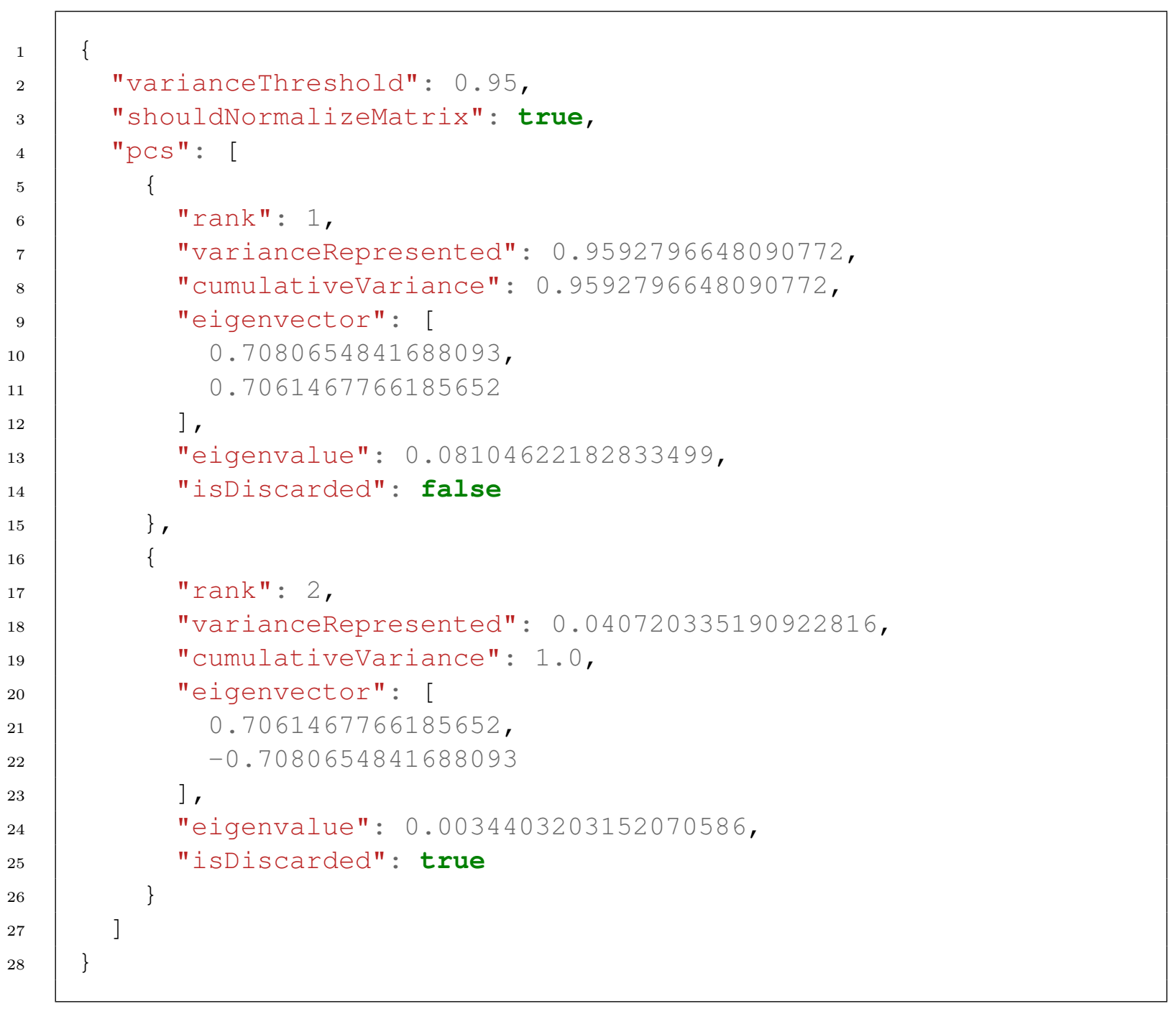

Listing 1: Resultado da aplicação da PCA no primeiro experimento para demonstrar a corretude da API.

três meses depois, após uma campanha para preenchimento dos identificadores dos autores nas bases científicas, que são usados como fonte da pesquisa para obtenção dos dados bibliométricos. Desse modo, foi possível observar a evolução temporal do resultado e reforçar ou refutar a conclusão inferida deles no primeiro momento, já que o volume de dados coletados das fontes de pesquisa aumentou em aproximadamente 8,5\% na segunda execução dos experimentos.

A seguir, serão apresentados esses experimentos e os resultados obtidos em ambos os momentos, bem como uma discussão acerca desses resultados e as conclusões inferidas.

\subsubsection{BP x EWQ}

O primeiro estudo realizado buscou compreender a correlação entre os níveis de bolsa de produtividade do $\mathrm{CNPq}(\mathrm{BP})$ e o Estrato Web Qualis (EWQ) da produção científica dos docentes. Para isso, foi usado um conjunto de dados no qual cada registro representa um docente da USP que possui BP e, em cada um deles, calculou-se o total de publicações classificadas nos diferentes EWQ 


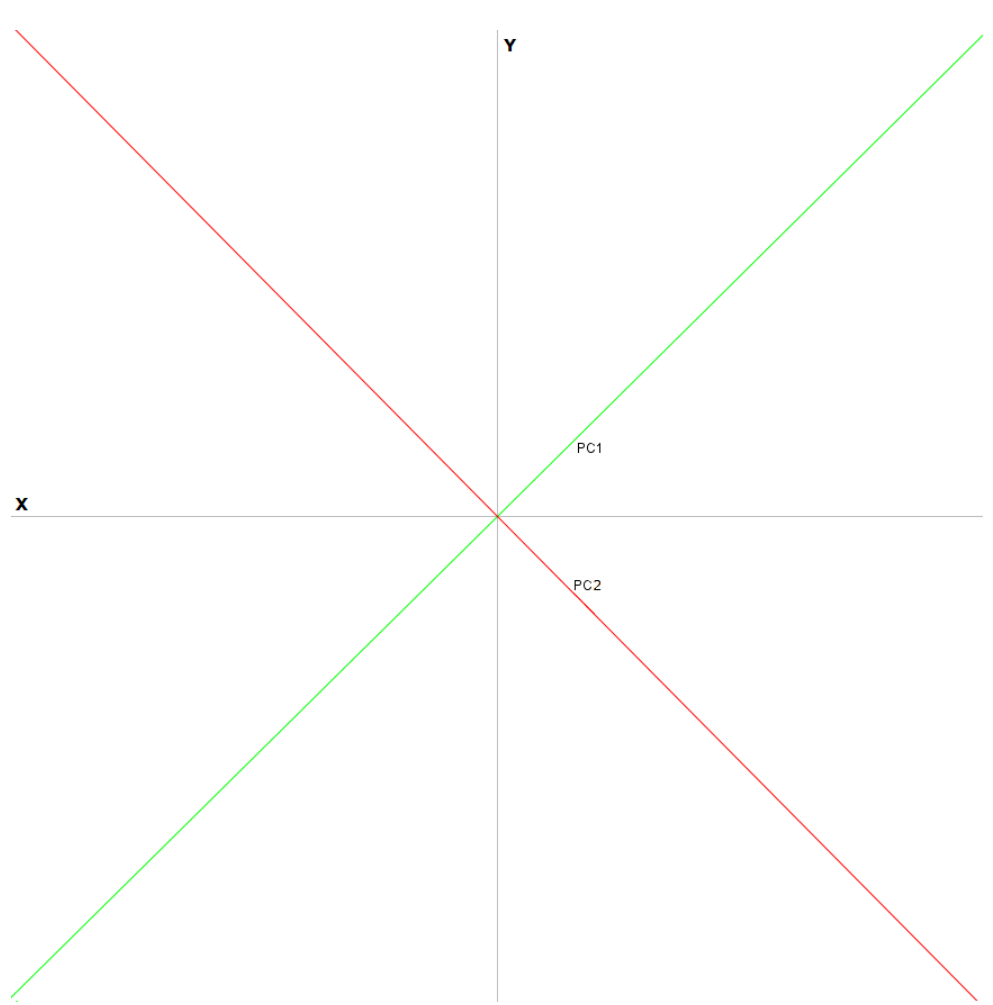

Figura 5.2: Principais componentes obtidas após a aplicação da ferramenta sobre os dados da Figura 5.1.

\begin{tabular}{|c|c|}
\hline Nivel da bolsa & Valor do Indicador \\
\hline PQ-2 & 1 \\
\hline PQ-1D & 2 \\
\hline PQ-1C & 3 \\
\hline PQ-1B & 4 \\
\hline PQ-1A & 5 \\
\hline PQ-SR & 5 \\
\hline
\end{tabular}

Tabela 5.1: Indicador quantitativo para representar a bolsa de produtividade do CNPq.

e criou-se um indicador para quantificar o nível da BP de acordo com o valor financeiro descontando o adicional de bancada ${ }^{1}$, como pode ser visto na Tabela 5.1 .

O experimento foi realizado no conjunto de dados completos e, em seguida, segmentado nas diferentes áreas de ciências (i.e. Biológicas, Exatas e Humanas). Um docente foi considerado como pertencente a uma área de ciências se em algum momento ele foi vinculado a uma Unidade de Ensino da USP pertencente a tal área, como docente (i.e. possuir um outro tipo de vínculo com a UE, como servidor não-docente, por exemplo, não é condição suficiente para integrar a área de ciências).

Os resultados da aplicação da PCA nesses conjuntos de dados podem ser vistos nas Figuras 5.4 e 5.5, sendo que a primeira foi aplicada com os dados coletados em abril de 2017 e a segunda três meses depois. Pode-se notar que a PC1 tem sua composição distribuída de maneira similar entre

\footnotetext{
${ }^{1}$ Esses valores podem ser encontrados na tabela Tabela de Valores das Bolsas de Produtividade no site do CNPq: http://cnpq.br/no-pais
} 


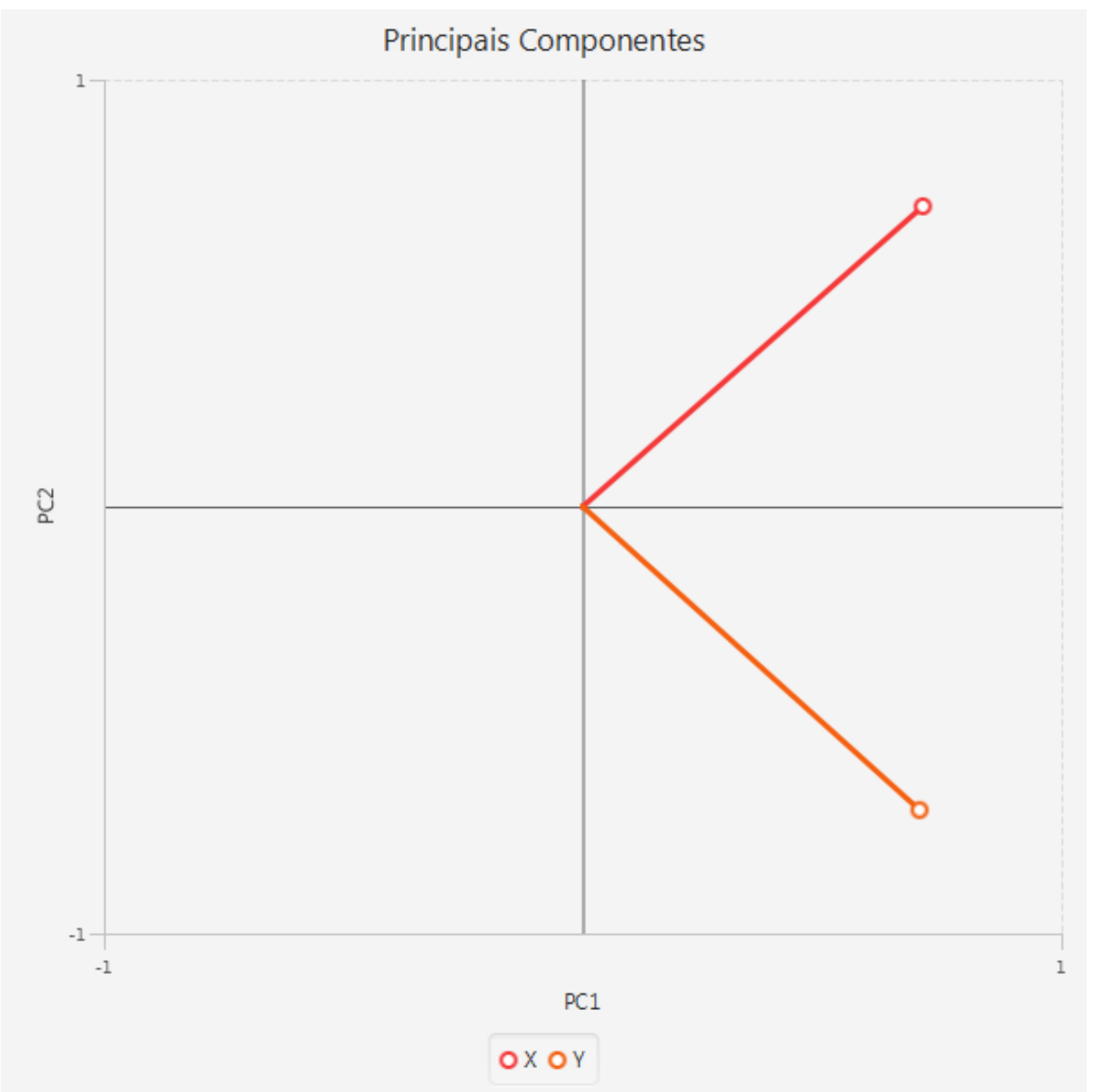

Figura 5.3: Gráfico de fatores gerado a partir do resultado do primeiro experimento. Pode-se observar que, como esperado, o peso das variáveis $X$ e $Y$ na composição da principal componente PC1, dado pela projeção dos vetores no eixo horizontal, é o mesmo, já que essa componente coincide com a reta $\mathbf{X}=\mathbf{Y}$. Já a segunda principal componente PC2 é composta pelas variáveis originais com a mesma magnitude, porém sinais inversos, já que essa componente se aproxima da reta $\mathbf{X}=-\mathbf{Y}$.

os indicadores analisados, já que as projeções desses sobre o eixo horizontal têm mesmo sentido e magnitude semelhante, principalmente no resultado mais recente. Isso nos leva a interpretar essa principal componente como a representação do total de produções, já que a classificação do Estrato Web Qualis parece não influenciar de maneira significativa em sua composição. Já a PC2 nos apresenta uma segmentação em sua composição que nos induz a interpretá-la como a representação da qualidade das publicações de acordo com o EWQ. Essa interpretação decorre do fato de que em todos os conjuntos de dados estudados, os indicadores que representam o total de publicações com classificação baixa no EWQ (i.e. B3, B4, B5 e C) ficaram no quadrante 2, os que representam o total de publicações com classificação alta no EWQ (i.e. A1, A2 e B1) ficaram no quadrante 3, ou seja, influenciam de maneira inversa a PC2, e o indicador de total de produções B2 (classificação média no EWQ) ficou próximo ao eixo horizontal, sem influenciar a PC2. Por último, nota-se que o indicador que representa a BP parece estar fortemente correlacionado ao total de produções de 
maior qualidade (i.e. A1 e A2), para todas as segmentações. A variância total explicada pela PC1 para a USP, área de Biológicas, Exatas e Humanas, respectivamente é de 49\%, 50\%, 47\% e 44\% e a pela PC2 é de $16 \%, 14 \%, 21 \%, 15 \%$.

Esse experimento nos mostra que é possível utilizar a PCA para, nesses conjuntos de dados estudados, reduzir a dimensionalidade mantendo aproximadamente $65 \%$ da variância original, substituindo os nove indicadores originais por duas novas dimensões: Total de produções (PC1) e Qualidade da produção científica (PC2). Para maior representatividade, pode-se utilizar mais componentes resultantes da aplicação da técnica.
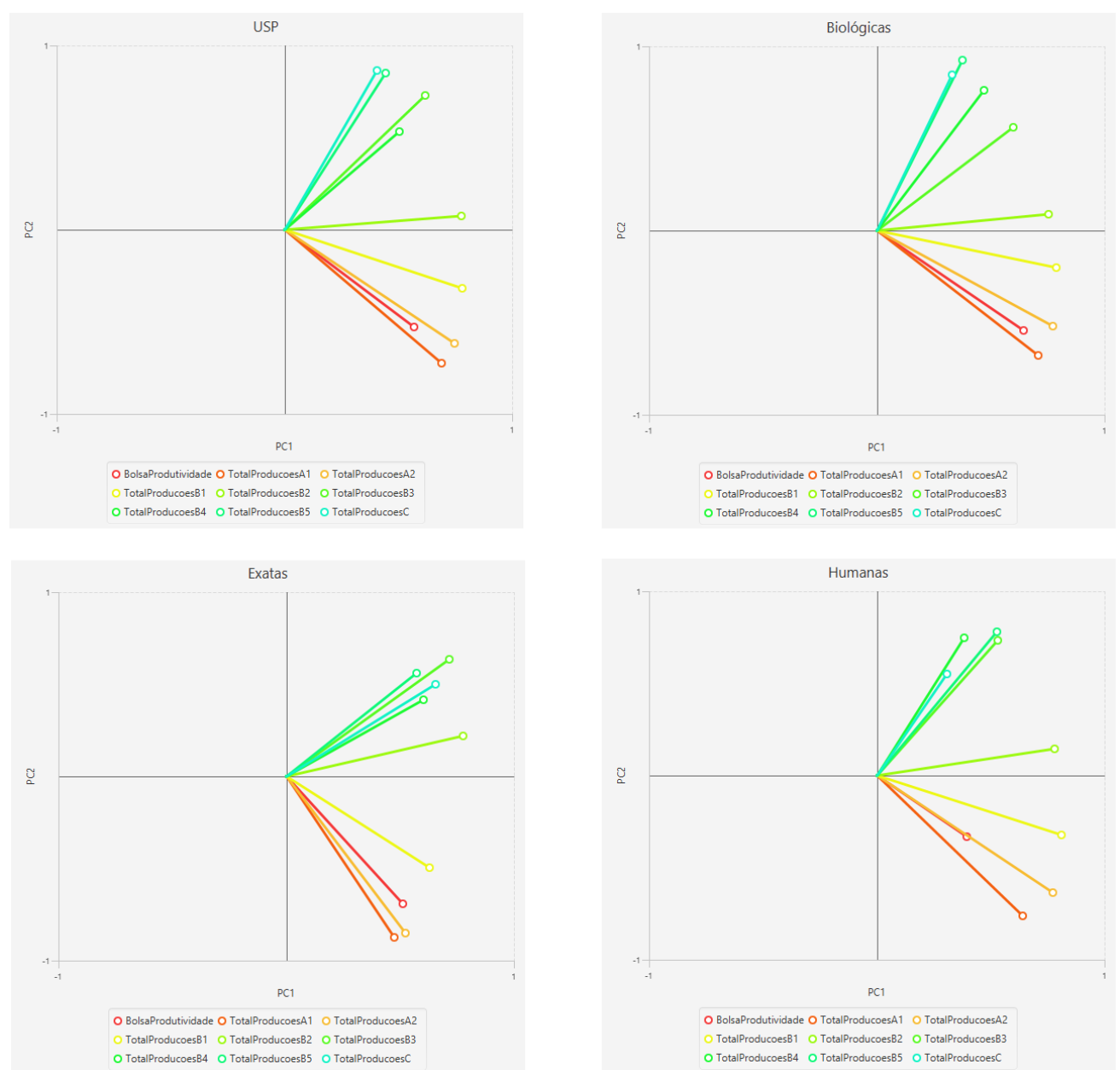

Figura 5.4: Resultado do primeiro estudo de caso aplicado aos dados coletados em abril de 2017.

\subsection{2 (PCW, PCG, PCS) x (IHW, IHG, IHS) x (CITW, CITG, CITS) x EWQ}

O objetivo do segundo experimento foi compreender a correlação entre as fontes de indicadores bibliométricos e a qualidade da produção científica, tentando inferir se há uma fonte mais relevante para a USP e, também, para as áreas de ciências das UE.

Para esse fim, foram usados, além do EWQ, os indicadores de total de produções, índice H e 

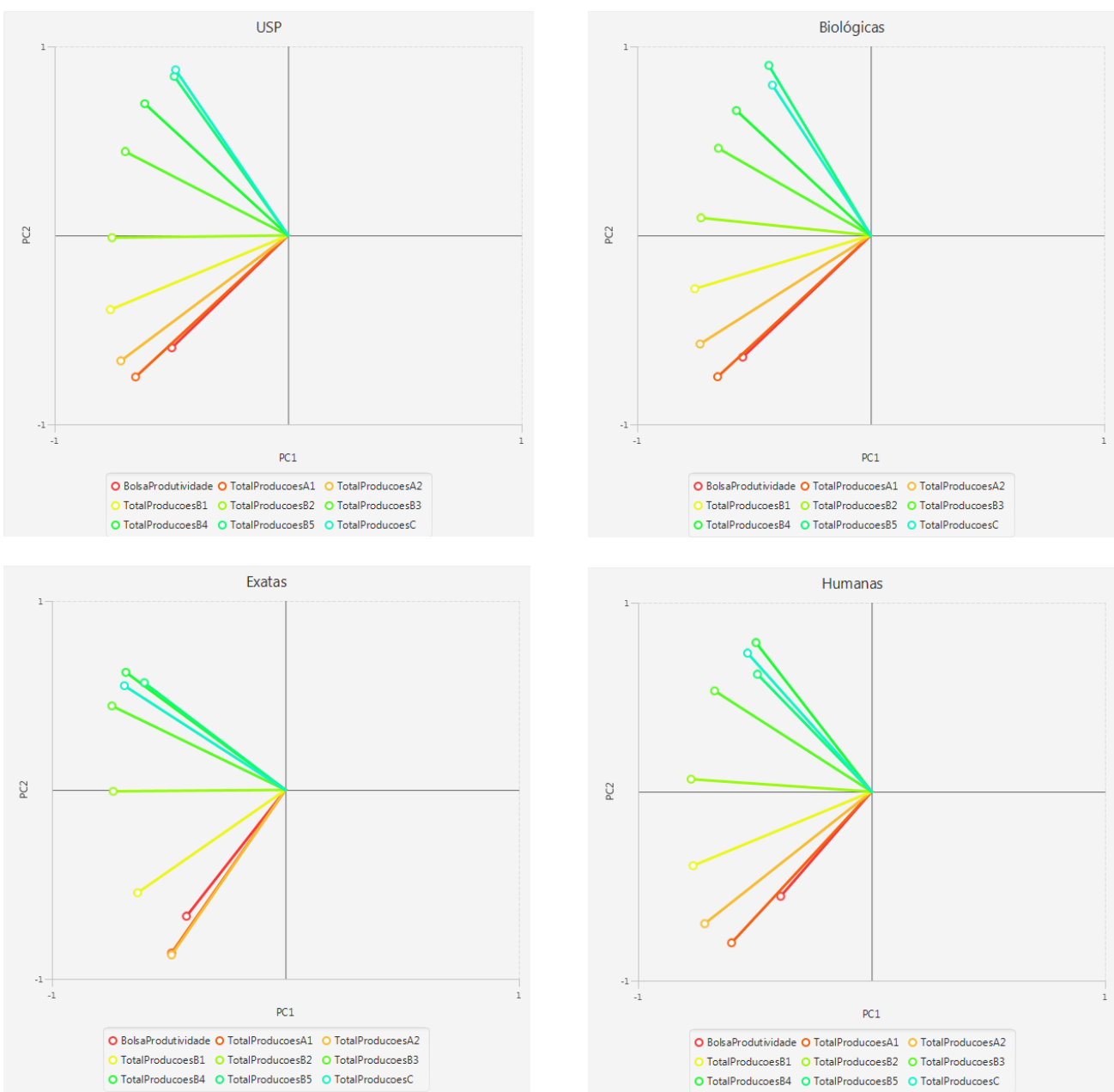

Figura 5.5: Os gráficos de fatores do primeiro experimento mostram uma possível correlação entre o indicador BP e o total de produções com EWQ A1 e A2, para todas as áreas de ciências e para a USP toda.

total de citações obtidos das diferentes fontes de índices bibliométricos: WOS, Scholar e Scopus. Esse experimento, como o primeiro, foi segmentado nas diferentes áreas de ciências.

Como almejou-se inferir a fonte de dados relevante em cada situação, os dados dos docentes que não possuíam informações em alguma base de dados foram considerados com valor 0 , contribuindo para identificar fontes não-relevantes.

No gráfico de fatores da Figura 5.7, pode-se notar que, para a USP como um todo e para a área de Ciências Biológicas, parece não haver uma correlação clara entre as fontes de dados e a qualidade da produção, evidenciando que não há uma fonte mais relevante para essas segmentações. Entretanto, na área de Ciências Exatas, há uma possível correlação entre os indicadores obtidos do WOS e Scopus e as produções com melhores EWQ, evidenciando uma maior importância dessas fonte de dados para essa área. Esse resultado é inferido do fato que os fatores PCW e PCS coincidem em direção, sentido e magnitude com os totais de produção com EWQ A1 e A2, ou seja, esses quatro indicadores compõem de maneira similar as principais componentes. Por último, na área de Ciências Humanas, observa-se que os indicadores das fontes WOS e Scopus situam-se em um quadrante diferente dos demais. A composição da PC2 nessa segmentação nos leva a uma suposição de que 
essas duas fontes não são muito relevantes para essa área de ciências, principalmente a fonte Scopus, já que seus indicadores compõem a segunda componente com uma magnitude muito maior que os demais. É interessante notar que não houve variação relevante entre a coleta de abril de 2017, vista na Figura 5.6 e a coleta mais atual, reforçando as suposições inferidas da aplicação da PCA.
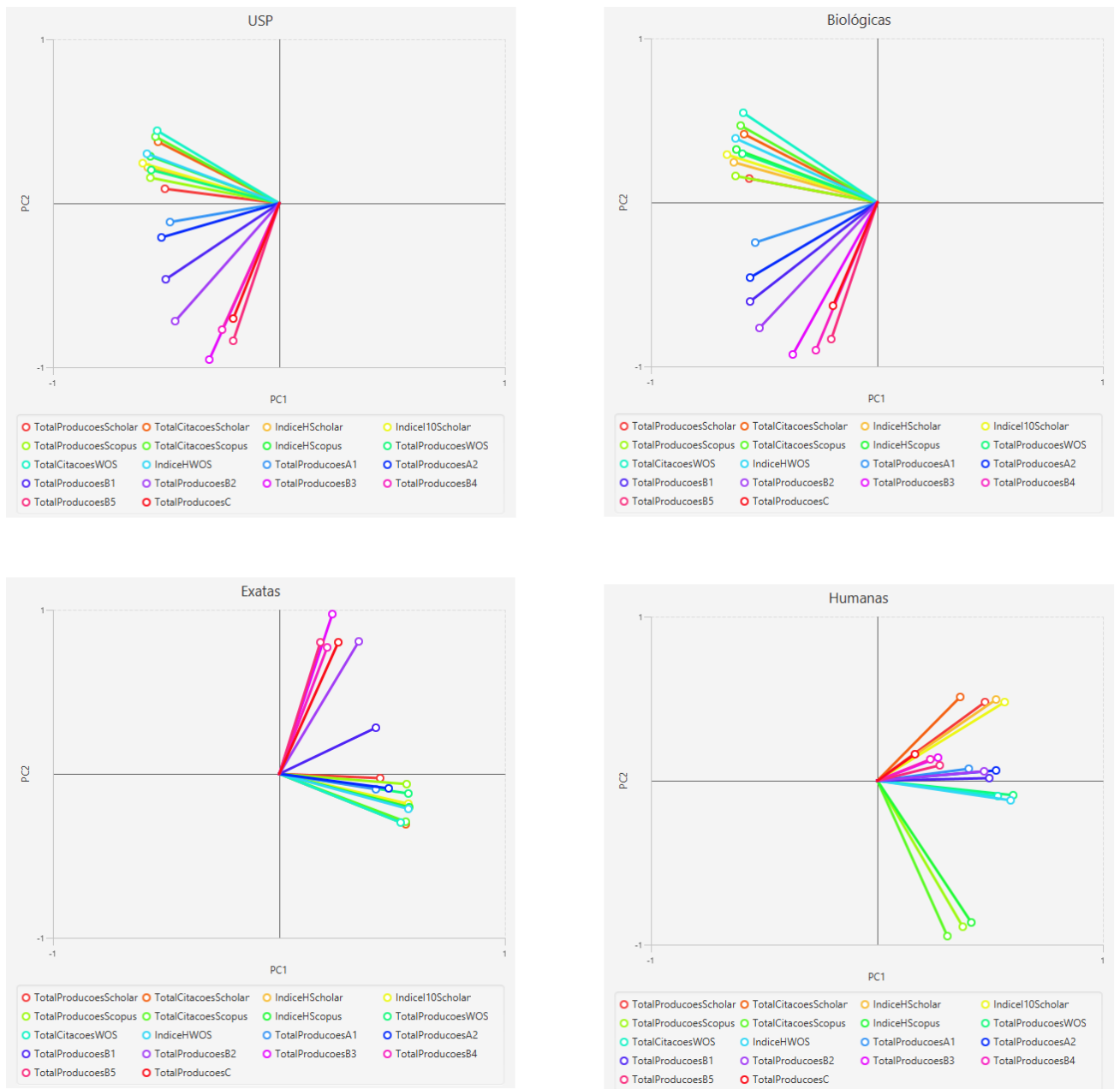

Figura 5.6: Resultado do segundo experimento com os dados coletados em abril de 201\%.

\subsection{3 (APL, TJRL, TEL, LCL, DPL) x (TME, TDO)}

O terceiro experimento foi executado sobre os dados da Plataforma Lattes e também de um dos indicadores acadêmicos da pós-graduação da USP, o total de títulos de mestrado e doutorado concedidos. O objetivo da análise era verificar se o volume de artigos publicados de um docente está correlacionado com o total de alunos orientados por ele e se essa correlação é válida para os demais tipos de produções e agregações: para a universidade como um todo e para cada área de ciências. O objetivo foi construído com base na hipótese de que para muitos cursos de pós-graduação a produção de artigos pelos alunos é obrigatória e de interesse dos mesmos e o orientador compartilha a autoria das publicações com o aluno. Além disso, a pesquisa feita durante os cursos pode levar 

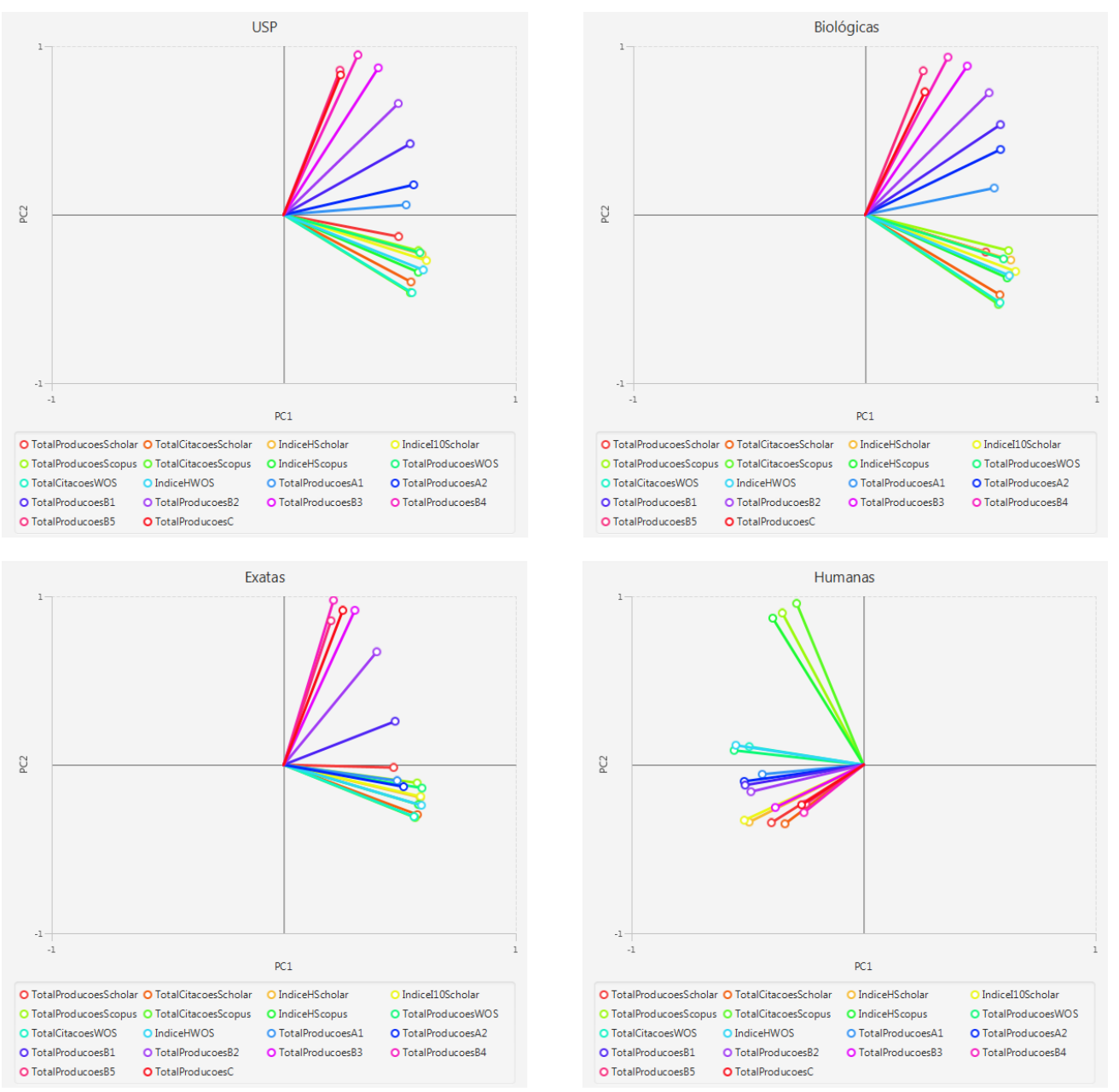

Figura 5.7: Os gráficos de fatores do segundo experimento mostram uma possível correlação entre a fonte de indices bibliométricos WOS e as produções de maior qualidade na área de Ciências Exatas e a não-correlação entre a fonte Scopus e as produções da área de Ciências Humanas.

o docente a outras publicações independentes. O gráfico de fatores da Figura 5.8 nos mostra que a hipótese provavelmente é correta para a USP como um todos e também para as diferentes áreas de ciências, já que a projeção no eixo da PC1 dos indicadores de total de títulos e artigos publicados é coincidente. Na USP e nas áreas de biológicas e exatas parece existir uma correlação entre o total de artigos publicados e o total de trabalhos em eventos. Isso pode ser explicado pelo fato de que a publicação de artigos normalmente é acompanhada com a apresentação do mesmo em conferências. Porém, apenas na visão USP a PC1 é muito representativa. No resultado por área de ciências a porcentagem da variância explicada por essa componente varia entre $37 \%$ e $45 \%$. A Figura 5.9 mostra o gráfico de dispersão dos pontos originais para toda a USP transformados de acordo com os scores obtidos nas duas principais componentes. As cores do gráfico representam a dimensão classificatória Área de Ciências. Pode-se notar uma menor dispersão dos dados referentes à área de exatas na segunda principal componente, que de acordo com o gráfico de fatores parece indicar o tipo de produção científica cadastrada na base Lattes. Essa menor dispersão pode indicar uma concentração de produções de um certo tipo para a área, provavelmente a de artigos e trabalhos 
publicados em eventos. Na área de humanas é possível notar uma maior dispersão dos dados, indicando que o tipo de produção é variado. A área de biológicas apresenta uma dispersão mais balanceada e a presença de vários pontos destoantes do conjunto principal.
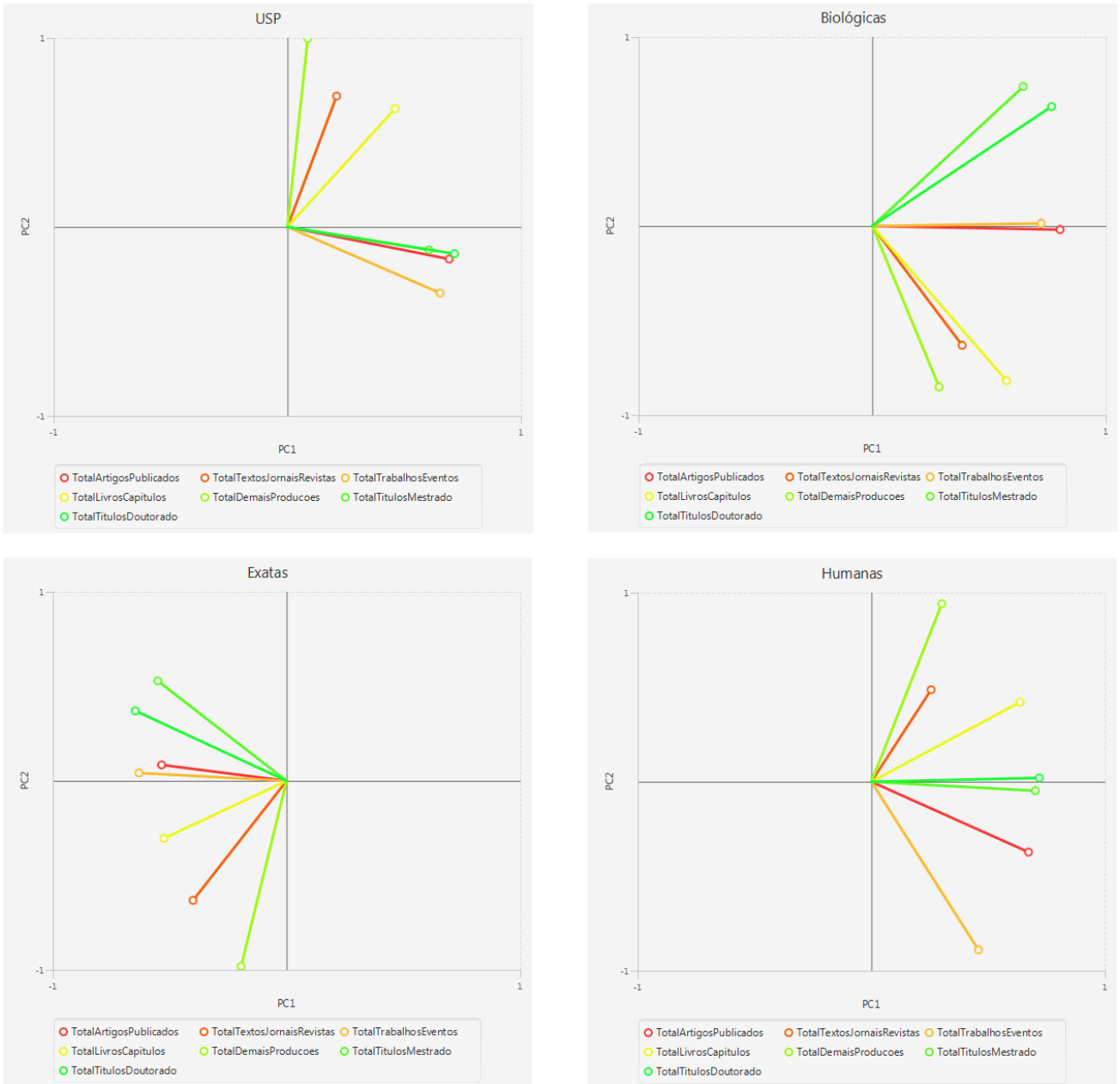

Figura 5.8: Gráfico de fatores do terceiro experimento, mostrando a provável correlação entre o total de alunos orientados e o total de artigos publicados pelos docente. A PC1 explica 70\% da variância dos dados e a PC2 $15 \%$ para a USP. 


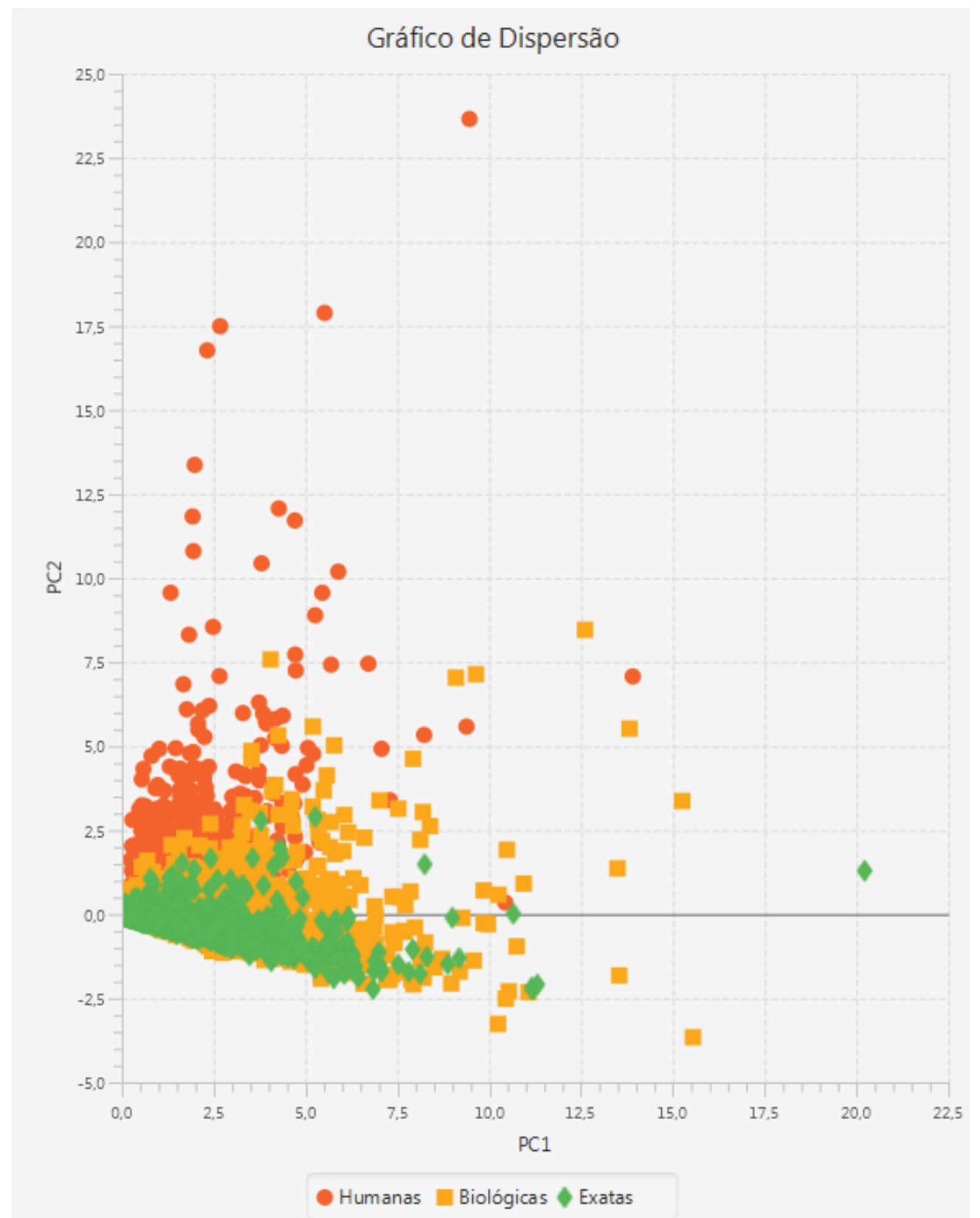

Figura 5.9: Gráfico de dispersão dos pontos originais do terceiro experimento, transformados de acordo com o score obtido nas duas principais componentes. Observa-se uma concentração de pontos na área de exatas e uma maior dispersão na de humanas. 


\section{Capítulo 6}

\section{Conclusões}

Neste capítulo serão apresentados comentários sobre o trabalho desenvolvido e sugestões de linhas para a continuidade da pesquisa.

\subsection{Comentários finais}

O trabalho de mestrado apresentado nesta dissertação forneceu uma maneira de integrar a aplicação da técnica de Análise de Componentes Principais a um ambiente de Data Warehouse corporativo. A implementação de uma API para tal finalidade contribuiu para a evolução dos sistemas corporativos da USP que seguem um novo paradigma para a instituição, provendo diferentes tipos de análises sobre os dados acadêmicos e administrativos da universidade.

As discussões sobre as estratégias de integração e os desafios que tiveram que ser superados contribuem para a comunidade científica como uma visão geral das preocupações relativas ao impacto da execução de cálculos periódicos sobre conjuntos de dados que sofrem alterações em curtos intervalos de tempo. O modelo de dados e o procedimento adotado para o armazenamento e atualização dos valores utilizados nas análises se mostra eficaz e extensível para outros tipos de ferramentas estatísticas. A maneira voltada para interfaces e classes abstratas com a qual a API foi desenvolvida permite a fácil compatibilização com outros SGBDs e demais tipos de entradas de dados, bem como a alteração dos procedimentos realizados por cada classe.

Por último, além da contribuição principal do trabalho, também foram apresentados estudos de casos sobre indicadores bibliométricos e acadêmicos da Universidade de São Paulo, evidenciando a utilidade da ferramenta e auxiliando na compreensão do relacionamento entre esses diversos aspectos da instituição com comentários e intuições sobre os resultados obtidos com a aplicação da PCA. 


\subsection{Trabalhos futuros}

O desenvolvimento da API e sua integração com Data Warehouses, assim como o estudo de indicadores bibliométricos, possibilitaram que autor ampliasse seu conhecimento nessas questões e, consequentemente, identificasse oportunidades de desenvolvimento e experimentação. Neste capítulo serão sugeridos alguns tópicos para continuidade da pesquisa em trabalhos futuros.

A primeira sugestão é a continuidade do desenvolvimento da API e uma maior integração com os SGBDs. Utilizando os métodos já desenvolvidos, refinando-os, e criando novas funcionalidades, seria possível implementar a extensão do código das bases de dados para utilizar a API internamente, adaptando-a de acordo com a implementação de cada SGBD. Nesse sentido, a própria linguagem SQL poderia ser estendida para a criação de objetos sobre consultas: da mesma maneira em que há um comando para criação de índices em tabelas, ou criação de views sobre consultas, haveria um comando que associaria uma consulta a uma série de estatísticas. Essa associação resultaria na criação das tabelas internas utilizada para a API e nos cálculos apresentados neste trabalho. A atualização dos valores com a estratégia de batch poderia ser embutida em comandos já existentes, como o update statistics do Sybase ou o optimize/analyze table do MySQL, ou um novo comando poderia ser criado para essa finalidade. Assim, as estatísticas sobre e entre as colunas do resultado das consultas estariam disponíveis para o usuário em tabelas como as de sistema, para serem usadas para qualquer fim desejado.

Outra sugestão seria aprofundar o estudo sobre Data Warehouses. Utilizando os resultados da API sobre os modelos operacionais e também sobre o próprio DW, pode-se estudar maneiras de particionar os dados eficientemente, estratégias para desenvolvimento de modelos multidimensionais concisos com a redução de dimensionalidade resultante da PCA e para segmentação dos dados em visões distintas. Nos trabalhos relacionados encontrados no Capítulo 3, há referências de pesquisas nessa linha que podem ser estudadas a fundo para a busca de novas oportunidades.

Por fim, o estudo de indicadores corporativos e acadêmicos da Universidade de São Paulo representa uma grande oportunidade. Neste trabalho, foram utilizados alguns indicadores relacionados à pesquisa. Entretanto, existe um leque muito maior de importantes indicadores para serem estudados. Por exemplo, os indicadores financeiros podem ser estudados juntamente com acadêmicos ou estruturais, com a finalidade de otimização de gastos. Os indicadores de graduação podem ser relacionados com indicadores sociais para a criação de modelos analíticos e preditivos para melhorar o acompanhamento individual dos alunos. A correlação entre as informações acadêmicas dos alumni (i.e. ex-alunos) e informações profissionais e econômicas atuais pode ser estudada, para aprimorar o acompanhamento e o relacionamento desses indivíduos com a instituição de ensino após a formação. 


\section{Referências Bibliográficas}

[ACHVH09] Sergio Alonso, Francisco Javier Cabrerizo, Enrique Herrera-Viedma e Francisco Herrera. h-index: A review focused in its variants, computation and standardization for different scientific fields. Journal of Informetrics, 3(4):273-289, 2009. 12

$\left[\right.$ ACSY $\left.^{+} 13\right]$ Arezoo Aghaei Chadegani, Hadi Salehi, Melor Md Yunus, Hadi Farhadi, Masood Fooladi, Maryam Farhadi e Nader Ale Ebrahim. A comparison between two main academic literature collections: Web of science and scopus databases. Asian Social Science, 9(5):18-26, 2013. 14

[And09] Mircea Andrecut. Parallel gpu implementation of iterative pca algorithms. Journal of Computational Biology, 16(11):1593-1599, 2009. 9, 28

[Bra03] Matthew Brand. Fast online svd revisions for lightweight recommender systems. Em SDM, páginas 37-46. SIAM, 2003. 19

[BVdSHC09] Johan Bollen, Herbert Van de Sompel, Aric Hagberg e Ryan Chute. A principal component analysis of 39 scientific impact measures. PloS one, 4(6):e6022, 2009. 18

[CA11] E Chandra e P Ajitha. Pca for heterogeneous data sets in a distributed data mining. Em Proceedings of the Fourth Annual ACM Bangalore Conference, página 29. ACM, 2011. 19

[CBF] André Casimiro, Marcos Broinizi e João Eduardo Ferreira. Principais componentes na ordenação de anuncios: um experimento em ambiente real de publicidade computacional. 20

$\left[\mathrm{DLP}^{+}{ }^{14}\right]$ Carlos Eduardo Driemeier, Liu Yi Ling, Angelica O Pontes, Guilherme M Sanches, Henrique CJ Franco, Paulo SG Magalhaes e João Eduardo Ferreira. Data analysis workflow for experiments in sugarcane precision agriculture. Em e-Science (eScience), 2014 IEEE 10th International Conference on, volume 1, páginas 163-168. IEEE, 2014. 20

$\left[\mathrm{DMCdM}^{+} 14\right]$ Luciano A Digiampietri, Jesus P Mena-Chalco, Pedro OS Vaz de Melo, Ana PR Malheiro, Dânia NO Meira, Laryssa F Franco e Leonardo B Oliveira. Brax-ray: An x-ray of the brazilian computer science graduate programs. PloS one, 9(4):e94541, 2014. 11, 17

[EEZ13] Rachid Elmansouri, Omar Elbeqqali e Elhoussaine Ziyati. Normed principal components analysis: A new approach to data warehouse fragmentation. Em Computer 
Systems and Applications (AICCSA), 2013 ACS International Conference on, páginas 1-4. IEEE, 2013. 18

[EYA ${ }^{+}$15] Tarek Elgamal, Maysam Yabandeh, Ashraf Aboulnaga, Waleed Mustafa e Mohamed Hefeeda. spca: Scalable principal component analysis for big data on distributed platforms. Em Proceedings of the 2015 ACM SIGMOD International Conference on Management of Data, páginas 79-91. ACM, 2015. 19

[EZEA12] Rachid Elmansouri, Elhoussaine Ziyati, Omar Elbeqqali e Driss Aboutajdine. The fragmentation of data warehouses: An approach based on principal components analysis. Em 2012 International Conference on Multimedia Computing and Systems, 2012. 18

[GSKM15] Antonia Gogoglou, Antonis Sidiropoulos, Dimitrios Katsaros e Yannis Manolopoulos. Bibliometric indices for the assessment of the citation curve tail. Em Proceedings of the 19th Panhellenic Conference on Informatics, páginas 305-310. ACM, 2015. 12, 18

[Hir05] Jorge E Hirsch. An index to quantify an individual's scientific research output. Proceedings of the National academy of Sciences of the United States of America, 102(46):16569-16572, 2005. 12

[HMM98] Peter M Hall, A David Marshall e Ralph R Martin. Incremental eigenanalysis for classification. Em BMVC, volume 98, páginas 286-295, 1998. 29

[Inm05] William H Inmon. Building the data warehouse. John wiley \& sons, 2005. 5

[JLH] Julie Josse, Sébastien Lê e François Husson. Multivariate analysis with the factominer package. 19

[JW ${ }^{+}$92] Richard Arnold Johnson, Dean W Wichern et al. Applied multivariate statistical analysis, volume 4. Prentice hall Englewood Cliffs, NJ, 1992. 11

[JZR ${ }^{+}$09] Dong Hyun Jeong, Caroline Ziemkiewicz, William Ribarsky, Remco Chang e Charlotte Visualization Center. Understanding principal component analysis using a visual analytics tool. Charlotte Visualization Center, UNC Charlotte, 2009. 19

[KC04] Ralph Kimball e Joe Caserta. The data warehouse ETL toolkit. John Wiley \& Sons, 2004. $5,6,7,15,36$

[LJH $\left.{ }^{+} 08\right]$ Sébastien Lê, Julie Josse, François Husson et al. Factominer: an r package for multivariate analysis. Journal of statistical software, 25(1):1-18, 2008. 19

[MNS06] Wolfgang Müller, Thomas Nocke e Heidrun Schumann. Enhancing the visualization process with principal component analysis to support the exploration of trends. Em Proceedings of the 2006 Asia-Pacific Symposium on Information VisualisationVolume 60, páginas 121-130. Australian Computer Society, Inc., 2006. 19 
[QWB04] Hairong Qi, Tsei-Wei Wang e D Birdwell. Global principal component analysis for dimensionality reduction in distributed data mining. Statistical data mining and knowledge discovery, páginas 327-342, 2004. 19

[sco] Scopus - sobre o scopus. https://www.elsevier.com/solutions/scopus. Acessado em: 2016-05-05. 14

[sho] Google Scholar - índice-i10. http://googlescholar.blogspot.com.br/2011/11/ google-scholar-citations-open-to-all.html. Acessado em: 2016-05-05. 14

[SKM15] Antonis Sidiropoulos, Dimitrios Katsaros e Yannis Manolopoulos. Ranking and identifying influential scientists versus mass producers by the perfectionism index. Scientometrics, 103(1):1-31, 2015. 18

$\left[\mathrm{SWC}^{+}\right.$02] Jung P Shim, Merrill Warkentin, James F Courtney, Daniel J Power, Ramesh Sharda e Christer Carlsson. Past, present, and future of decision support technology. Decision support systems, 33(2):111-126, 2002. 5

[TBAKBG14] Wafa Tebourski, Wahiba Ben Abdessalem Kara e Henda Ben Ghezela. New data warehouse designing approach based on principal component analysis. Em Software Engineering, Artificial Intelligence, Networking and Parallel/Distributed Computing (SNPD), 2014 15th IEEE/ACIS International Conference on, páginas 1-6. IEEE, 2014. 18

[TP91] Matthew Turk e Alex Pentland. Eigenfaces for recognition. Journal of cognitive neuroscience, 3(1):71-86, 1991. 28

[Wel62] BP Welford. Note on a method for calculating corrected sums of squares and products. Technometrics, 4(3):419-420, 1962. 29 